University of Massachusetts Amherst

ScholarWorks@UMass Amherst

Doctoral Dissertations 1896 - February 2014

$1-1-1974$

\title{
Empathy training as the major thrust of a staff development program.
}

Elaine La Monica Rigolosi

University of Massachusetts Amherst

Follow this and additional works at: https://scholarworks.umass.edu/dissertations_1

\section{Recommended Citation}

Rigolosi, Elaine La Monica, "Empathy training as the major thrust of a staff development program." (1974). Doctoral Dissertations 1896 - February 2014. 4119.

https://scholarworks.umass.edu/dissertations_1/4119

This Open Access Dissertation is brought to you for free and open access by ScholarWorks@UMass Amherst. It has been accepted for inclusion in Doctoral Dissertations 1896 - February 2014 by an authorized administrator of ScholarWorks@UMass Amherst. For more information, please contact scholarworks@library.umass.edu. 
FIVE COLLEGE DEPOSITORY 
Copyright (C) 1974

Elaine Lynne La Monica

All Rights Reserved

ii 


\section{EMPATHY TRAINING AS THE MAJOR THRUST}

\section{OF A STAFF DEVELOPMENT PROGRAM}

A Dissertation Presented

By

ELAINE LYNNE LA MONICA

Submitted to the Graduate School of the University of Massachusetts in partial fulfillment of the requirements for the degree of DOCTOR OF EDUCATION

December

Human Relations and Counseling 


\section{EMPATHY TRAINING AS THE MAJOR THRUST \\ OF A STAFF DEVELOPMENT PROGRAM}

A Dissertation Presented

By

ELAINE LYNNE LA MONICA

Approved as to style and content by:

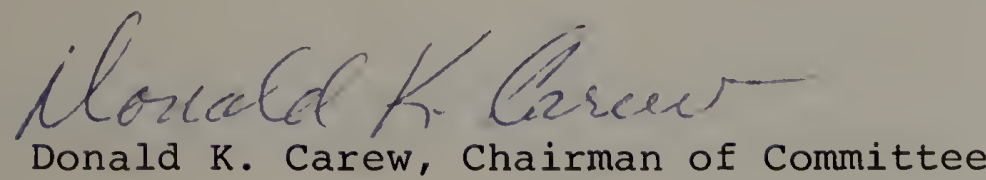

thern E Wirkér

Alvin E. Winder, Member

Kemech IV. Blan har d

Kenneth H. Blanchard, Member

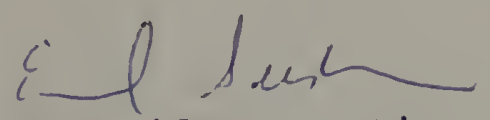

Earl Seidman, Acting Dean School of Education

December 1974 
To the many people who have been involved in the creation, process and completion of my dissertation, I wish to formally express my deepest appreciation--now and always.

To my Mother and Father, for inspiring in me the confidence from my childhood to pursue my goals. To my Mother, for walking with me through every phase of my learning.

To my sister, Diane, for her unending belief in me throughout my life.

To Donald Carew, Chairman of my Doctoral Committee and my dearest friend, for his continuous presence, understanding and guidance during my entire educational process; and, most important, for helping me to find and believe in myself.

To Alvin Winder, Anne Marie Haase and Kenneth Blanchard, members of my Doctoral Committee and treasured friends, for consistently providing me with ideas, knowledge, empathy and energy.

To Gerald Weinstein, for becoming a part of my Doctoral Committee and giving me needed assistance and encouragement. 
To my colleagues, friends and raters, Karen Johnson and Judy Karshmer, for their continuous support and for their earnest, conscientious efforts in rating the instruments used in my study around my deadlines. To my dear high school English Professor and friend, Irma B. Lidner, for her arduous and love-filled hours of editing.

To my closest friends, Philip Denning and Patricia Lynch, for their constant concern, support and understanding whenever I needed them.

To the many other people in my world with whom I have experienced and grown.

\footnotetext{
"And there are those who give and know not pain in giving, nor do they seek joy, nor give with mindfulness of virtue;

They give as in yonder valley the myrtle breathes its fragrance into space.

Through the hands of such as these God speaks, and from behind their eyes He smiles upon the earth."
}

Kahlil Gibran

The Prophet 1951, p. 20. 


\title{
Empathy Training as the Major Thrust \\ of a Staff Development Program
}

(December 1974)

\author{
Elaine Lynne La Monica, B.S., Columbia Union College \\ M.N., University of Florida \\ Directed by: Dr. Donald K. Carew
}

\section{ABSTRACT}

Nursing by definition is considered a helping profession. Even though its goal is one of providing growth-facilitating support and assistance, there is quantitative and qualitative evidence that the transactions between these helpers and their clients often do not prove beneficial. It was necessary, therefore, to look into what is meant by the helping relationship and how one learns to become a helper.

The purpose of the study was to obtain an objective measure of the level-of-empathy of professional nurses practicing in an acute-and-chronic-care hospital facility. For those nurses who scored low in empathy, a short-term, human-relations modeled Staff Development Program was designed specifically to train those helping professionals to increase their abilities to perceive and respond with 
greater empathy. The program was outlined to relate to any of the helping professions.

The results of the study indicated that all of the nurses tested possessed an extremely low level-of-empathy, and that the Staff Development Program significantly raised their levels of empathy. More training is needed to enable the majority of subjects to at least reach the minimal facilitative levels of empathy necessary to truly help another person. 
TABLE OF CONTENTS

Page

ACKNOWLEDGEMENTS • • • • • • • • • • • • • • • • • • iv

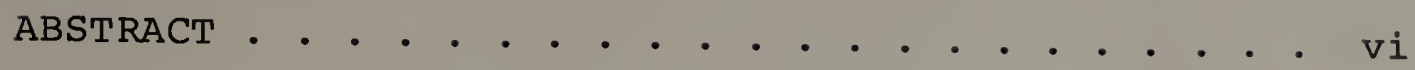

LIST OF TABLES • • • • • • • • • • • • • • • • . xi

Chapter

I. INTRODUCTION . . . . . . . . . . . . 1

Rationale for the Study. . . . . . . . 3

Statement of the Problem . . . . . . . . . . 7

Purpose of the Study . . . . . . . . . . . 8

Definitions of Terms . . . . . . . . . . . . . 10

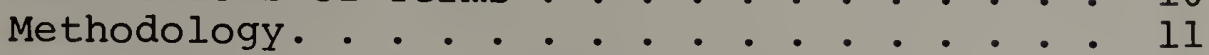

Significance of the study. . . . . . . . . . 13

Limitations of the Study . . . . . . . . . 14

Organization of the Remainder of the

Dissertation . . . . . . . . . . 15

II. SELECTIVE REVIEW OF THE LITERATURE . • • • . 17

Introduction . . . . . . . . . . . . . 17

History and Evolution of Carkhuff's

Model for Helping. . . . . . . . . . 21

Assumptions Relating to Robert Carkhuff's

Model for Helping. . . . . . . . 27

Clinical Model for Helping . . . . . . 27

The Helper in the Helping Process. . . . 33

The Helpee in the Helping Process. . . . 36

The Contextual and Environmental

Influences in the Helping Process. . . . 39

The Importance of Training People in the

Helping Roles to Perceive and Respond

with Empathy . . . . . . . . . . . 41

The Rationale for Nurses to be Educated to

Perceive and Respond with Empathy. • • • 47

The Rationale for Using the Human Relations

Training Model in a Staff Development

Program. 
III. RESEARCH DESIGN AND METHODOLOGY. . . . . . 59

Introduction . . . . . . . . . . . 59

Program Description. . . . . . . . . . . 59

Introduction to the staff Development Program. . . . . . . . . . . . 59

The Construction and Rationale for the Staff Development Program. . . . . 65

Research Facility. . . . . . . . . . 77

Description of the Sample. . . . . . . . . 78

Hypotheses . . . . . . . . . . . . . . 79

Instrumentation. . . . . . . . . . . . . 80

Data Collection. . . . . . . . . . . . . 84

Selection and Training of Raters . . . . . 86

Data Analysis. . . . . . . . . . . . 88

Trainer/Investigator's Level-

of-Functioning . . . . . . . . . . 93

IV. RESULTS AND DISCUSSION . . . . . . . . 95

Introduction . . . . . . . . . . . 95

Hypothesis I • • • • . . . . . . . . . 95

Hypothesis II. • • • • • . . . . . . . 98

Hypothesis III . . . . . . . . . . . . . . 101

Discussion of the Results. . . . . . . . 106

Evaluation of the Staff Development

Program. . . . . . . . . . . . 114

V. SUMMARY, LIMITATIONS, IMPLICATIONS

AND RECOMMENDATIONS. . . . . . . . . . 122

Introduction . . . . . . . . . . . . 122

Summary of the Results . . . . . . . . . 122

Limitations of the Study . . . . . . . . 125

Implications of the Study. . . . . . . . . 128

Suggestions for Further Research . . . . . 133

VI. PUBLICATION. . . . . . . . . . . 137

Abstract . . . . . . . . . . . . . 137

Introduction . . . . . . . . . . . . . . . 138

Method . . . . . . . . . . . . . 141

Results. . . . . . . . . . . . . . . 144 
Discussion . . . . . . . . . . . . . . 147

Conclusions. • . . . . . . . . . . . . . . . . . . .

Tables . . . • • . . . . . . . . . . . 154

References . . . . . . . . . . . . . . . 158

BIBLIOGRAPHY • • • . . . . . . • • . 162

APPENDIX • • • • • • . . . . . . . . 177

Appendix A: Carkhuff's Index of

Communication . . . . . . . 178

Appendix B: Carkhuff's Empathy Scale. . . 186

Appendix C: Personal Data Sheet and

Contract. . . . . . . . . 187

Appendix D: Inter-rater Reliability Test. 188

Appendix E: Announcement of a Staff

Appendix F: Perceiving Empathy... . . . • 190

Appendix G: Perceiving Feelings . . . . . 194

Appendix H: Responding with Empathy . . . 197

Appendix I: Vocabulary of Affective

Adjectives. . . . . . . 200

Appendix J: Ineffective Communication

Styles. . . . . . . . . 204

Appendix K: Evaluation of the Program . . 208 
Table

Page

1. Communication: Design of Helpee Stimulus

Expressions Index. . . . . . . . . . .

2. Communication: Ratings of Facilitative

Conditions and Response Repertoire of

Helper Responses to Helper Stimulus

Expressions. . . . . . . . . . .

3. Rater Evaluations of Responses for Inter-

rater Reliability Measurement. . . . . .

4. Mean Helping Scores for Subjects Pretested in Group I and Group II: Hypothesis I. . .

5. Measures of Central Tendency and

Variability: Hypothesis I. . . . . . .

6. Mean Helping Scores for Subjects Posttested in Groups I, II, and III: Hypothesis II. .

7. Measures of Central Tendency and Variability: Hypothesis II. . . . . . 100

8. Mean Helping Scores for Subjects Posttested in Group I and Group II: Hypothesis IIIA.

9. Mean Helping Scores for Subjects Posttested in Group I and Group III: Hypothesis IIIA.

10. Mean Helping Scores for Subjects Posttested in Group II and Group III: Hypothesis IIIB 105

11. Mean Helping Scores of Twenty-four

Registered Nurses Pretested in Group I and Group II . • • • • • • • • • • • • • •

12. Mean Helping Scores of Thirty-nine

Registered Nurses Posttested in Group I, Group II and Group III. . . . . . .

13. Comparison of the Mean Prestest and Posttest Helping Scores: Group I. 
dedicate these pages to

$$
\text { 几 }
$$

For the unknowing,

a simple stroke of the pen;

for the unfeeling,

a simple hieroglyphic;

but,

for me,

the brightness which has guided and sustained

me

as I probed darkly through the exciting adventure of

I'entrecoeur humaine! 
$\begin{array}{lllllllllllllll}C & H & A & P & T & E & R & I\end{array}$

INTRODUCTION

The major focus of the study was to provide a setting and a program enabling people in the helping professions to increase their awareness and ability to be supportive to other human beings. Even though nursing, counseling, psychotherapy and medicine are called helping professions, there is quantitative and qualitative evidence that the transactions between these helpers and their clients often do not prove beneficial. It is necessary, therefore, to look into what is meant by the helping relationship.

The study of helping relationships was broadly based on the knowledge that the world one creates is composed of both what is taken from others and the environment and what is given to them. The phrase "We reap what we sow" applies in human relations, as well as in general. All too frequently, one expects from his fellows more than he gives. Within each person is a vast potential for growth; everyone is capable of giving more (Gazda, Asbury, Balzer, Childers, Desselle, \& Walters, 1973).

The assumption that one develops not only from what he takes in but also from what he gives out has further implications for the study. The impact is twofold, resulting in growth for the helper as well as the helpee. 
To reach the facilitative level that involves and effects constructive, growth-stimulating human encounters, it is necessary for the helper and the helpee both to develop a sense of self. Rogers (1965) described this evolution of the self as follows: "As a result of interaction with the environment, and particularly as a result of evaluational interaction with others, the structure of self is formed-an organized, fluid, but consistent conceptual pattern of perceptions of characteristics and relationships of the 'I' or the 'me' together with values attached to these concepts (p. 498)."

The remainder of this chapter will be devoted to a further discussion of the introductory rationale for the study. A statement of the problem with which the study is concerned will then be made, followed by discussion of the purpose. The objectives and hypotheses of the study will be included in this section. Several frequently used terms will be defined, and the methods and procedures used in the investigation briefly described. Following that, emphasis will be directed to the significance and limitations of the study. A summary of the organization of the remainder of the dissertation will conclude this chapter. 
Rationale for the Study

The rationale for the study has been derived from the experiences and writings of authors working in the helping professions. It will touch on the areas of the primary conditions in helping, the core condition of empathy, interpersonal competence, helping and helper effectiveness and the application to the nursing profession.

The primary conditions for helping are: empathy, respect, warmth, genuineness, self-disclosure, concreteness, confrontation and immediacy of relationship (Carkhuff, 1969d). The major condition considered in the study was empathy. Empathy has been found to be the primary ingredient in any helping relationship (Carkhuff, 1969d; Combs, Avila \& Purkey, 1973; Gazda et al., 1973; Pierce \& Zarle, 1972; Rogers, 1961; Truax \& Carkhuff, 1967; Truax \& Wittmer, 1971; Truax, Wittmer \& Wargo, 1971). Combs, Avila and Purkey (1973) described empathy as "the capacity to place one's self in another's shoes, to perceive as he does (p. 185)." They further stated that helpers must be able to understand the private world of the helpee in terms of feelings, attitudes, wants and goals. This requires reaching inside the skin of another person. Blocher (1966) divided empathy into two components. The cognitive component involves psychological understanding while the affective component is feeling with a person. 
Combs and Snygg (1959) discussed empathy in terms of feeling like another person or placing oneself in another's shoes. Buchheimer (1963) addressed empathy within the context of several dimensions of the counseling process. These dimensions and meanings in relation to empathy are:

(1) The tone of the counseling relationship is an expressive and possibly nonverbal dimension based upon expressions of warmth and spontaneity.

(2) The pace involves appropriateness and the flow of the relationship.

(3) The counselor's perception relates to the abilities of the counselor to abstract the core of the client's concerns and respond to these in an acceptable, constructive manner.

(4) Strategy relates to the predictive or roleplaying aspect of the relationship.

(5) Leading involves the resourcefulness of the counselor in moving the relationship in the direction of the client's concerns.

It has been shown that empathy involves more than a simple understanding and reflection of the client's verbalizations. Empathy operates throughout the helping process and signifies a central focus and feeling with and in the helpee's world. 
Further research supported the concept that if a helper could perceive and respond with empathy accurately, the remaining dimensions of the helping relationship could then be discriminated rather easily (Berenson, Carkhuff, Friel \& Leitner, 1968; Carkhuff, 1969d; Carkhuff \& Berenson, 1967; Carkhuff, Kratochvil \& Friel, 1968; Truax \& Carkhuff, 1967). Carkhuff (1969d) also stated that the helper level-of-functioning is directly related to his effectiveness in a relationship. If he does not possess the quality of empathy, the results to the helpee may be detrimental, actually causing more harm than good. This is the most critical aspect of all supportive helping processes. "If a helper cannot establish himself as a person who is himself living at more effective levels than the distressed person, if the helper cannot establish that given the same circumstances he could bring about a more effective resolution, there is no meaningful basis for helping (Carkhuff, 1969d, p. 45)." Further research has supported this principle (Anthony, 1971; Berenson, Mitchell

\& Laney, 1968; Berenson, Mitchell \& Moravec, 1968;

Carkhuff \& Burstein, 1970; Friel, Berenson \& Mitchell, 1971; Truax \& Carkhuff, 1963).

Jourard (1971) correlated the helper's ability to effect constructive growth in helpees with what Foote and cottrell (1955) called interpersonal competence. This is described as the ability of the helper to produce 
valued, desirable outcomes in his transactions with people. Professionals who have achieved interpersonal competence are those who are able to achieve desirable outcomes in their encounters with their clients; the outcome is measured in terms of the signs exemplifying the quality of care given the helpee. Professionals must therefore possess and use empathy in the helping process as a vehicle to effect overt and measureable changes.

The research now addresses the role of the nurse in the helping process. A nurse is defined by Webster (1969) as a person who is educated to provide care and curative help or treatment to any in need. Virginia Henderson (1966) stated: "The practice of professional nursing means the performance for compensation of any act in the observation, care, and counsel of the ill, injured, or infirm, or in the maintenance of health or prevention of illness of others, or in the supervision and teaching of other personnel, or the administration of medications and treatments as prescribed by a licensed physician or dentist; requiring substantial specialized judgment and skill and based on knowledge and application of the principles of biological, physical, and social science (p. 3)."

Nursing by definition is considered a helping profession. Given that nurses are considered helpers and should possess interpersonal competence, the research asked two questions: First, what is the empathy level 
of practicing professional nurses in an acute-and-chroniccare facility today? Second, can a Staff Development Program provide the necessary training to improve the level-of-empathy in a helping relationship so that the results are more likely to be facilitative? These questions flow into the next section which addresses itself to the problem.

\section{Statement of the Problem}

The critical importance of helpers' maintaining a high functional level has been previously explained. Empathy has been defined as the key ingredient in any helping relationship (Carkhuff, 1969d). Many efforts have been made to measure the levels-of-functioning in the helping professions, as well as test training programs designed to raise a helper's level on the core dimensions in the helping process.

The investigation addressed the problem of testing the effectiveness of a relatively short training program based on Carkhuff's model for helping, with the key focus being on the core dimension of empathy. The Staff Development Program was designed to relate to any of the helping professions. The sample chosen for investigation in the study was nurses. Research has shown that little emphasis has been placed on directly developing within nurses the 
abilities to perceive and respond with empathy. It was with this knowledge and presumption of need that the study was undertaken.

\section{Purpose of the study}

The purpose of the study was to obtain an objective measure of the level-of-empathy, using Carkhuff's Index of Communication (1969d), of professional nurses practicing in an acute-and-chronic-care hospital facility. For those nurses who scored low on the Index of Communication, 2.0 or below, a Staff Development Program was designed specifically to train those professionals to increase their abilities to perceive and respond with greater empathy.

The following objectives flow from the above-stated purpose:

1. To assess the level of empathy using an Index of Communication scale of a sample of professional nurses practicing in an acute-and-chronic-care Hospital facility.

2. To provide for those nurses who scored low in empathy, a Staff Development Program specifically to increase their empathic perceptions and responses. 


\section{To test statistically the effectiveness of the Staff Development Program.}

Given that there were nurses who had low levels-ofempathy and that those same nurses participated in a Staff Development Program, the following null hypotheses were tested in the research. The rejection level for each hypothesis was at the .05 level of significance.

1. There is no significant difference of mean scores on Carkhuff's Index of Communication between practicing nurses pretested in Group I, the experimental group, and Group II, the control group.

2. There is no significant difference of mean scores on Carkhuff's Index of Communication between the posttest scores of Group I, the experimental group, and the posttest scores of Groups II and III, the control groups.

3. Upon rejection of Hypothesis II, the following two hypotheses were to be tested: (A) There is no significant difference between posttest scores of Group I and Group II, and Group I and Group III; (B) there is no significant difference between posttest scores from Group II and Group III. 


\section{Definitions of Terms}

In order to provide greater clarity for the reader of the study, the following expressions are defined below in terms of their meanings for the purposes of the study.

Associate Degree Program: An Associate Degree Program is a community-college-level nursing program requiring approximately two years of full-time education after high school.

\section{Baccalaureate Program: A Baccalaureate Program is a} University-based program granting a college degree in nursing and requiring a minimum of four years of fulltime education.

Diploma Program: A Diploma Program is a hospital level nursing program requiring approximately three years of full-time hospital-based training after high school.

Dyad: A dyad is a group of two (Webster, 1969). Empathy: For the purposes of the study, Carkhuff's

(1973) following definition of empathy will be used:

A word which we use when one individual is hearing or understanding another. Empathy involves crawling inside of another person's skin and seeing the world through his eyes.... Empathy involves experiencing another person's world as if you were he ( $p .58)$. Helping Relationship: Carkhuff (1973) defined this

as follows:

A process leading to new behavior for the person being helped: the helper must guide him in his development. An effective helper is initially nourishing or responsive. This nourishment prepares 
the person being helped for the more directionful or initiative behavior of the helper $(p, 6)$.

Rogers (1961) further clarified it:

A relationship in which at least one of the parties has the intent of promoting the growth, development, maturity, improved functioning, improved coping with life of the other. The other, in this sense, may be one individual or a group (pp. 39-40).

Index of Communication: Carkhuff's (1969d) standardized, valid index to assess a person's level of communication skills. The instrument is described in detail in Chapter III.

Registered Nurse: Registered Nurse is a title and license given nurses upon graduation from a nursing program and after having passed a standardized licensure examination. The examination is administered by the State Board of Nursing in the state to which one applied. A license permits a nurse to practice in that state only. Reciprocity for licenses in other states may be obtained by application to the specific state Board of Nursing in which one wishes to practice.

\section{Methodology}

This section contains a brief description of the methods and procedures used in the study. A more detailed treatment of the same subject will be given in Chapter III. 
The sample employed in the study consisted of thirtynine employed, female Registered Nurses from Wesson Memorial Hospital, Springfield, Massachusetts. Wesson Memorial Hospital is a general acute-and-chronic-care facility. All of the Registered Nurses had obtained their education in either a Diploma school of Nursing or an Associate Degree Program.

The thirty-nine nurses were divided by self-selection into Group I, the experimental group, or Groups II and III, the control groups. The members of Group I participated in a seven-week Staff Development Program. The participants in Groups II and III provided the controls for testing the effectiveness of the designed program.

The basic instrument used in the study was Carkhuff's Index of Communication (1969d). This instrument purports to reveal the respondent's level of facilitative skills. It is comprised of sixteen short paragraphs which expressed the thoughts and feelings of a women client. Subjects were instructed to respond to the written material as if the woman had expressed herself to them and they wanted to help her. The responses were evaluated by two independent, reliable raters using Carkhuff's Empathy Scale (1969d). Rater reliability was established by use of the Kendall rank correlation coefficient (Siegel, 1956) on the Inter-rater Reliability Test. 
The members of the experimental group, Group I, took the Index of Communication before and after participating in the staff Development Program. Members in Group II took the Index of Communication at the same times as Group I, but did not participate in the staff Development Program. The participants in Group III took the Index of Communication only at the end of the staff Development Program and also did not participate in the program.

The data from the pretests of Group I and Group II were analyzed by use of the Mann-Whitney U Test (Siegel, 1956). The posttests were analyzed by use of the KruskalWallis one-way analysis of variance (Siegel, 1956) to see if a variance in the posttest scores existed. Following Hypothesis III, if a variance did exist, the Mann-Whitney U Test (Siegel, 1956) would be used to specify the exact place of the variance.

\section{Significance of the Study}

The major importance of the problem has been alluded to earlier in the study and will be covered with detail in later portions of the study. Only helping professionals who possess at least a minimal facilitative level-offunctioning can be expected to provide help constructively to another person in need. A helper who has a low level 
is not merely unproductive; he possesses the power actually to harm another person with whom he is working.

The challenge of the study is in assessing the level of nurses practicing today and providing them with a short-term program that is intended to raise their functioning to a higher plateau. Since nursing is by definition a helping profession (Henderson, 1966), it seems paramount that nurses possess the knowledge, skills and experience necessary to practice truly professional nursing.

The implications that rest within the study also encompass all helping professions. The study may add further support and insight into the need specifically to investigate helper's levels-of-functioning, provide training and retraining programs on a continuous, dynamic basis. This may insure that helpers are really fulfilling their professional goals.

\section{Limitations of the Study}

The nature of the study imposed the following limitations. Further discussion of the limitations of the study will be presented in Chapter $V$.

It is difficult to generalize the findings to the nursing population as a whole, due to the small number of subjects. 
Even though theoretically grounded in its approach, the study used educational examples and did not show the possible significance of using nursing problems in the Staff Development Program.

The research did not test whether an increase in empathy skills resulted in an increase in the level-offunctioning in the clinical setting. While this is true, however, research has shown that transfer does take place (Carkhuff, 1969e; Martin \& Carkhuff, 1968; Paul, 1967; Truax \& Carkhuff, 1966).

There are problems in assessing the long-term effects of a short-term program. Trainees occasionally return to environments that do not support or reinforce their activities and learnings (Meadow \& Tillem, 1963; Munger, Myers \& Brown, 1963).

\section{Organization of the Remainder of the Dissertation}

Chapter II provides a selective review of the related literature and research done, involving helping relationships and human-relations-modeled training programs.

Chapter III discusses the designed Staff Development Program and presents a detailed description of the methodology and procedures used in the study. 
Chapter IV presents the results of the study in statistical and narrative form. Data relating to the original hypotheses form the crux of this chapter.

Chapter $\mathrm{V}$ addresses the results of the study. The results are considered in terms of implications, possible limitations and suggestions for further research. Chapter VI provides a summary of the entire investigation in publishing format. 


\author{
C H A P T E R \\ SELECTIVE REVIEW OF THE LITERATURE
}

\title{
$\underline{\text { Introduction }}$
}

A generally accepted viewpoint is that most of human behavior is learned; it evolves as a consequence of persons interacting with their environment. In essence, one learns to be the kind of being one is. This process occurs as a product of interactions between individuals. The quantity and quality of interpersonal relationships influence one's unique personality development. One is what he is today primarily through people, and it is through further such relationships that he will grow into tomorrow's self (Otto, 1970).

Carkhuff (1973) used the analogy of an infant to emphasize that the way in which one's environment and his relationships with important people in his life evolve, largely determines his self-perception. An infant who is totally dependent would likely not live more than a few hours if left alone. An old man seizes life's last opportunity to understand, be understood and to develop meaning for himself at that point in time. Each one then depends on himself and others in the environment together and at the same time. A crisis in one's life may lead to greater growth or greater deteriora- 
tion, depending on what is done for each other and the skills used to help one another. Weigand (1971) wrote, "How we interact, relate and transact with others, and the reciprocal impact of this phenomenon, form the single most important aspect of our existence (p. 247)."

The basic assumption of the comprehensive helping model is: "All effective interpersonal processes share a common core of conditions conducive to facilitative human experiences (Carkhuff, 1969e, p. 7)." Core conditions receiving the most impressive backing from research are: empathy, respect, warmth, genuineness, self-disclosure, concreteness, confrontation and immediacy of relationship (Anthony, 1968; Berenson \& Mitchell, 1968b; Carkhuff, 1968a, 1968b, 1969d; Collingwood, 1971; Collingwood \& Renz, 1969; Mitchell, Mitchell \& Berenson, 1970; Muehlberg, Pierce \& Drasgrow, 1969; Truax, 1970a, 1970b; Truax \& Carkhuff, 1967; Truax \& Wittmer, 1971; Truax, Wittmer \& Wargo, 1971). Carkhuff (1969d) found empathy to be the key ingredient. It seems safe to assume therefore that increasing one's level of empathy does increase his function-value in a helping relationship.

Focusing on the nurse as a helper, Orlando (1961) described the task as distinguishing "between her understanding of general principles and the meanings which she must discover in the immediate nursing situation in order to help the patient (p. 1)." In order to accomplish this, 
she must understand the meanings to the patient of all she observes and then exercise her professional functions with relation to the patient's needs and world. In essence, the nurse must know and be able to validate how her actions and reactions help or hinder her patient in the context of his private world (Orlando, 1961). This validation process involves finding out where the patient is, what he needs, and how to meet the needs, expressed in an acceptable frame of reference for the individual patient. The process described is analogous to the helping process and involves major emphasis on communication skills and empathy.

Dorothy Smith (1964) emphasized the importance of developing an environment in which a nurse can perform at the top of her abilities. She identified poor communication as one of the prime deterrents to effective patient care. The writings of Florence Flores (1962), Frances Reiter Kreuter (1957), and Florence Weiner (1951) emphasized this point. The impact of these writings is paramount, since facilitative communication is a major focus of interpersonal competence, and poor communication in nurses has been documented. Grace Eckelberry (1971) wrote that whatever blocks to communication there are between the nurse and the patient, it is the former's responsibility to initiate it, thus starting the chain of interaction which will reveal the patient's needs and a way in which the 
nurse can meet them. The degree to which a helpee can be open and genuine depends not only on his ability but, most important, on the helper (Truax \& Carkhuff, 1967). When one uses the humanistic approach, it is done with the goal of understanding another person in terms of how that person views himself. Gazda et al. (1973) viewed man as a being who "(I) achieves his uniquely human qualities through interpersonal contact, (2) is aware of himself and his existence, and (3) is capable of making choices which guide his behavior (p. 5)."

Research has shown that the human-relations model is successful in facilitating growth and elevating function levels in interpersonal relationships (Appley \& Winder, 1973; Berenson, 1971; Gazda, 1971; Hefele, 1971; Hirschberg, Carkhuff \& Berenson, 1967).

In summary, the introduction alluded to the following areas which are covered in this chapter: (1) The history and evolution of Carkhuff's model for helping; (2) the assumptions relating to Carkhuff's model for helping; the importance of training people in the helping roles to perceive and respond with empathy; (4) the rationale and need for nurses to possess these skills in their practice; and (5) the rationale for the human-relations-training model for staff development. 


\section{The History and Evolution of Carkhuff's Model for Helping}

In delineating the history of Carkhuff's model for helping, it is necessary to look at the experiences and writings of Carl Rogers (1961), who expressed, "I speak as a person, from a context of personal experience and personal learnings (p. 1)." "I have found a way of working with individuals which seems to have much constructive potential (p. 29)." Rogers (1961) shared what he had learned during his experiences and encounters in all human relationships. He developed the following general hypothesis regarding the facilitation of personal growth:

If I can create a relationship characterized on my part:

by a genuineness and transparency, in which I am my real feelings;

by a warm acceptance of and prizing of the other person as a separate individual;

by a sensitive ability to see his world and himself as he sees them;

Then the other individual in the relationship: will experience and understand aspects of himself which previously he has repressed; will find himself becoming better integrated, more able to function effectively;

will become more similar to the person he would like to be;

will be more self-directing and self-confident;

will become more of a person, more unique and more self-expressive;

will be more understanding, more acceptant of others;

will be able to cope with the problems of life more adequately and more comfortably (pp. 37-38). 
Based on this general hypothesis, Rogers (1961)

further posed the questions: "What are the characteristics of those relationships which do help, which do facilitate growth (p. 4l)?" "Is it possible to discern those characteristics which make a relationship unhelpful, even though it was the sincere intent to promote growth and development (p. 41)?" There was not a large amount of empirical research that would give objective answers at the time Rogers asked these questions (1957-1958). Most of the following studies focused on the attitudes of the helper, which either promoted or inhibited growth. Baldwin, Kalhorn and Breese (1945) made a careful study of parent-child relationships. They concluded that of the various attitudes exhibited by parents toward children, the "acceptant-democratic" one seemed most growth-facilitating. These children showed accelerated intellectual development, more originality and emotional security. In direct contrast to this, children whose parent's attitudes were classified as "actively rejectant" showed opposite effects.

Rogers (1961) suggested that these findings most likely apply to other relationships as well. "The counselor or physician or administrator who is warmly emotional and expressive, respectful of the individuality of himself and of the other, and who exhibits a nonpossessive caring, probably facilitates self-realization much 
as does a parent with these attitudes (p. 42)." He drew the analogy from parental attitudes to helper attitudes and added that the helper must express "acceptant-democratic" attitudes in his behavior. He did not clearly distinguish attitudes from behavior. It is important to point out that Hersey and Blanchard (1972) addressed the attitudes or predispositions of the helper/manager as different from behavior, which tend to be actions perceived by others. Attitudes of empathy, respect, warmth and concern can then be viable only if the behavior of the helper is perceived as such by the helpee.

Whitehorn and Betz (1954) investigated the degree of success physicians found while working with schizophrenic patients on a psychiatric ward. They found that helpful physicians primarily made use of active personal participation. They tended to see the schizophrenic client in terms of the personal meaning which various behaviors had to him and worked toward goals rooted in the personality of the patient. They developed a rapport in which the client felt trust and confidence in the physician. These approaches were in contrast with those of the physician who used procedures such as interpretation, instruction, advice or emphasis on practical care.

Another study investigated the way in which a person being helped perceived the relationship. Heine (1950) studied individuals who had gone for psychotherapeutic 
treatment. The clients reported similar changes in themselves regardless of the orientation of the therapist. The major elements they found helpful in their environment centered on the trust they had felt for the therapist, the feelings of being understood, and the independence they had in making decisions. The therapist procedure found to be most helpful was clarification and openly stating feelings that the client had approached hesitantly. The identified unhelpful elements included lack of interest, remoteness, superfluous sympathy and emphasis on past history rather than on present problems.

Fiedler (1953) found that expert therapists, regardless of their orientation, formed similar elements that characterized their relationships. These included empathy, a sensitivity to the client's attitudes and a warm interest minus emotional overinvolvement. Seeman (1954) noted that psychotherapeutic success is closely tied to a mutual liking and respect for client and therapist. Rogers (1961) discovered that "it is the attitudes and feelings of the therapist, rather than his theoretical orientation, which is important (p. 44)." It is also "the way in which his attitudes and procedures are perceived which makes a difference (p. 44)." Halkides (1958) also affirmed that a high degree of empathic understanding was significantly associated with successful therapy, as were a high degree of unconditional, positive regard and the counselor's genuineness. 
Rogers (1961) posed other questions asked of himself in a helping relationship rather than didactically explicating characteristics of one in a helping profession. These served to integrate his experiences with his learning through research studies. They are the following :

1. Can I be in some way which will be perceived by the other person as trustworthy, as dependable or consistent in some deep sense (p. 50)?

2. Can I be expressive enough as a person that what I am will be communicated unambiguously (p. 5l)?

3. Can I let myself experience positive attitudes toward this other person--attitudes of warmth, caring, liking, interest, respect (p. 5l)?

4. Can I be strong enough as a person to be separate from the other (p. 52)?

5. Am I secure enough within myself to permit him his separateness (pp. 52-53)?

6. Can I let myself fully into the world of his feelings and personal meanings and see these as he does ( $p .53)$ ?

7. Can I be acceptant of each facet of this other person which he presents to me? Can I receive him as he is (p. 54)?

8. Can I act with sufficient sensitivity in the relationship that my behavior will not be perceived as a threat ( $p .54)$ ?

9. Can I free him from the threat of external evaluation ( $p$. 54)?

10. Can I meet this other individual as a person who is in process of becoming, or will I be bound by his past and by my past (p. 55)? 
Rogers (1961), moreover, reached two important conclusions. The first conclusion was that if he could answer all of the above affirmatively, then indeed, any relationship in which he was involved would be helpful and involve growth. Since he felt that he could not answer most of them positively, however, he worked in an affirmative direction. The second conclusion was that the degree toward which he could create relationships which facilitated the growth of others as individuals would be a measure of the growth he himself had achieved. This was based on his suspicion that the optimal helpingrelationship is that created by a psychologically mature person.

It was with this background that Carkhuff (1969d) went on to state the core conditions necessary to promote facilitative human relationships; namely, empathy, respect, warmth, genuineness, self-disclosure, concreteness, confrontation and immediacy of relationship. In short, the functioning level of the helper in these core conditions is directly related to his effectiveness in a relationship.

It is with this foundation that the review of the literature proceeds to a study of Carkhuff's model for helping. 


\section{Assumptions Relating to Robert Carkhuff's Model for Helping}

Clinical model for helping. Carkhuff's (1969d)

work stemmed from the basic assumption that counseling and psychotherapy are aspects of interpersonal and relearning processes or, generally, human relations. From this assumption, research has documented that human encounters may have constructive or destructive effects and that all effective processes share a common bond of conditions that are conducive to facilitative human experiences (Berenson \& Carkhuff, 1967; Berenson \& Mitchell, 1968a; Carkhuff \& Berenson, 1967; Rogers, Gendlin, Kiesler \& Truax, 1967; Truax \& Carkhuff, 1967). This research led Carkhuff (1969d) to a model for effective and ineffective functioning. Each point in one's life, during which he has contact with another person, designated by society as more knowing or less knowing, can result in effects that enable either person to grow further or to deteriorate. The severely deteriorated person, who seems to be functioning ineffectively in all of his relationships, can be viewed as a product of prolonged retarding relationships. By comparison, the person who has experienced a series of facilitative relationships will function at high or effective levels in most areas of his existence. Those persons who are neither totally effective nor ineffective in coping with 
life's processes are those who have had a series of mixed relationships, some effective; some, harmful. This can be equated to Hersey and Blanchard's (1972) effective and ineffective cycles.

The effective cycle in organizational theory is one in which high expectations by leaders produce high performance of followers. This process spirals upward and builds upon itself. The ineffective cycle is one during which low expectations imposed on followers produce low performance and spirals downward. Human relationships can be analyzed in the same way if one would add to the effective/ineffective cycles the variable of the leader's ability to communicate effectively. Constructive and facilitative experiences with other persons during crisis points in one's life produce a spiral upward and provide a new level from which to continue growth. Ineffective or deteriorating experiences produce the opposite effects, spiraling downward, thus placing a person on a lower levelof-functioning from which he must then regrow. It seems clear then to project that a series of helpful relationships reinforce one at an elevated level, whereas a series of ineffective relationships can be extremely harmful.

Going back to Hersey and Blanchard's (1972) theory, it appears logical to conclude therefore that if a leader's high expectations of followers were coupled with facili- 
tative communication skills, he may catalyze an effective cycle. Likewise, if he joined low expectations with poor communication skills, an efficacious downward cycle might result. This same point also confirms Beck's (1963) existential view that the total organism of man reacts to any situation. One cannot react intellectually or emotionally to the exclusion of the other. Man also behaves in terms of his subjective view of reality, not according to some externally defined objective. Every person has his own heredity and experiences unique to himself. From these, it is to be expected that each will behave differently from others whose experiences are different.

According to Carkhuff (1969d): "Each significant encounter, then, between more knowing and less knowing persons may be considered a crisis in the lives of both groups. Whether an individual grows or deteriorates is dependent in large part upon the interaction of the activities of both the more knowing and the less knowing persons (p. 22)." A person's basic directionality depends a great deal upon what happens at each critical stage in his development, even though different resources and predispositions of individuals are involved (Carkhuff, $1969 d)$

From the assumptions that all interpersonal learning or relearning processes may be for better or for worse, 
and constructive or destructive results can be accounted for by the level of facilitative facets offered by the more knowing person, Carkhuff (1969d) offered some propositions and corollaries that constitute his model for understanding and helping.

Proposition I. "Growth and deterioration are physical, emotional and intellectual (p. 24)."

Corollary I. "Growth is reflected in the actualization of the individual's physical, emotional and intellectual resources (p. 24)."

Corollary II. "Deterioration (retardation) is reflected in the deterioration (retarded development) of the individual's physical, emotional and intellectual resources (p. 24)."

Corollary III. "The conditions of effective helping are physical, emotional and intellectual (p. 25)."

Corollary IV. "The goals of all helping processes involve (1) understanding the physical, emotional, and intellectual worlds and (2) being able to act upon these worlds (p. 25)."

Proposition II. "Physical, emotional, and intellectual growth or deterioration is dependent upon first person, second person, and contextual and environmental variables (p. 25)." All variables are relevant to growth or deterioration of either or both persons. The first person is considered either parents, teachers or counselors. The 
second person is children, students or clients. Contextual variables include conditions of the setting and environmental variables are those conditions offered by others in the individual's environment (Carkhuff, 1969d).

Corollary I. "The level of functioning of the first person has a potentially critical effect upon the level of functioning of both the first and second persons in a relationship (p. 25)."

Corollary II. "The level of functioning of the second person has a potentially critical effect upon the level of functioning of both the first and second persons in the relationship (p. 26)."

Corollary III. "The level of conditions offered by the environment and the context within which the helping relationship takes place has a potentially critical effect upon the level of functioning of both the first and second persons in the relationship (p. 26)."

Corollary IV. "The growth or deterioration of all parties involved is dependent upon the interaction of all relevant first person, second person, and contextual and environmental variables (p. 26)."

Proposition III. "The physical, emotional, and intellectual effects of facilitative or retarding experiences at crisis points are cumulative (p. 27)."

Corollary $I$. "The more retarding experiences an individual has had, the less he is able to employ con- 
structive experiences and the more vulnerable he is to destructive experiences (p. 27)." This is in accord with what was described earlier regarding Hersey and Blanchard's (1972) effective and ineffective cycles.

Corollary II. "The more facilitative experiences an individual has had, the more he is able to employ constructive experiences and the less vulnerable he is to destructive experiences (p. 27)."

Corollary III. "The change in the level of functioning of the physical, emotional, or intellectual dimensions will influence the level of functioning of the other dimensions in the same direction (p. 27)." Changes in the physical dimensions influence the emotional or intellectual dimensions in the same direction. This principle is analogous to Maslow's (1968) hierarchy of needs. Only when physical, safety and affiliation needs are satisfied can one grow in the higher needs of esteem and selfactualization. Basic human physical needs have the highest strength when unsatisfied.

Corollary IV. "The change in one problem area of functioning will influence the change in the functioning of other areas in the same direction (p. 28)."

It can be seen that the rehabilitation process involves integrating the physical, emotional and intellectual conditions within an individual so that he will be able to understand and act upon all phases, internal and external, 
of his physical, emotional and intellectual environment (Carkhuff, 1969d). "In a real sense, then, the helping process is a process of rehabilitation as well as a process of personal emergence and/or re-emergence. It is a process in which each barrier looms higher than the last but one in which the rewarding experiences of surmounting previous hurdles increases the probability of future successes. If the helper is not committed to his own physical, emotional, and intellectual development, he cannot enable another to find fulfillment in any or all of these realms of functioning (Carkhuff, 1969d, p. 31)."

The helper in the helping process. It has been previously stated that the level of facilitative conditions offered by the helper is correlated with the indexes of constructive helpee gain or change (Berenson \& Carkhuff, 1967; Carkhuff \& Berenson, 1967; Truax \& Carkhuff, 1967). However, more assertive, active offerings involving direction, confrontation and action-oriented dimensions must be offered, in addition to receptiveness and warmth, to account for a truly significant degree of gain in an effective helping process (Carkhuff, 1969d).

The helper's contribution can be divided broadly into two components: understanding and action. The understanding phase can be equated with a feminine dimension. This dimension includes responsive elements such as empathy, respect, warmth, genuineness and self-disclosure. The 
masculine, action-oriented dimension includes concreteness, confrontation and immediacy of relationship. The understanding component consists of those dimensions offered in response to the expressions of the person being helped; action-oriented dimensions are initiated by the helper (Carkhuff, 1969d). It is important to note that studies of helper-training characteristics have suggested that traditional feminine response patterns have been demonstrated with helper trainees. Farson (1954), McClain (1968) and Patterson (1967) have summarized that helpers tend to get high scores on social service interests and nurturant inclinations as well as on indexes of more traditionally feminine personality dispositions such as restraint, friendliness, deference and affiliation. Low scores were observed on more aggressive, assertive and achievement-oriented traits. A comprehensive model for the helping process should be viewed as containing both types. Carkhuff (1969d) expressed this succinctly in his following statements: "The effective helper is both mother and father. The whole person has incorporated both the responsive and assertive components. He (or she) can understand his internal and external physical, emotional, and intellectual world with sensitivity and can act upon these worlds with responsibility (p. 34)."

These two components of helping--understanding and action--can be seen as phases in the helping process. 
Phase I, understanding, enables the helpee to probe inwardly by exploring and experiencing the core of his existence. The facilitative conditions of empathy, respect, warmth and self-disclosure employed during this phase offer the helpee both a stimulus and reinforcer. In turn, this serves to lower the helpee's defenses, thereby enabling the helpee to elicit more meaningful material (Carkhuff, 1969d). "High levels of facilitative conditions enable the helper to understand the helpee and the helpee to experience the feeling of being understood (Carkhuff, 1969 d, p. 42)."

The second phase is correlated with the actionoriented dimension. Carkhuff and Berenson (1967) call this the upward phase, or period of "emergent directionality." After having explored himself, the distressed person experiences a need to act on his world in a more effective manner than in his previous encounters. Since trust and understanding have previously been established in Phase $I$, the helper can now be a guide in this actionoriented dimension (Carkhuff, 1969d).

The two phases of helping have been shown to be essential components to a comprehensive helping model. They may not be sequential and distinctive but they must be self-contained. The helper must be functioning at a level in which the helper is established by the helpee as a model for effective living (Carkhuff, 1969d). 
"Helping is in fact a highly interactional and, hopefully, a lifelong process involving both phases in different problem areas (Carkhuff, 1969d, p. 44)."

The helpee in the helping process. The helping process has been described as being a highly interactional life-long process involving the helper and the helpee. It is necessary to study the contributions made by the latter in the process in order to understand fully the effect of helper variables. Helpee dimensions can be delineated as follows: (I) what the helpee brings with him; how the helpee reacts within the helping process; and (3) what changes were elicited in the helpee as a result of the helping process (Carkhuff, 1969d).

The factors that a helpee brings with him can be divided into the demographic characteristics of the helpee's population and its levels of functioning. There is little or no research relating helpee-demographic characteristics to treatment outcome. Social class and racial variables have received support. Banks, Berenson and Carkhuff (1967) found that the counselors who either were similar or could generate perceived similarity were seen by black college students as more effective change agents. Anderson and Anderson (1962), Banks (1972), Carkhuff and Pierce (1967), Correll (1955) found that racial similarity was a source of increased client selfexploration while social class had no statistical 
significance. Winder and Hersko (1955) and Hollingshead and Redich (1958) reported that both counselors and psychologists, themselves middle class, facilitated self-exploration in clients of similar social status and discouraged it in clients of lower social status. Gardner (1972) investigated the variables of race, education and experience as significant factors in the degree to which counselors are perceived as effective by black college students. He found all three to be significant sources of effect for student ratings. The implications rest with selecting counselors with similar backgrounds. The works of Rogers et al. (1967) and Truax and Carkhuff (1967) gave evidence that helpees who were seen by motivated helpers, regardless of social class or demographic characteristics, had an opportunity for constructive change.

The helpee's level-of-functioning is the second division of what he brings with him to the relationship. There is little evidence to indicate that assessments of levels-of-functioning are in any way correlated with differential treatment (Carkhuff, 1968a; Carkhuff \& Berenson, 1967; Pagell, Carkhuff \& Berenson, 1967; Spiegel \& Spiegel, 1967; Thorne, 1967; Truax \& Carkhuff, 1967). "Traditional diagnosis does not make a difference (Carkhuff, 1969d, p. 50)." 
Another important aspect of the helpee's contribution is what he does within counseling. This includes the helpee's sets, expectancies, motivation and process variables. Sets and expectancies influence motivation and thus the process and its outcome (Carkhuff, 1969d). Carkhuff (1969d) stated that "basically what the helpee expects and, indeed, needs are a high level of understanding in his life (p. 52)." Helping-process variables, which include helpee self-exploration, problem expression and the immediacy of experiencing, is essential to constructive helpee change or gain (Carkhuff, 1969d; Carkhuff \& Berenson, 1967). "The degree to which the helpee can explore himself within the helping process is related to the degree to which he changes constructively (Carkhuff, 1969d, p. 54)." Writings of Carkhuff and Berenson (1967) and Truax and Carkhuff (1967) confirm this point.

The outcome of the helping relationship is a reflection of the goals of counseling. The helpee must be autonomous (Carkhuff, 1969d). "The helper's task is thus to serve as a guide on the helpee's journey toward finding himself and acting upon who he is. Through the helper's eyes and ears the helpee can come to see and hear the sights and sounds of life; with the helper's hands he can learn to touch and to act; through the helper's life he can come to find his own life (Carkhuff, 1969d, p. 62)." 
The contextual and environmental influences in the

helping process. The last set of variables that must be considered in the process includes environmental and contextual influences (Carkhuff, 1966; Carkhuff \& Berenson, 1967). The helper and helpee do not interact in a vacuum. The setting in which helping takes place, as well as the environment and people to which the helpee must return, incorporates critical variables (Goffman, 1956, 1961; Jones, 1953; Rapaport, 1960; Scheff, 1966, 1967; Shibutani, 1961; Smelser \& Smelser, 1963;

Wesseu, 1964). Within the rationale for helping, Carkhuff (1969d) maintained, "what the helpee learns to do within the context of the helping relationship can be generalized to other significant areas of his life (p. 69)."

Since there has been relatively little systematic investigation conducted in this area, Carkhuff (1969d) has drawn a number of conclusions based on his assumptions concerning the variables of environmental and contextual influences, as follows:

(1) "Contextual and environmental variables are primarily modifiers of the effects of the helper-helpee interaction (p. 70)."

(2) "Contextual variables can be controlled in such a way as to maximize the constructive effect of both the helping experience and the environment (p. 70)." This is accomplished by closely approximating the helpee's 
environment in order to facilitate generalization of the learning experiences (Carkhuff, 1969d).

(3) "Environmental variables can be influenced in such a way as to constitute an effective source of treatment (p. 70)." The environment, including the people in that environment, must be a part of treatment (Carkhuff, 1969d).

(4) "Together contextual and environmental variables constitute a significant source of differential treatment (p. 71)." In this sense, these variables can be utilized into forming preferred modes of treatment. This enables the helpee to maximize opportunities constructively to gain in and out of the helping process (Carkhuff, 1969d). The critical importance of both the environmental and contextual variables can be viewed by using an existential framework. It would be more difficult to take another person's behavior for granted if one were to place himself in the bed, home and position of that person. This approach would close the gap between human needs and the availability of social services (Carkhuff, 1969d).

Carkhuff (1969d) summed up the importance of considering environmental and contextual variables in this way: "We must not be bound to our past knowledge except insofar as it leads us to sources of new learnings (p. 74)." 
The Importance of Training People in the Helping Roles to Perceive and Respond with Empathy

It has previously been stated in this chapter that there is a common core of conditions conducive to facilitative human experiences. Research has proven these to be the following: empathy, respect, warmth, genuineness, self-disclosure, concreteness, confrontation and immediacy of relationship (Anthony, 1968; Berenson \& Mitchell, 1968b; Carkhuff, 1968a, 1968b, 1969d;

Collingwood, 1971; Collingwood \& Renz, 1969; Gazda et al., 1973; Mitchell, Mitchell \& Berenson, 1970; Muehlberg, Pierce \& Drasgrow, 1969; Truax, 1970a, 1970b; Truax \& Carkhuff, 1967; Truax \& Wittmer, 1971; Truax, Wittmer \& Wargo, 1971). Carkhuff (1969d) found empathy to be "the key ingredient of helping (p. 173)." He also emphasized that "the key throughout all group helping processes is the level of functioning of the leader (Carkhuff, 1969e, p. 131)." These two principles will be the foci of discussion in this section.

The effectiveness accounted for within the helping relationship has little to do with the fact that the treatment process may be traditional or not (Carkhuff, 1969e). The documented key to effective process and outcome in a helping relationship has been found to be the helper's level-of-functioning. Carkhuff and Berenson (1967) defined "the minimal level of self-sustaining facilitation (p. 50)" 
to be at the 3.0 level of a five-point scale. A complete discussion of Carkhuff's Empathy scale can be found in Chapter III. Berenson, Mitchell and Laney (1968) and Berenson, Mitchell and Moravec (1968) discovered some inconsistencies in research literature concerning the minimal level of conditions in which an effective process of helping can take place. They use 2.5 on a five-point scale to distinguish a high-level counselor from a low one. Whatever the precise cut-off point, the evidence obtained from a number of naturalistic studies is consistent: "Helpees of high-level-functioning helpers demonstrate constructive change on a variety of indexes while those of low-level-functioning helpers do not change or even deteriorate (Carkhuff, 1969e, p. 24)." These studies include the following investigations: Berenson and Carkhuff (1967), Carkhuff and Berenson (1967), Rogers et al. (1967), and Truax and Carkhuff (1967).

Even though outcome criteria in different disciplines may not be directly comparable, the predictive evidence obtained from a helper's level-of-functioning is similar for counseling and psychotherapy (Pagell, Carkhuff \& Berenson, 1967); education (Aspy \& Hadlock, 1969); and parent-child treatment (Carkhuff \& Bierman, 1970). Pagell, Carkhuff and Berenson (1967) studied a variety of indexes measuring client gains in interpersonal functioning through therapy. They found that therapists who were functioning 
above minimal facilitative levels and at least above the levels of their clients had subjects who demonstrated the greatest growth in interpersonal functioning.

Friel, Berenson and Mitchell (1971) found that lowfunctioning therapists seemed to interact with those under their care, yet not attend to the person or the immediate relationship. In contrast, the high-functioning therapist interacted with and for the client. The interaction varied in response to the results at the moment.

Using an interview with a physically disabled patient, Anthony (1971) discriminated between a low-functioning counselor, 1.74 on a five-point scale, and a high-functioning one at 3.18. He found meaningful distinctions between individuals functioning slightly below level three and those functioning at a minimal facilitative level of 3.0 .

Truax, Wittmer and Wargo (1971) studied hospitalized psychiatric patients during group therapy. They concluded there was a positive relationship between the levels of accurate empathy, nonpossessive warmth and genuineness elicited by the therapist and the degree of patient improvement.

Another source of learning involved manipulating the helper's level-of-functioning and studying the effects upon helpee functioning. In studies of hospital inpatients having schizophrenia (Cannon \& Pierce, 1968; Truax \& Carkhuff, 1965) and low-level-functioning college students 
(Holder, Carkhuff \& Berenson, 1967) it was concluded that high-level helpers influenced the low-level helpee in direct proportion to the facilitative conditions offered. Helpers offering high conditions enabled the helpee to explore himself more efficiently. Conversely, when low levels were offered, the helpee explored himself less effectively. Piaget, Berenson and Carkhuff (1967) found that low-level-functioning helpers tended with time to pull low-level helpees down toward their modal level. Thus far, we have looked at the absolute level of helper functioning. It must be noted that the directionality of movement is also of critical importance. Kratochvil, Aspy and Carkhuff (1967) discovered that counselors whose level-of-functioning was constantly high from the beginning to the end of treatment had clients who demonstrated constructive change. Those helpers who decreased their levels during the course of helping showed helpees who declined.

The impact of these studies can be seen as having direct implications for the progress of helping. "The high-level-functioning helper engages all of the helpee's resources in a process that culminates in the helpee's constructive growth. The low-level-functioning helper involves the helpee in a subtractive process that results in deterioration over time (Carkhuff, 1969e, p. 25)." 
The degree to which a helper is functioning at a high level has been demonstrated to be directly proportionate to the level of helpee change during the helping process. The primary core dimensions which are used in testing the helper's functional level have been elucidated. Empathy has been determined to be the primary ingredient in any helping process. Carkhuff (1969d) found that if a helper can perceive and respond accurately with empathy, the remaining dimensions of the helping process can be discriminated rather readily. The balance of this section will focus on the importance of perceiving and responding with empathy in a helping process.

Truax and Carkhuff (1967) stated that the level of accurate empathy offered by the therapist is directly proportionate to the client's outcome in therapy. The emphasis is on moving the client to levels of feeling and experience deeper than those he has communicated, yet with the range of expression that the client can utilize for his own purposes (Carkhuff \& Berenson, 1967). Fox and Goldin (1964), Katz (1963) and Truax and Carkhuff (1966) had already confirmed that the therapist's ability to communicate at elevated levels of empathic understanding is correlated with his allowing himself to merge into the client's experience, reflect on this, experience without judging, cope with his own anxiety and communicate this understanding to his client. As the therapist moves into 
his client's world and probes previously unexplored areas of human living and relationships, his communication of awareness provides the client with the experiential base necessary for change (Carlton, 1967). The therapist's self-understanding is translated directly to his ability to "tune in" on the client's wave length and enables the latter to overcome alienation and isolation in his experiences (Carkhuff \& Berenson, 1967).

In addition, Kratochvil, Aspy and Carkhuff (1967) also substantiated that the counselor's level-offunctioning must be consistent and constant. This applies in the discussion of empathy. Even earlier Cartwright and Lerner (1963) had determined that the therapists final, not initial, level-of-empathy was related to patient improvement. The therapist's effectiveness, therefore, is related to his constant and continuing depth of understanding rather than to his ability to "technique it" during the initial phase of therapy (Truax \& Carkhuff, 1963).

It must be noted that empathy is not purely the client-centered mode of reflection. Truax and Carkhuff (1964) established that the measures of empathy documented as being those most highly predictive of change integrated the client-centered notion of the reflection of feelings and the analytic emphasis placed upon diagnostic accuracy. The helper level and the importance of perceiving and responding with empathy in the helping process cannot be 
underrated. Allerand (1964) underscored the fact that it is the manner of the therapist that is paramount; if he is an open, fully human, nonmechanical being, he communicates understanding which fosters growth. Bordin (1955) declared that there is the optimum amount of empathy beyond which too little psychological tension exists to initiate a process of change and growth. These fine lines of discrimination between possible growth and deterioration of the helpee must be studied. Helpers, to be effective, must have a facilitative level-of-functioning and must perceive and respond with empathy to enable their clients to grow constructively.

\section{The Rationale for Nurses to be Educated to Perceive and Respond with Empathy}

As has been reiterated, empathy has been found by Carkhuff (1969d) to be "the key ingredient of helping (p. 173)." Webster (1969) defined this word as an appreciative perception or understanding of another person. Evidence of its critical importance for the functioning of helping-professionals has been documented in previous sections of this chapter. The investigation will not address itself to the rationale for nurses to be educated in thus perceiving and responding with empathy.

According to Kalisch (1971b), empathic functioning is a logical criterion in judging the effectiveness of nurse- 
practitioners. An examination of nursing-education objectives and learning experiences showed few attempts to increase empathy specifically in students and graduate nurses. Behavioral-science courses and similarly oriented content in nursing curricula have usually been indirectly allied with the development of empathy, but research indicated that intellectual acceptance failed to equip the professional nurse with practical skills needed. Findings from research strikingly substantiated this observation.

Terming knowledge in psychology as "psychologicalmindedness", Chance and Meaders (1960) measured this variable and empathy on a group of subjects. The results indicated that the more psychologically-minded the students were, the less empathy they exhibited.

Having surveyed eighty-one different studies on one's ability to understand the feelings of others, Taft (1955) found no relationship between the amount of education in the behavioral sciences and high levels-of-empathy.

Investigating post-internship clinical psychology students, Bergin and Soloman's (1963) results showed these functioning at levels ranging from 1.91 to 3.84 on a ten-point scale of empathy with level 1.0 as the lowest degree. This study also demonstrated that there was a negative correlation between practicum and academic grades. Other studies have demonstrated a consistent decrease 
in empathy as the training and experience in psychology increases (Arnhoff, 1954; Melloh, 1964; Weiss, 1963).

Eisenman (1972) researched whether student nurses high in creativity, as measured by perceptual preferences for complexity, would be more amenable to clients labeled mentally ill or physically disabled. He contrasted this with student nurses low in creativity. Results indicated that those who had a preference for complexity displayed increased acceptance while others who preferred simplicity displayed decreased acceptance. Eisenman (1970) further found that student nurses became less creative during the course of nursing school. This has important implications as to the ways in which nurses respond to patients, since patients can be viewed as possessing a stigma. Not only does nursing education fail to educate people to perceive and respond specifically with empathy, but it seems that the gestalt of nursing education has an effect that dampens the student's creativity. This may render a student with decreased abilities and motivation to discover, improvise and develop new effective modes of patient care not didactically taught to her during her nursing education. Nursing education is, therefore, suffering from two angles: first, the specific lack of education in empathy skills; and second, the general deterioration of creativity talents which may render some graduates unable to discover 
and search for the important concepts they should have learned during their education.

Duff and Hollingshead (1968) found that 718 of Registered Nurses sampled, 808 of Licensed Practical Nurses and $74 \%$ of nurse's aides showed no evidence of empathy toward patients. Even before this Jourard (1964) had pointed out that nurses could promote the real selfbeing and honest self-disclosure of their patients by empathically acknowledging what is expressed. Yet, he said, this is usually lacking in nurses whom he described as having "rigid interpersonal behavior."

The review of the literature has attempted to document that the traditional modes of educating professional nurses fails to relate content into actual person-to-person processes. The psychodynamics, developmental etiologies, levels-of-consciousness and other intellectual aspects must be bridged into language effects, feeling tones, movements and content in communication. Smith (1966) concluded that "the development of psychological-mindedness seems to be a dubious way of increasing empathic accuracy (p. 105)."

In the following portion of this chapter, the rationale for using the human relations model in staff development will be the major focus in educating people to perceive and respond with empathy. 


\section{The Rationale for Using the Human Relations \\ Training Model in a \\ Staff Development Program}

The outstanding need to educate all helping professionals to perceive and respond with empathy has been documented in this chapter. This section addresses itself to the question, what is the best approach to facilitate learning of empathy?

Moving back to look at the history of the human relations model, Matarazzo (1965) reviewed counseling and psychotherapeutic processes and concluded that the group helping-processes was a self-taught art with few guiding principles. There were controversies between practitioners who concentrated upon the individual helpee within the group, those who fixed upon interpersonal relationships within the group and others who gave chief attention to the interaction between the group and the individual, with no affirmative conclusions being reached. Out of the traditional model of group psychotherapy, there developed a number of experiental types. For example: growth groups (Gazda, 1969; Lubin \& Lubin, 1967), encounter and marathon groups (Bach, 1966; Moustakas, 1972; Murphy, 1969; Stoller, 1967), the self-directed groups (Berzon \& Soloman, 1966; Rogers, 1967), the sensitivity and "T" groups (Benne, 1969; Bradford, Gibb \& Benne, 1964; Schein \& Bennis, 1965), and humanistic-experiential ones (Berne, 1964; Perls, 1969; Schutz, 1967). 
The human relations training model, which grew out of the T-Group model, was developed at Bethel by the organization called the National Training Laboratories. The model has been documented as being effective (Appley \& Winder, 1973).

There are several underlying assumptions about the nature of the learning process distinguishing T-Groups and human relations training from other models of learning. These assumptions are:

1. Learning Responsibility. Each participant is responsible for his own learning. What a person learns depends upon his own style, readiness, and the relationships he develops with other members of the group.

2. Staff Role. The staff person's role is to facilitate the examination and understanding of the experiences in the group. He helps participants to focus on the way the group is working, the style of an individual's participation, or the issues that are facing the group.

3. Experience and Conceptualization. Most learning is a combination of experience and conceptualization. A major $\mathrm{T}-\mathrm{Group}$ aim is to provide a setting in which individuals are encouraged to examine their experiences together in enough detail so that valid generalizations can be drawn.

4. Authentic Relationships and Learning. A person is most free to learn when he establishes authentic relationships with other people and thereby increases his sense of self-esteem and decreases his defensiveness. In authentic relationships persons can be open, honest, and direct with one another so that they are communicating what they are actually feeling rather than masking their feelings. 
5. Skill Acquisition and Values. The development of new skills in working with people is maximized as a person examines the basic values underlying his behavior, as he acquires appropriate concepts and theory, and as he is able to practice new behavior and obtain feedback on the degree to which his behavior produces the intended impact (Seashore, 1970, pp. 15-16)."

The goals and outcomes of human relations training are classified according to potential learning involving individuals, groups and organizations (Seashore, 1970). The metagoals of the laboratory method involve inquiry, collaboration, rational conflict resolution and the freedom to exercise choice. These processes are shared by the staff and the participants (Appley \& Winder, 1973). This team further stated that in a relatively safe world, members can test and learn trust, risk-taking, openness and interdependence. Studies by Gibb (1971), Harrison and Lubin (1965) and Miles (1965) have all found the T-Group method an effective method of increasing interpersonal communication.

Carkhuff, Collingwood and Renz (1969) investigated the effects of didactic training upon trainee levels of discrimination and communication. Their results indicated that exclusive didactic training yielded significant improvement in discrimination but very little generalization of learning in communication skills.

Carkhuff and Truax (1965b) evaluated the effects of an integrated didactic and experiential approach to 
training. They found that these two combined were basic to the training program, in addition to having a trainer who was a role model in offering high levels-of-empathy, respect, concreteness and genuineness.

Carkhuff (1969f), Carkhuff and Banks (1970) and Carkhuff and Bierman (1970) discovered that to effect differences in communication, training must employ a behavioristic, interpersonal approach preceding practice in communication.

Several studies confirmed the need and success of providing experiential, interpersonal and intrapersonal group training for helping professionals (Berenson, Carkhuff \& Myrus, 1966; Foulds, 1969; Martin and Carkhuff, 1968; Truax, Silbur \& Wargo, 1966; Vitalo, 1971).

With conclusions based on research and experience, Carkhuff (1969e) offered several propositions that led him to prefer the group training mode.

Proposition I. "The core of functioning or dysfunctioning (health or psychopathology) is interpersonal (p. 130)."

Proposition II. "The core of the helping process (learning or relearning) is interpersonal (p. 130)." Proposition III. "Group processes are the preferred mode of working with difficulties in interpersonal functioning (p. 130)." Group processes can obviously insure the greatest amount of learning for the greatest 
number of people at one time (Carkhuff, 1969e).

Proposition IV. "Systematic group training in interpersonal functioning is the preferred mode of working with difficulties in interpersonal functioning (p. 130)."

Carkhuff (1969e) made use of all sources of learning: experiential, didactic and role-modeling. He stressed that the key in all group helping-processes is the levelof-functioning of the leader (Carkhuff, 1969a, 1969b, 1969c). The use of high-functioning leaders results in an atmosphere whereby trainees/helpees can move toward higher levels of functioning, as well as providing multiple potential helpers/trainers for individual group members (Carkhuff, 1969e).

The advantages of human-relations-modeled group processes that include all sources of learning under the direction of a high-functioning leader are numerous. They apply in both training and helping.

Each helpee has the following opportunities:

1. to act out his characteristic behaviors;

2. to observe the characteristic behaviors of others;

3. to communicate directly with another person other than the helper;

4. for dispensing with unsuccessful defenses and expressing himself freely in the context of a facilitative group atmosphere;

5. to share in the helper's clarification and interpretation of the behavior of another; 
6. to try out new behaviors directly with others;

7. to have the experience of helping as well as being helped;

8. to be valued by more than one person;

9. to focus upon the generalities of experience within the group;

10. to obtain a definition of social reality (Carkhuff, 1969e, p. 181).

Advantages discriminating group over individual processes for the trainer/helper are also significant.

The helper has an opportunity to:

1. observe directly the behaviors of the individual helpees;

2. facilitate communication between individual helpees;

3. create a facilitative group atmosphere within which each group member may come to serve as a helper;

4. focus directly upon the generalities in the group experience;

5. utilize his resources in such a way as to get a maximum return in human benefits for a minimum of investment of time and energy on the part of the helper (Carkhuff, 1969e, p. 181).

It is important to note the limitations of group processes for the helper/trainer and helpee/trainee. They may be more difficult for the helper to control, since there are more individuals and interactions to which the helper must attend. An effective leader can minimize these conditions, however, and handle group crises just as he would a crisis in individual treatment. If 
necessary, individual treatment can be offered concurrent with group processes (Carkhuff, 1969e).

Several conclusions can be reached regarding the preference of the human relations model in training and treatment. This model is goal-and-action-directed and provides a work-oriented structure through which experiential and therapeutic processes can take place. It emphasizes practice in the behavior one wishes to effect and leaves the trainee/helpee with tangible and usable skills. Longer retention of these skills is promoted, since they are learned as a result of direct teaching, shaping and modeling. Group members can be systematically selected and there is a built-in means for assessing the effectiveness of the program because the very nature of systematic training involves steps that lead to measurable outcomes (Carkhuff, 1969e). "In summary, what can be accomplished individually can be accomplished in groups--and more! What can be accomplished in groups can be accomplished in systematic training--and more (Carkhuff, 1969e, p. 184)!" This chapter has covered the following five areas: (1) The history and evolution of Carkhuff's model for helping; (2) the assumptions relating to Carkhuff's model for helping; (3) the importance of training people in the helping roles to perceive and respond with empathy; (4) the rationale for nurses to be educated to perceive 
and respond with empathy; and (5) the rationale for using the human relations training model in a staff Development Program. 


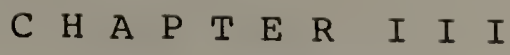 \\ RESEARCH DESIGN AND METHODOLOGY
}

\title{
Introduction
}

This chapter presents detailed descriptions of the design, methods and procedures used in the study. Separate sections of the chapter are devoted to the Staff Development Program which includes an introduction and the construction and rationale of the program. A description of the research site and the study sample follows. Additional sections describe the hypotheses, instruments used in the study, data-collection process and the procedures used to analyze the data. The final sections enumerate the selection, training and reliability of the raters, as well as the trainer/investigator's level-offunctioning.

\section{Program Description}

Introduction to the Staff Development Program. It has been previously documented that empathy was found to be the primary ingredient in any helping relationship (Carkhuff, 1969d; Gazda et al., 1973; Rogers, 1961). Further research supported the concept that if a helper could perceive and respond accurately with empathy, the remaining dimensions of the helping relationship could then be easily discriminated (Carkhuff, 1969d; Berenson, 
Mitchell \& Laney, 1968; Carkhuff \& Berenson, 1967; Carkhuff, Kratochvil \& Friel, 1968; Truax \& Carkhuff, 1967). The importance of possessing a high level of helping skills has been previously explicated. The Staff Development Program prepared by the investigator was based on this knowledge. It was outlined specifically to educate people in the helping professions to increase their abilities to perceive and respond with empathy. The effectiveness of the program in accomplishing this goal was analyzed. A detailed description of the procedure will be given in a later section of this chapter.

The Staff Development Program was planned around a human relations model. Group training as a preferred mode of learning was based on the following propositions (Carkhuff, 1969e):

(1) The core of functioning is interpersonal. The assumption is that interpersonal processes reflect intrapersonal dynamics; what is going on within an individual is manifested in the behavior between individuals.

(2) The core of the helping process is interpersonal. Helping implies that other people are involved. "Constructive interpersonal learning experiences constitute the corrective antidote for destructive interpersonal learning experiences (p. 131)." 
(3) Group processes are the preferred mode of learning interpersonal functioning. Groups are inherently interpersonal; they offer the means not only to work with a trainer but also to relate to other members as well as to the group as a whole. "Group processes offer the prospect for the greatest amount of learning for the greatest number of people at one time (p. 130)."

(4) Systematic group training in interpersonal functioning is the preferred mode of learning interpersonal processes. Training in interpersonal skills is the crux of coping with life. "Systematic training in interpersonal skills affords a means of implementing the necessary learning in progressive gradations of experience which insure success of learning (p. 131)."

Carkhuff (1969e) further found that when the goal is "having the trainees incorporate and retain long-term changes in perception and communication, and indeed, in their life styles, then an integrated approach with teaching built upon an experiential and modeling base is most effective (p. 170)." Lieberman, Yalom and Miles (1973), in their most recent and significant research, stated that success in encounter skills depended on imparting cognizant skills.

The human-relations-modeled staff Development Program was designed for use with all people in the helping professions. The sample chosen for investigation 
in the study was professional nurses, based on documented need as described in Chapter II, and because of the investigator's close association with and work in the nursing profession.

An outline of the Staff Development Program follows with the projected and actual time sequence of the program.

\begin{tabular}{lccc} 
Content & Week & $\begin{array}{c}\text { Projected } \\
\text { Hours }\end{array}$ & $\begin{array}{c}\text { Actual } \\
\text { Hours }\end{array}$ \\
\hline $\begin{array}{c}\text { Introduction to the } \\
\text { Program }\end{array}$ & 1 & 1 hour & $1 \frac{1}{2}$ hours \\
$\begin{array}{l}\text { Signing of Contracts } \\
\text { f }\end{array}$ & & &
\end{tabular}

I. Training in Perceiving

A. Assessment of

Perceptual Ability

Pretest: Carkhuff's

Index of Communication
B. Training in
2
1 hour
1 hour
Perceiving
Phase One
Use of Empathy Scale

Phase Two

3

1 hour

$1 \frac{1}{2}$ hours

Nonverbal

Behavior

Phase Three

4

1 hour

$1 \frac{1}{2}$ hours

Core Condition

of Empathy

II. Training in Responding 5

1-2 hours

2 hours

A. Responding with

Empathy

Ineffective 6
Communication Styles

III. Summary

Applications in Practice

1-2 hours

$1 \& 3 / 4$

1 hour $\quad 1 \frac{1}{2}$ hours

Posttest: Carkhuff's

Index of Communication 
Training Time: The sessions were held once a week for seven weeks.

Projected hours: Seven to nine hours. Actual hours: 10 and $3 / 4$ hours.

The length of the program depended solely on the necessary content. Research had shown that those best prepared to assist helpees were those who could discriminate, communicate and respond at high levels-offunctioning (Carkhuff, 1969e). For this reason, greater training time was given to responding dimensions rather than perceiving dimensions because a person can perceive accurately without responding appropriately (Carkhuff, 1969d, 1969e). The program was then blocked into an appropriate, feasible schedule. The projected schedule represented the minimum numbers of hours and weeks. Since it was known from previously documented studies that sections in responding require the greatest impetus, it facilitated the purposes of the study to cover all of the material according to group needs. The projected time-framework was therefore open to change. Sessions were held once a week.

After developing the content of the Staff Development Program, the investigator reviewed the literature to document the effectiveness of similar programs with relation to their length. Research showed that effective training programs vary in length as well as intensity of 
experience. Vitalo (1971) reported results at greater than the .001 level of significance in a training program of fifteen hours. Berenson, Carkhuff and Myrus (1966), Carkhuff and Truax (1965a), Pierce and Drasgrow (1969), and Pierce, Carkhuff and Berenson (1967) demonstrated the efficacy of successfully training people in shortterm programs of fifteen to thirty hours. Collingwood (1969) studied a group of 98 undergraduate students who received ten hours of experiential and didactic training. The trainees demonstrated gains at a .001 level of significance, with the mean score climbing in pretesting to posttesting from 1.49 on a five-point scale to 2.77 . Carkhuff (1970) documented training success for a twoweek intensified experience and Carkhuff and Bierman (1970) for a twenty-hour program extended over ten weeks. Prior to implementing the full investigation, a pilot study was done with the raters as part of their training.

With a brief knowledge of the rationale and outline of the Staff Development Program design, the study will now provide a detailed description of the construction and rationale of the program. 


\section{The Construction and Rationale for the Staff}

Development Program. There were two major divisions of the content in the program: perceiving and responding. The area of perceiving will be considered first. Perception was in two main divisions: assessment of perceptual ability and training in perceiving, which was composed of three phases.

The assessment of an individual's perceptual ability assumed that his accurate perception was a prerequisite to his ability to respond correctly (Carkhuff, 1969d, 1969e). Carkhuff (1969d, 1969e) further showed, however, that even perceiving accurately did not necessarily guarantee accurate responses. High-level perception, however, is a prerequisite for high-level response. It was therefore necessary to assess the trainee's perceptual skills prior to training. Carkhuff's Index of Communication (Appendix A) was administered to assess the perceptual ability of each nurse self-selected into the program. Any nurse who scored higher than 2.0 on the Index of Communication was to be eliminated from participation in Group I and Group II in the investigation. This follows the data analysis procedures described in a later portion of this chapter.

The second section in perceiving involved three phases. Each phase will be reported individually. The reader should note that only examples from tools and materials used in the Staff Development Program will be 
presented in the body of the investigation. The complete materials can be found in the appendix.

In Phase One of training in perceiving, the goal was to enable the trainee to begin to develop a feeling for accurate and inaccurate perceptions, as well as for facilitating and nonfacilitating responses. An example from the helpee situations used is the following (Appendix F) :

Helpee Situation 3

Tenth-grade girl to teacher: "I just hate to go home after school. If I'm not fighting with my parents, they're fighting with each other. It's always so uncomfortable at home."

Helper Responses

19. "You are dissatisfied with your home life in comparison with school."

20. "It's hard to cope with the constant fighting in your home, yet you don't know what you can do about it."

21. "Why do you have trouble with your parents?"

22. "It's upsetting not being able to feel comfortable at home with family fights every day."

23. "You really hate to go home because you feel so uncomfortable as a result of all the fighting between your parents and yourself."

24. "You're tired of being greeted in your home by harsh words and an unpleasant atmosphere. You'd just like to feel that you could go home and feel welcome."

25. "The situation at home makes you feel uneasy." 
26. "Do you think it is something that will blow over?"

27. "Why don't you threaten to move out?"

$$
\text { (Gazda et al., 1973, pp. 74-75). }
$$

The trainee was then introduced to Carkhuff's Empathy Scale (Appendix B). The trainer discussed the first situation by presenting the stimulus statement, discussing surface feelings expressed in the stimulus statement and rating the level of response according to Carkhuff's Empathy Scale. When members were confident in the use of the rating system, they were instructed to rate the other helpee situations. Discussion of the situations, responses and ratings of the trainees followed.

Phase Two of training in perceiving concentrated on nonverbal behavior or expressive movements and contextual variables. Nonverbal behavior and all related features of a person tell us something about the kind of person he is and what he is saying (Gazda et al., 1973).

McGowan and Schmidt (1962) noted that it is possible that nonverbal communication is one of the variables that distinguishes an experienced counselor from a novice. It is his ability to pick up and respond to minimal nonverbal cues in an accurate manner. Recent literature stressed the importance of such cues in therapeutic interaction 
(Duncan, 1969; Ekman \& Friesan, 1968; Ellsworth \& Ludwig, 1972; Hinchliffe, Lancashire \& Roberts, 1971).

The powers of observation were the focus in order to increase sensitivity to the nonverbal cues of others. Phase Two was accomplished by use of the following exercises:

Observation Exercise (Blanchard, 1973). Members of the group divided into dyads. They were instructed to sit facing one another for one minute and observe everything about their partner. Items suggested to note included posture, eye contact, placement of hands and feet, facial expressions, physiological reactions such as flushing, perspiring, tightening or relaxing of muscles and the attire of individuals. Then members of each dyad turned back to back and the agreed-upon member changed five things about himself. When this was accomplished, members once again faced each other. The observing member attempted to notice the changes. Roles were then reversed. Processing followed.

Body Talk (Pfeiffer \& Jones, 1972). Each group member had several turns expressing certain emotions with his body. The trainer distributed to members slips of paper containing emotions and the part(s) of the body to be used in expressing each. Other participants tried to guess what feeling was being expressed. Processing followed. 
Nonverbal Feedback (La Monica, 1974). Paired group members took turns in developing hypothetical counseling situations and then role-playing the situations. One member of the dyad was the counselor; the other, the counselee. The trainer gave instruction to role-play effective and ineffective styles of listening nonverbally. All group members gave feedback on their reactions to what they had observed regarding nonverbal communication. Processing followed.

In the final phase of this training, Gazda et al., (1973) found that the trainee was involved in experiencing and learning a specific core condition. The core condition for the study was empathy, which Carkhuff (1969d) had found to be the primary ingredient in helping.

The following experience attempted to meet the goal of Phase Three. Involved was the trainee's ability to perceive accurately surface and underlying feelings (Gazda et al., 1973). Examples used in this section included the following (Appendix G):

Situation 1

Teacher to teacher: "I'm so mad at myself! I was upset and tired and I blew-up at my class for no reason. I know some of them felt hurt."

Feelings present: upset, mad, angry, tired, guilty, ashamed, uncomfortable. 
Situation 2

Student to student: "I am so mad! It seems as if every time I have to study, these certain girls pick that time to go wild. They run up and down the hall yelling and in and out of my room asking me questions. I know I could go to the library, but I don't think it's fair for me to have to leave. What really frustrates me is that they always seem to make better grades than I do, without ever studying."

Feelings present:

Situation 6

Student teacher to another student teacher: "Today I was helping Blaine read a story. It was about a little bear that had parents that loved him. Blaine then reported to me that his parents hated him, but he was glad because he hated his parents, too. I could tell by his reactions that he was very sensitive about this so I changed the subject. There must be a way to help him, but I was so overwhelmed with his sudden remark, I just didn't know what to say."

Surface feelings:

Underlying feelings:

(Gazda et al., 1973, pp. 67-68).

The first situation was used as an example. Members were then instructed to do the situations in which they had to identify only the feelings present. These emotions were discussed in the group. Each member then looked over the feelings perceived in these situations and classified them as either surface or underlying feelings. Following discussion of both types, trainees were asked to complete the rest of the situations, identifying surface and underlying feelings. Discussion and processing followed. 
Discussion of the major division of training in perceiving has previously been given. The second major division of the Staff Development Program was training in responding. The most time was devoted to this area, since it was established that in order to communicate effectively, one must be able to respond accurately to perceived feelings (Carkhuff, 1969d). Training in responding was divided into two sections: responding with empathy and ineffective communication styles.

It was first necessary to look at the goals and rationale for responding with empathy and explain the guidelines to the trainees.

"To respond means, among other things, to answer, reply, act, behave (Gazda et al., 1973, p. 54)." As used in this program, it included verbal and nonverbal behavior, as well as direct physical activities, such as embracing and touching.

As stated previously, Carkhuff (1969d, 1969e) said that before one can respond accurately, one must learn to perceive accurately. This section in responding was therefore a summary and extension of what had previously been learned. This fits into the theoretical model of communication, which includes a sender, message and receiver on a continual, dynamic basis. 
Gazda et al. (1973) explicated guidelines for responding with empathy.

(1) Verbal and nonverbal behavior should be in the intense focus of the helper.

(2) The helper should formulate responses of empathy in a language and manner that is most easily understood by the helpee.

(3) The tone of the helper's response should be analogous to that of the helpee.

(4) The helper should actively use empathy in responding to the helpee.

(5) In addition to concentrating on what the helpee is expressing, the helper should be aware of what is not being expressed.

(6) The helper must accurately interpret responses to the helpee and use them as a guide in developing future responses.

The following examples of the situations used in responding with empathy were intended to utilize and expand all of the principles learned previously.

Helpee Situations

1. Student to student: "Since I got out of the army, school just hasn't been the same. The things I had fun doing when I was here before seem real silly now."

Helper Responses

Formula: You feel because Natural: 
2. Student to teacher after school: "We all like your class, but we seem to do the same thing every day. Class would be more interesting if you would do something besides lecturing."

Helper Responses

Formula: You feel because

Natural:

3. Teacher to teacher: "At every PTA meeting, only the parents of the good kids come. The parents I really need to see are the ones who never show up."

Helper Responses

Formula: You feel

because

Natural:

(Gazda et al., 1973, pp. 75-76).

Each member was instructed to write formula responses for the situations first. These were discussed by the group. Following this discussion and utilizing the Vocabulary of Affective Adjectives (Appendix I), each member formulated more natural responses that served as a flowing way to express perceived feelings with appropriate responses. Processing and discussion followed.

Responding with empathy was the first division of training in responding: a study of ineffective communication styles was the second.

studying ineffective communication styles was designed to increase the trainee's awareness of the many ways of responding that might be not only unhelpful but actually 
harmful. It was intended that trainees should be able to formulate good responses based on what they had learned previously (Gazda et al., 1973).

The following examples of situations used in this section illustrated responses that are not helpful

(Appendix J) .

Helpee Situation 2

Teacher to another teacher: "Consultants!

Consultants! They keep sending these people around with their impractical ideas!"

Helper responses that are not helpful:

1. SWAMI: "You better make them think you follow their suggestions. If you don't, it will get back to the principal."

The Swami knows and predicts exactly what is going to happen. By declaring the forecast, the Swami relieves himself of responsibility and sits back to let his prophecy come true.

2. JUDGE: "Sounds like your attitude may have kept you from giving their ideas a fair chance."

3. SIGN PAINTER: "You're just a complainer! You don't seem to like anything that happens!" The Sign Painter thinks a problem can be solved by being named. He has a unlimited inventory of labels to affix to persons and their problems.

4. DRILL SERGEANT: "You need to adapt their ideas to your own situations. Try thinking of it that way next time they come."

The Drill Sergeant gives orders and expects them to be obeyed. Because he knows just what the helpee should do, he sees no need to give explanations or listen to the helpee's feelings, or to explain his commands to the helpee.

Helper response that follows the model: 
Helpee Situation 5

Teacher to another teacher: "I don't know what
to do with this class! They won't learn anything!"

Helper responses that are not helpful:

1. DETECTIVE: "What's causing the problem?"

2. FLORIST: "With all your ability? I can't believe that! Why, you're the best teacher in the building!"

3. JUDGE: "Have things been bad all year? You know if you got off to a bad start with your class, you are going to have a hard time changing them."

4. SIGN PAINTER: "You're a born pessimist!"

5. DRILI SERGEANT: "First get them all tested. Then ability group them. Keep your problem students busy with simple projects so they won't bother
others. Then...."

6. GURU: "Things always look the worst before they get better."

7. SWAMI: "If you don't get some results with them pretty soon there will be trouble! They take achievement tests next month, you know."

8. FOREMAN : "Let's stop for pizza on the way home tonight and forget about school for a while."

9. MAGICIAN: "You're imagining things--that's a good class and you know it. They're learning a lot more than you give them credit for!"

Helper response that follows the model:

(Gazda et al., 1973, pp. 63-65).

Trainees were asked to discuss why each response in these situations was unhelpful, delineating underlying and surface feelings presented. They then formulated responses 
that followed a helper's model and explained their reasoning. Processing and discussion followed.

The two major divisions of the Staff Development Program were training in perceiving and training in responding with empathy. The last week's content provided a summary of this learning, with application to the specific helping profession. In addition to receiving feedback on every session, participants were asked to discuss openly the program and their reactions, feelings, suggestions, and integrations into their individual practices. For the investigation, which used a sampling of nurses, it was the practice of nursing. These subjective evaluations and other qualitative information were kept by the investigator in a journal. Trainees also wrote an evaluation of the program (Appendix $K$ ). These evaluations will be presented and discussed in Chapter IV. The posttest, using Carkhuff's Index of Communication, was given during the last session.

The program-description section has attempted to delineate for the reader the outline, rationale and content of the Staff Development Program. The three areas of foci were training in perceiving, training in responding and the summary. The program was spread over seven weeks with sessions held once a week. The total length of the program was approximately ten and three-quarter hours. 


\section{$\underline{\text { Research Facility }}$}

For several reasons Wesson Memorial Hospital, Springfield, Massachusetts, was the research facility chosen for the study. First, the institution was most willing to support such a study. The administrative staff, as well as the people in the Department of Nursing, expressed their belief that the study would have direct value to their institution and contribute significantly to the professional literature. The investigator has had

a great amount of contact with Wesson Memorial Hospital over the past seven years and has found the people associated with the hospital to be most supportive of all educational processes.

The second reason for selecting Wesson Memorial Hospital was that it seemed to be representative of all medium-sized, urban, acute-and-chronic-care facilities. It has experienced a rapid expansion of its facilities in the past decade concurrently with changes to progressive philosophies of patient care and education.

The final reason for using Wesson Memorial Hospital as the research facility was that it purports to be concerned with increasing the level of patient care given at the hospital. This factor is one of the end-results of having nurses raise their levels of helping skills. 


\section{Description of the Sample}

The sample employed in the study consisted of 39 employed, female, Registered Nurses from Wesson Memorial Hospital, Springfield, Massachusetts. The research facility was previously described. Of the 39 nurses, two changed their positions to another facility immediately prior to commencing the Staff Development Program. During the investigation, however, these two subjects continued to participate with the staff of said hospital in the program.

These Registered Nurses had obtained their education in either a Diploma School of Nursing or an Associate Degree Program. In an effort to eliminate the variable of added education in the applied behavioral sciences, nurses educated in a Baccalaureate Program were excluded from the sample. The ages ranged from 21 to 45 years. The participants had worked actively as nurses for a minimum of six months preceding the investigation. The positions in the hospital included Staff Nurses, Assistant Head Nurses and Head Nurses. They were continuously employed during the study.

Of the 39 who volunteered and were eligible for participation in the study, 24 scored less than 2.0 on Carkhuff's Index of Communication. These were divided into two groups: Group I and Group II. Group I received the pretest, Staff Development Program and posttest. 
Group II received only the pretest and posttest. The remaining 15 nurses contained within the sample were in Group III, which received only the posttest. Their scores ranged from 1.23 to 2.23 .

\section{Hypotheses}

Given that there were nurses who had low levelsof-empathy and those same nurses participated in a Staff Development Program designed specifically to increase their abilities to perceive and respond with empathy, the following null hypotheses were tested in the research. The rejection level for each hypothesis was at the .05 level of significance.

1. There is no significant difference of mean scores on Carkhuff's Index of Communication between practicing nurses pretested in Group I, the experimental group, and Group II, the control group.

2. There is no significant difference of mean scores on Carkhuff's Index of Communication between the posttest scores of Group I, the experimental group, and the posttest scores of Groups II and III, the control groups. 
3. Upon rejection of Hypothesis II, the following two hypotheses were to be tested: (A) There is no significant difference between posttest scores of Group I and Group II, and Group I and Group III; (B) there is no significant difference between posttest scores from Group II and Group III.

\section{Instrumentation}

There were two major areas in which instruments were used for data analysis: Those to assess the Staff Development Program and the ones used to assess the raters.

Instruments used to assess the Staff Development

Program. Carkhuff's Index of Communication (1969d) was the primary instrument given to all subjects in the study sample (Appendix A). The instrument is composed of sixteen short paragraphs that suggest feelings and content often revealed within the counseling relationship. Table 1 contains Carkhuff's delineation of the content of the instrument.

Each situation reads as a segment of a conversation in which a woman expresses some of her thoughts and feelings. The task for the respondents was to read each excerpt, assume that the material contained had been 
TABLE 1

COMMUNICATION: DESIGN OF HELPEE STIMULUS

EXPRESSIONS INDEX

\begin{tabular}{|c|c|c|c|}
\hline \multirow[b]{2}{*}{ Problem Areas } & \multicolumn{3}{|c|}{ Affect } \\
\hline & $\begin{array}{l}\text { Depression- } \\
\text { Distress } \\
\end{array}$ & $\begin{array}{l}\text { Anger- } \\
\text { Hostility }\end{array}$ & $\begin{array}{l}\text { Elation- } \\
\text { Excitement }\end{array}$ \\
\hline Social-interpersc & Excerpt 1 & Excerpt 5 & Excerpt 9 \\
\hline Educational-vocational & Excerpt 2 & Excerpt 6 & Excerpt 10 \\
\hline Child-rearing & Excerpt 3 & Excerpt 7 & Excerpt 11 \\
\hline Sexual-marital & Excerpt 4 & Excerpt 8 & Excerpt 12 \\
\hline Confrontation of helper & Excerpt 15 & Excerpt 16 & Excerpt 13 \\
\hline Silence & & Excerpt 14 & \\
\hline
\end{tabular}

(Carkhuff, 1969d, p. 99).

expressed to them and they desired to be of help to the woman. The final task for the respondents was that they write down their best response under the circumstances described above.

The validity of the instrument itself as well as that of the written form was investigated by Greenberg (1968). He established the close relation between the following three conditions: (1) responding in writing to helpee stimulus expressions; (2) verbally responding to helpee stimulus expressions; and (3) responding in a helping role. He documented that written and verbal responses to helpee stimulus expressions were valid indexes of the assessment of a counselor's level-offunctioning in the helping role. 
Carkhuff's index has been used with a number of different kinds of people. Table 2 provides the data from the index and shows comparisons of the way different populations responded. His Index of Communication was given to each subject in the sample as well as to the trainer/investigator.

The second instrument used in assessing the staff Development Program was Carkhuff's Empathy Scale (Appendix B), which measures empathic understanding in interpersonal processes. Carkhuff's original scale was modified by omitting level five, which exists only in intense relationships (Gazda et al., 1973). The key to the empathy rating was the proximity of the helper's response to the helpee's expression in relation to the helpee's expressed affect and content.

The last instrument used to assess the staff Development Program was the Personal Data Sheet (Appendix C). This was developed by the investigator to obtain necessary information about each participant--to insure her eligibility to become part of the sample. The contract for full participation, completion of group requirements, and permission for the investigator to publish the results of the study was also a part of this instrument.

The three instruments used in the study to assess the Staff Development Program have been described. The 
TABLE 2

COMMUNICATION: RATINGS OF FACILITATIVE CONDITIONS

AND RESPONSE REPERTOIRE OF HELPER RESPONSES TO HELPEE STIMULUS EXPRESSIONS

\begin{tabular}{|c|c|c|c|}
\hline \multirow[t]{2}{*}{$\begin{array}{l}\text { Populations } \\
\text { (Levels) }\end{array}$} & \multirow{2}{*}{$\begin{array}{c}\mathrm{N} \\
\text { (Number } \\
\text { of } \\
\text { Subjects) }\end{array}$} & \multicolumn{2}{|c|}{$\begin{array}{c}\text { Level of Communication } \\
\text { (Ratings of Helper } \\
\text { Responses on } \\
\text { Five-point Scales) } \\
\end{array}$} \\
\hline & & Mean & $\begin{array}{l}\text { Standard } \\
\text { Deviation }\end{array}$ \\
\hline \multicolumn{4}{|l|}{ General Population } \\
\hline $\begin{array}{l}\text { Outpatients } \\
\text { Parents }\end{array}$ & 10 & 1.5 & 0.4 \\
\hline $\begin{array}{l}\text { Parents } \\
\text { Military }\end{array}$ & $\begin{array}{l}20 \\
10\end{array}$ & $\begin{array}{l}1.5 \\
1.6\end{array}$ & $\begin{array}{l}0.5 \\
0.5\end{array}$ \\
\hline \multicolumn{4}{|l|}{ College students } \\
\hline Freshmen & 330 & 1.6 & 0.5 \\
\hline Upperclass philosophy & 30 & 1.5 & 0.5 \\
\hline Student leaders & 30 & 1.5 & 0.5 \\
\hline Volunteer helpers & 30 & 1.5 & 0.2 \\
\hline Senior psychology & 30 & 1.6 & 0.5 \\
\hline \multicolumn{4}{|l|}{ Lay Personnel } \\
\hline Lay teachers & 50 & 1.6 & 0.5 \\
\hline Lay counselors & 50 & & 0.4 \\
\hline \multicolumn{4}{|l|}{ Professionals } \\
\hline Teachers & 20 & 1.8 & 0.6 \\
\hline $\begin{array}{l}\text { Beginning psychology } \\
\text { graduate students }\end{array}$ & 10 & 1.9 & 0.5 \\
\hline $\begin{array}{l}\text { Experienced counselors } \\
\text { (not systematically } \\
\text { trained) }\end{array}$ & 20 & 2.2 & 0.5 \\
\hline $\begin{array}{l}\text { Experienced counselors } \\
\text { (systematically } \\
\text { trained) }\end{array}$ & 10 & 3.0 & 0.4 \\
\hline
\end{tabular}

(Carkhuff, 1969d, p. 101).

instrument used to assess the raters' reliability will be discussed next. 
Instrument used to assess rater reliability. The Inter-rater Reliability Test was the instrument used in establishing reliability between two raters (Appendix D). The situations in the instrument were taken from Gazda's et al. (1973) training situations in perceiving empathy. The correct ratings were given by Gazda using a fourpoint Empathy Scale.

Following training, each rater took the Interrater Reliability Test. She was instructed to rate each helper response according to Carkhuff's Empathy Scale. Reliability was established by using the instrument. A detailed description of the rater training and reliability assessment will be discussed in a later section of this chapter.

\section{Data Collection}

The data was collected in the summer of 1974. In June 1974, the Director of Nursing at Wesson Memorial Hospital sent out an announcement designed by the investigator to all Registered Nurses concerning the Staff Development Program (Appendix E). Prior to the first meeting and following the announcement, the investigator personally went to visit all nurses of the seven-to-three and three-to-eleven shifts in the hospital to invite them to the meeting and answer any of their questions. Thirty-six nurses promised they would 
attend; twenty-eight actually came. Fifteen subjects agreed to participate in the staff Development Program and were given the Index of Communication at the first session in June 1974. Twelve subjects were eligible to participate in the sample investigated. The remaining thirteen members took the Index of Communication at the same time and were assigned to Group II, pending eligibility in the sample. During the week that followed, the investigator again visited the hospital and requested Registered Nurses to respond to the questionnaire, until there were thirteen participants in Group II that fit into the needs of the sample. The investigator handdelivered and picked up the indexes based on the subjects' schedules.

At the conclusion of the staff Development Program, August 1974, members of Group I, the experimental group, took the posttest using Carkhuff's Index of Communication. Members of Group II, the control group, were contacted by telephone and times were set for when the investigator could personally deliver and collect their posttests. The investigator further visited the hospital to request nurses to participate in Group III, the second control group, and fill out Carkhuff's Index of Communication once. These were also personally hand-delivered and gathered by the investigator. All questionnaires for the three groups were received by the second week of August 1974 . 
Broadly speaking, the request for nurses to participate in the study was very well received. Attrition in Group I was nil. One member from Group II was deleted because she could not be contacted in time to meet the investigator's deadline.

\section{Selection and Training of Raters}

Independent raters were needed in the study, to decrease the possibility of a conscious or unconscious bias in rating the open-ended subjects' responses to Carkhuff's Index of Communication. Each subject was free to respond by writing whatever seemed an appropriate answer to the situations in the space provided on the form. This was done with the assumption that they intended helping the hypothetical person who had expressed thoughts and feelings. The responses therefore had to be evaluated according to Carkhuff's Empathy Scale in order to produce numerical scores.

Two raters were selected for this project. Both were nurses with the Master's level of education and were Educators in Nursing at the University of Massachusetts, School of Health Sciences, Amherst. Rater A had completed her Master's degree in psychiatric nursing. Rater B had a medical and surgical nursing background and was also a Doctoral Candidate in the school of Education, University of Massachusetts. 
The rater-training session lasted one day. The raters were taken through the Staff Development Program designed previously as their training in order to enable them to have a complete, systematic understanding of Carkhuff's model for helping. This was provided by the trainer/ investigator. In addition to providing the raters with a systematic approach to their learning, this gave the trainer/investigator the opportunity to go through the training program before its use on the subjects of the study.

The investigator/trainer then used Gazda's et al. (1973) practice situations in rating helper responses. With extremely positive results, ratings were compared item-by-item with those of the experts provided by Gazda. High levels of discrimination in this exercise were demonstrated. Continuing attempts were made to clarify the raters' understanding of the Empathy Scale during this period.

After these nurses had gone through the training program and practice-rating session, the final goal of the rater-training process was to obtain a measure that would establish inter-rater reliability. This was intended to document that the earlier phases of training resulted in a high degree of consistency between the raters' ratings. The Inter-rater Reliability Test (Appendix D) used to accomplish this goal consisted of 
three situations involving twenty responses. Each rater independently evaluated the twenty responses, rating them according to Carkhuff's Empathy Scale. Table 3 contains the ratings of Rater $\mathrm{A}$ and Rater $\mathrm{B}$.

The Kendall rank correlation coefficient (Siegel, 1956) was used to determine the reliability of these raters. The results of analysis determined the rater reliability to be at .83 , which showed a high degree of agreement between two raters.

All Indexes of Communication were rated by each rater, the mean of the two measurements being used to evaluate the study statistically.

\section{Data Analysis}

The data collected included mean scores of two independent rater's scores generated by subject's responses to Carkhuff's Index of Communication (Appendix A) and personal data (Appendix C) relating to the sample previously described. The Index of communication is standardized; the data sheet is not. The trainer's score on Carkhuff's Index of Communication will be presented in the final section of this chapter. Presentation of the trainer's score is based on Carkhuff's (1969d) work in which he remarked, "The best index of future criterion is a previous index of that criterion (p. 85)," with: "If we want to predict effective 
TABLE 3

RATER EVALUATIONS OF RESPONSES FOR INTER-RATER RELIABILITY MEASUREMENT

\begin{tabular}{|c|c|c|}
\hline Response & Rater A & Rater B \\
\hline (1) & 2.0 & 2.0 \\
\hline (2) & 3.0 & 2.0 \\
\hline (3) & 1.5 & 1.5 \\
\hline (4) & 1.5 & 1.5 \\
\hline (5) & 2.0 & 2.0 \\
\hline (6) & 2.0 & 2.5 \\
\hline (7) & 1.5 & 1.5 \\
\hline (8) & 1.0 & 1.0 \\
\hline (9) & 1.5 & 1.5 \\
\hline (10) & 1.5 & 1.5 \\
\hline (11) & 1.5 & 1.5 \\
\hline (12) & 1.0 & 1.0 \\
\hline (13) & 2.0 & 2.5 \\
\hline (14) & 1.5 & 1.5 \\
\hline (15) & 3.0 & 3.0 \\
\hline (16) & 2.0 & 2.0 \\
\hline (17) & 4.0 & 3.5 \\
\hline (18) & 1.0 & 1.0 \\
\hline (19) & 2.0 & 2.0 \\
\hline$(20)$ & 3.0 & 3.0 \\
\hline
\end{tabular}


helping, we need to obtain an index of the prospective helper trainee's level of functioning in the helping role (p. 86)." Obviously the trainer's effectiveness in training nurses to perceive and respond with empathy is directly proportionate to his own ability to do likewise.

Group I consisted of twelve nurses in the sample who were given Carkhuff's Index of Communication at the onset of the study and who had received scores of 2.0 or less on the Index of Communication. This self-selected group was engaged in the Staff Development Program as previously outlined. The Index of Communication was administered as a posttest of the program. Instructions at the beginning of the instrument were previously described in this chapter.

Group II consisted of twelve nurses in the sample who took Carkhuff's Index of Communication at both the start and completion of the Staff Development Program. Nurses participating in Group II had to have a pretest score of 2.0 or less on Carkhuff's Index of Communication to be eligible to participate in Group II. Group II was not involved in the Staff Development Program and provided the control for testing the effectiveness of the Staff Development Program.

The remaining fifteen nurses comprised the second control section, Group III, and took Carkhuff's Index 
of Communication only at the conclusion of the staff Development Program, without having taken part in the program. This group controlled the test-retest variable. All members in this group were included, regardless of their scores on the Index of Communication.

The Indexes of Communication were rated on Carkhuff's Empathy Scale (Appendix B) by two raters trained on Carkhuff's model for helping. Inter-rater reliability was established by having each rater score three sets of situations involving twenty-responses (Appendix D), again using Carkhuff's Empathy scale. Reliability of the raters was determined by use of the Kendall rank correlation coefficient (Siegel, 1956) and the results were discussed earlier in this chapter.

The pretest helping scores from Group I and Group II were compared by the Mann-Whitney U Test (Siegel, 1956). This measured whether the two groups came from the same population. It tested the first hypothesis that there is no significant difference between Group I and Group II on the pretest. The posttest helping scores from all three groups were analyzed by use of the Kruskal-Wallis one-way analysis of variance by ranks (Siegel, 1956). This tested Hypothesis II. If Hypothesis II was rejected, the Mann-Whitney U Test (Siegel, 1956) would be used to evaluate where the difference in scores lay. This tested Hypothesis III. 
In each analysis, the mean, median and quartile deviation will be presented. These statistics are pertinent to describing the central tendencies and variability of scores when nonparametric statistics are used (Siegel, 1956).

All subjects were offered the opportunity to have their scores discussed with them. No one else was given any individual's score by the investigator. A code number, known only to the investigator, was assigned each subject's responses; all scores were referred to by group number.

Members of all groups contracted for attendance and completion of all requirements of their group. For those persons in the Staff Development Program, the trainer/investigator contracted with them to provide time at their convenience for making-up any material missed during an absence. This contract eliminated the possibility of members not participating and attending fully in the Staff Development Program, since poor attendance would have limited the significance of the results obtained in the research. All group members were also asked to sign a permission form to share in the research study and have the results published. 


\section{Trainer/Investigator's Level-of-Functioning}

Chapter II documented the key to effective process and outcome in a helping relationship; namely, the helper's level-of-functioning (Anthony, 1971; Aspy \& Hadlock, 1969; Berenson \& Carkhuff, 1967; Cannon \& Pierce, 1968; Carkhuff, 1969d, 1969e; Carkhuff \& Berenson, 1967; Carkhuff \& Bierman, 1970; Friel, Berenson \& Mitchell, 1971; Holder, Carkhuff \& Berenson, 1967; Kratochvil, Aspy \& Carkhuff, 1967; Pagell, Carkhuff \& Berenson, 1967; Piaget, Berenson \& Carkhuff, 1967; Rogers et al., 1967; Truax \& Carkhuff, 1965, 1967; Truax, Wittmer \& Wargo, 1971).

The investigator of the study was the developer and trainer of the Staff Development Program. The trainer took Carkhuff's Index of Communication before the Staff Development Program commenced. The Index of Communication was rated by the two raters already described in this chapter. The trainer's mean score by the two raters according to Carkhuff's Empathy Scale was 3.96 on a four-point scale. Carkhuff and Berenson (1967) defined the minimal level-of-functioning for a trainer/helper as 3.00 on a five-point scale.

In summary, this chapter has described the program with complete delineation of the Staff Development Program. The research facility, sample description, 
hypotheses, instrumentation, methods for collection of data, selection and training of raters, procedures for data analyses and the trainer/investigator's level-offunctioning have been described in detail. This information was intended to serve as a basis for understanding the results and analysis of the investigation in the following chapters. 


\author{
$\begin{array}{lllllllllllllllllllll}C & H & A & P & T & E & R & I & V\end{array}$ \\ RESULTS AND DISCUSSION
}

\title{
Introduction
}

This chapter presents the results of the investigation. The data are presented in statistical format with narrative comment to provide clarity. A detailed discussion of the implications of the investigation appears in Chapter $\mathrm{V}$.

The basic data presented in this chapter were derived from scores on Carkhuff's Index of Communication. The term "helping scores" used herein refers to those scores obtained on Carkhuff's Index of Communication.

The remainder of the chapter is divided into three sections which present the data associated with each hypothesis. The fourth section presents a discussion of the results of the data analyses. The final section addressed the subjective evaluations of the staff Development Program by the trainer/investigator and the subjects.

\section{Hypothesis I}

The first null hypothesis predicated that there was no significant difference of mean scores on Carkhuff's Index of Communication between practicing nurses pre- 
tested in Group I, the experimental group, and Group II, the control group.

Mean scores for the two groups in Hypothesis I are given in Table 4 . The reader is reminded that according

\section{TABLE 4}

MEAN HELPING SCORES FOR SUBJECTS PRETESTED IN GROUP I AND GROUP II: HYPOTHESIS I

\begin{tabular}{cccc}
\hline \hline & \multicolumn{2}{c}{ GROUP } & \multicolumn{2}{c}{ G } & \multicolumn{1}{c}{ NuUP } \\
\hline Number & $\overline{\mathrm{X}}$ & Number & $\overline{\mathrm{X}}$ \\
\hline$(1)$ & 1.23 & $(1)$ & 1.38 \\
$(2)$ & 1.56 & $(2)$ & 1.36 \\
$(4)$ & 1.26 & $(3)$ & 1.51 \\
$(5)$ & 1.35 & $(4)$ & 1.38 \\
$(6)$ & 1.48 & $(5)$ & 1.35 \\
$(7)$ & 1.35 & $(6)$ & 1.39 \\
$(8)$ & 1.38 & $(7)$ & 1.68 \\
$(9)$ & 1.43 & $(8)$ & 1.54 \\
$(10)$ & 1.61 & $(9)$ & 1.61 \\
$(11)$ & 1.70 & $(10)$ & 1.31 \\
$(12)$ & 1.64 & $(11)$ & 1.65 \\
& 1.70 & $(12)$ & 1.73 \\
& & &
\end{tabular}

to Carkhuff's Empathy Scale, higher scores indicate higher levels of helping skills. The scale adopted for use in 
the study had a possible range from one to four. It should also be noted that each individual's score is the mean of scores received on the sixteen separate items contained in the Index of Communication.

The mean scores represent the mean of two independent raters' results rounded off to the nearest hundredth decimal.

Measures of central tendency used were the mean and median. The measure of variability was the quartile deviation (Siegel, 1956). These computations of the scores obtained from the pretest given members of Group I and Group II are presented in Table 5.

\section{TABLE 5}

MEASURES OF CENTRAL TENDENCY AND VARIABILITY: HYPOTHESIS I

\begin{tabular}{lcc}
\hline ITEM & GROUP I & GROUP II \\
\hline $\mathrm{N}$ & 12 & 12 \\
$\overline{\mathrm{X}}$ & 1.47 & 1.49 \\
Median & 1.45 & 1.45 \\
$\mathrm{Q}$ & .135 & .13 \\
Range & .47 & .42 \\
\hline
\end{tabular}

A Mann-Whitney U Test was performed on the data from the pretests of Group I and Group II to establish 
whether or not the two independent groups had been drawn from the same population. A $U$ value of equal or less then 37 would have shown a significant difference in the population for a two-tailed test at alpha $=.05$ (Siegel, 1956). In the investigation a $U$ value in Hypothesis $I$ of 66.5 was obtained. This showed that there was no significant difference in the pretest scores of Groups I and II, representing a distribution in the two groups which had underlying continuity. Hypothesis I failed to be rejected.

In summary, the results of the Mann-Whitney U Test used to establish that the two independent samples had been drawn from the same population showed no significant difference between the two groups at alpha $=.05$.

\section{HYPOTHESIS II}

The second null hypothesis was that no significant difference of mean scores on Carkhuff's Index of Communication existed between the posttest scores of Group I, the experimental group, and the posttest scores of Group II and Group III, the control groups.

Mean scores for the three groups in Hypothesis II are given in Table 6 . The helping scores of all members participating in Group III are presented. 
TABLE 6

MEAN HELPING SCORES FOR SUBJECTS POSTTESTED IN GROUPS I, II, AND III: HYPOTHESIS II

\begin{tabular}{|c|c|c|c|c|c|}
\hline GROUP & $I$ & GROUP I & II & GROUP & III \\
\hline Number & $\bar{X}$ & Number & $\bar{x}$ & Number & $\overline{\mathrm{X}}$ \\
\hline (1) & 2.19 & (1) & 2.20 & (1) & 1.64 \\
\hline (2) & 2.74 & (2) & 1.49 & $(2)$ & 1.60 \\
\hline (3) & 2.39 & (3) & 1.80 & (3) & 1.56 \\
\hline$(4)$ & 1.78 & $(4)$ & 1.61 & (4) & 1.53 \\
\hline (5) & 2.68 & (5) & 1.64 & (5) & 1.86 \\
\hline (6) & 2.21 & (6) & 1.63 & (6) & 1.23 \\
\hline (7) & 2.38 & $(7)$ & 1.58 & $(7)$ & 2.10 \\
\hline (8) & 2.16 & (8) & 1.45 & (8) & 1.45 \\
\hline (9) & 3.14 & (9) & 1.48 & (9) & 1.84 \\
\hline$(10)$ & 3.38 & $(10)$ & 1.66 & $(10)$ & 2.14 \\
\hline (11) & 2.71 & (11) & 1.56 & (11) & 1.60 \\
\hline$(12)$ & 3.24 & $(12)$ & 1.88 & $(12)$ & 1.35 \\
\hline & & & & (13) & 1.35 \\
\hline & & & & (14) & 2.23 \\
\hline & & & & (15) & 1.71 \\
\hline
\end{tabular}

Measures of central tendency and variability of the scores obtained from the posttests given Group I, Group II, and Group III are presented in Table 7. 
TABLE 7

MEASURES OF CENTRAL TENDENCY AND VARIABILITY: HYPOTHESIS II

\begin{tabular}{lccc}
\hline ITEM & GROUP I & GROUP II & GROUP III \\
\hline $\mathrm{N}$ & 12 & 12 & 15 \\
$\overline{\mathrm{X}}$ & 2.58 & 1.66 & 1.67 \\
Median & 2.53 & 1.62 & 1.60 \\
$\mathrm{Q}$ & .37 & .105 & .315 \\
Range & 1.60 & .75 & 1.00 \\
\hline
\end{tabular}

A Kruskal-Wallis one-way analysis of variance by ranks was used to determine whether the differences within the sample signified genuine population differences or were merely chance variations (Siegel, 1956). The statistic used in the Kruskal-Wallis test, defined by its formula, tests for the value of $\mathrm{H}$. It is distributed as chi square with df $=\mathrm{k}-1$. An $\mathrm{H}$ value of equal or greater than 13.82 would have shown that the three groups came from the same population with respect to averages at alpha $=.001$ (Siegel, 1956). In the investigation an $\mathrm{H}$ value of 20.5641 , corrected for ties, was obtained. This showed that there was a significant difference in the three groups at greater than alpha $=.001$. Consequently, Hypothesis II was rejected. 
In summary, the results of the Kruskal-Wallis oneway analysis of variance used to determine whether the differences within the sample indicated genuine population differences showed that there was a significant difference in the three groups at greater than alpha $=.001$.

\section{HYPOTHESIS III}

The third null hypothesis assumed that if Hypothesis II was rejected, then the following two null hypotheses would be tested: (A) There is no significant difference between the posttest scores of Group I and Group II, and between Group I and Group III; (B) there is no significant difference between posttest scores from Group II and Group III.

Hypothesis II showed a difference did exist in the posttest scores from Group I, Group II and Group III at greater than alpha $=.001$. Hypothesis III was developed to determine exactly where the difference lay among the three. The Mann-Whitney $U$ Test was used to accomplish this purpose.

The investigation addressed null Hypothesis IIIA first, which claimed there was no significant difference between the posttest scores of Group I and Group II, and between Group I and Group III. Mean scores for the posttest of Group I and Group II are presented in Table 8 . 
TABLE 8

MEAN HELPING SCORES FOR SUBJECTS POSTTESTED IN GROUP I AND GROUP II: HYPOTHESIS IIIA

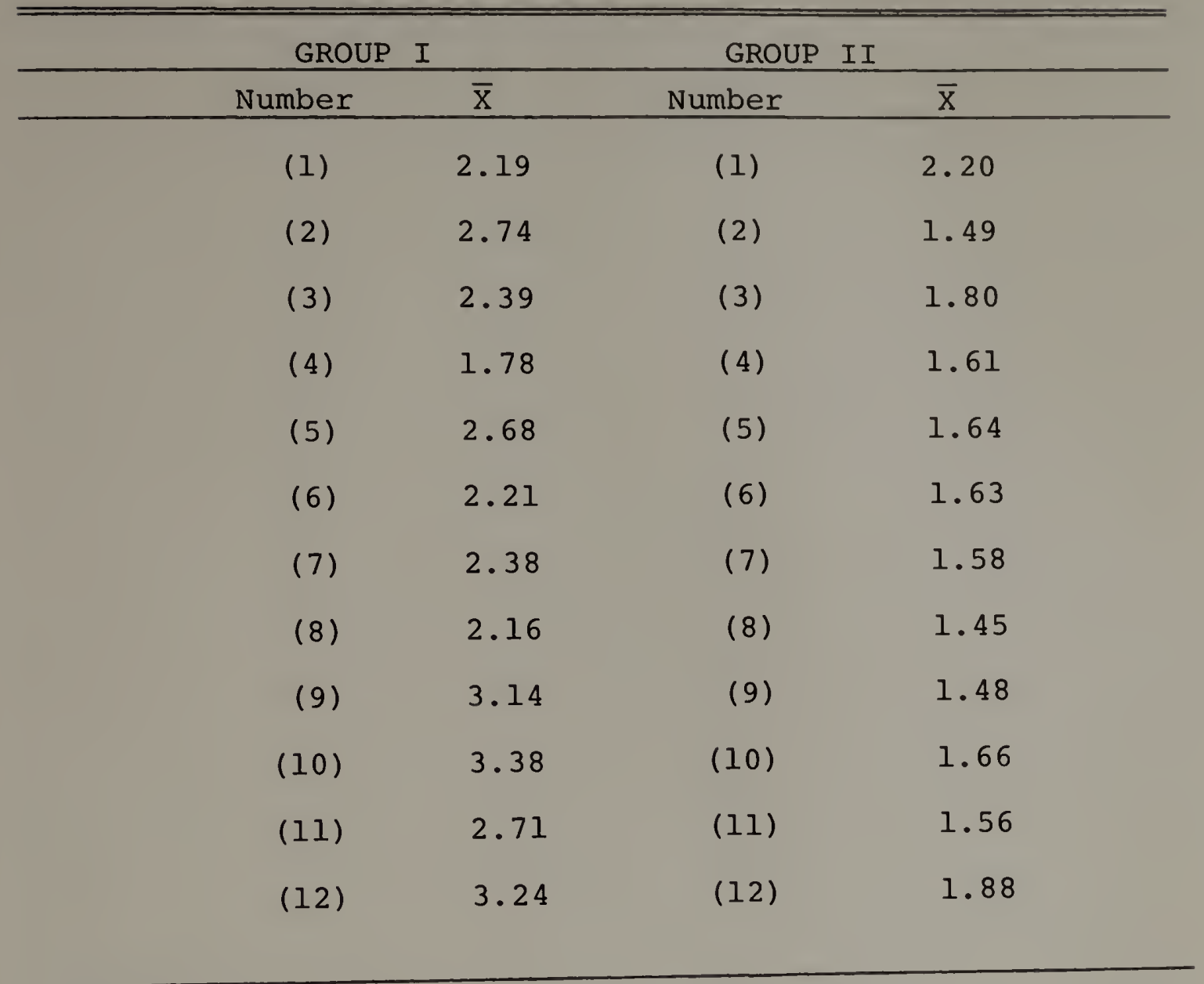

Using the Mann-Whitney U Test, a U value of equal or less than 20 would have shown a significant difference in the population for a two-tailed test at alpha $=.002$ (Siegel, 1956). The investigation obtained a U value in Hypothesis IIIA of 5. This showed that there was indeed a significant difference between the scores obtained 
from the posttests of Group I and Group II at greater than alpha $=.002$.

The study now addresses the posttest scores of Groups I and III, in order to complete analysis of Hypothesis IIIA. The mean scores for the posttest of these groups are presented in Table 9.

Again using the Mann-Whitney $U$ Test, the $U$ value of equal or less than 28 would have shown a significant difference in the population for a two-tailed test at alpha $=.002($ Siegel, 1956). In the posttest scores of Groups I and III, a U value of 8 was obtained. This showed again that there was a meaningful difference between the scores obtained from the posttests of Groups I and III at greater than alpha $=.002$.

As a result of testing the difference in posttest scores from Groups I and II, and Groups I and III, significant population differences were revealed in both tests at levels greater than alpha $=.002$. Hypothesis IIIA was thereby rejected.

In summary, Hypothesis IIIA was rejected as variance between Group I and Group II, and between Group I and Group III, was significantly different at greater than alpha $=.002$.

In testing null Hypothesis IIIB which stated that there was no significant difference between posttest scores from Group II and Group III, a Mann-Whitney U 
TABLE 9

MEAN HELPING SCORES FOR SUBJECTS POSTTESTED IN GROUP I AND GROUP III: HYPOTHESIS IIIA

\begin{tabular}{|c|c|c|c|}
\hline \multicolumn{2}{|c|}{ GROUP I } & \multicolumn{2}{|c|}{ GROUP III } \\
\hline Number & $\overline{\mathrm{x}}$ & Number & $\bar{x}$ \\
\hline (1) & 2.19 & (1) & 1.64 \\
\hline (2) & 2.74 & (2) & 1.60 \\
\hline (3) & 2.39 & (3) & 1.56 \\
\hline (4) & 1.78 & (4) & 1.53 \\
\hline (5) & 2.68 & (5) & 1.86 \\
\hline (6) & 2.21 & (6) & 1.23 \\
\hline (7) & 2.38 & (7) & 2.10 \\
\hline (8) & 2.16 & (8) & 1.45 \\
\hline (9) & 3.14 & (9) & 1.84 \\
\hline (10) & 3.38 & $(10)$ & 2.14 \\
\hline (11) & 2.71 & (II) & 1.60 \\
\hline$(12)$ & 3.24 & (12) & 1.35 \\
\hline & & (13) & 1.35 \\
\hline & & $(14)$ & 2.23 \\
\hline & & (15) & 1.71 \\
\hline
\end{tabular}

Test was again used. Mean scores for the two groups in Hypothesis IIIB are given in Table 10.

The Mann-Whitney $U$ Test was used on the posttest scores from Groups II and III to establish whether or 
TABLE 10

MEAN HELPING SCORES FOR SUBJECTS POSTTESTED IN GROUP II AND GROUP III: HYPOTHESIS IIIB

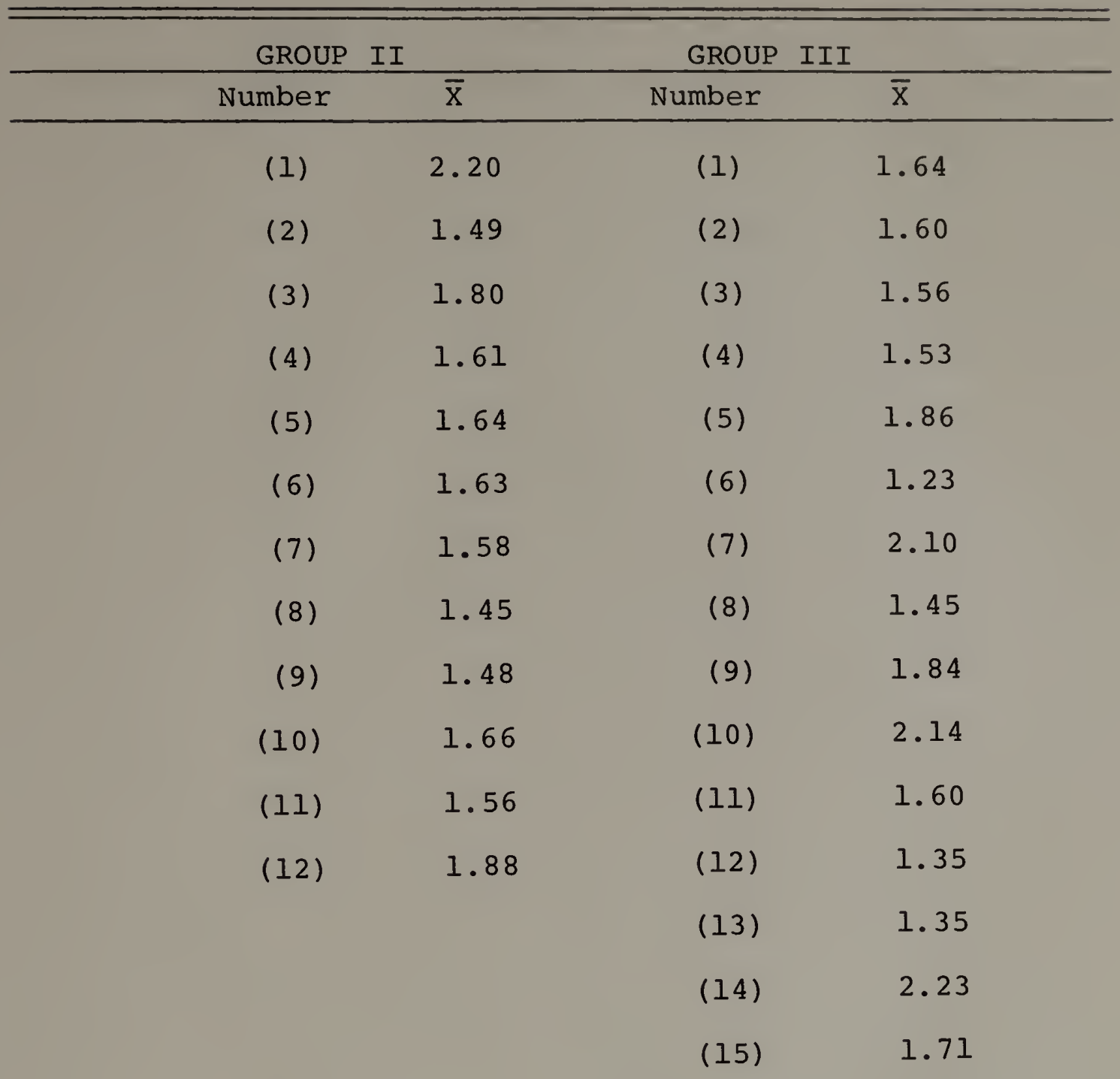

not these independent samples had been drawn from the same population. A U value of equal or less then 49 would have shown a significant difference in the population for a two-tailed test at alpha $=.05$ (Siegel, 1956). In the 
investigation, a $U$ value in Hypothesis IIIB of 87.5 was obtained. Hence there was no significant difference in the posttest scores of Groups II and III; the scores had underlying continuity. Hypothesis IIIB therefore failed to be rejected. No effect of pretesting appeared in Group II.

Summarizing the analysis of Hypothesis IIIA and IIIB, the Mann-Whitney $U$ Tests established that there were important differences at greater than alpha $=.002$ between the posttest scores from Groups I and II, and Groups I and III. There was no real difference between the posttest scores of Group II and Group III.

Analysis of Hypothesis II showed a significant variance in the posttest scores of Groups I, II and III at greater than alpha $=.001$. Further testing in Hypothesis III explicitly pointed out that the variance in the scores existed in Group I at greater than alpha $=.002$. Group II and Group III showed no essential differences in scores.

\section{Discussion of the Results}

The purpose of the study was to assess the levelof-empathy of a sample of professional nurses practicing in an acute-and-chronic-care hospital facility. For those nurses scoring low in empathy, a staff Development 
Program was provided specifically to increase their abilities to perceive and respond with empathy. The effectiveness of the Staff Development Program was tested. Although the literature clearly suggested that helpers needed to have a minimal facilitative level-of-functioning in the core conditions of helping in order truly to help another person (Carkhuff, 1969d), it is less clear that nurses possess the level of helping skills necessary to achieve this goal. Since nurses are by their own definition considered helpers (Henderson, 1966), the study centered on them as a sample to be used in the investigation.

Carkhuff (1969e) identified empathy to be the primary ingredient in any helping relationship. He further found that if a helper is able to perceive and respond with empathy accurately, the remaining dimensions of the helping model can be discriminated rather easily. With this in mind, the investigator developed a Staff Development Program primarily focusing on empathy. The program was designed for use with all professions involved in the helping processes. The final portion of the staff Development Program was provided to relate specifically to individual areas and professions involved in the helping processes.

The standardized instrument used to measure the subjects' level-of-empathy was Carkhuff's Index of 
Communication (Carkhuff, 1969d). Two trained, reliable raters independently evaluated the raw data using Carkhuff's Empathy Scale (Carkhuff, 1969d). The scores from two raters were averaged, thus providing a mean score for each subject on the Index of Communication. The data for Group I, the experimental group, and Groups II and III, the control groups, was evaluated statistically for each of the three hypotheses described in Chapter III. The data associated with the first hypothesis clearly suggested that the members of Group I and Group II represented a sample of the population with underlying continuity. Table 11 lists the mean helping scores of the two groups in rank order. The reader is reminded that the scores from Group III were analyzed with the posttest scores of Groups I and II and therefore are not presented at this time.

Carkhuff and Berenson (1967) defined "the minimal level of self-sustaining facilitation (p. 50)" to be at 3.0 on a five-point scale. Carkhuff (1969e) further identified the fact that helpers who do not possess this level-of-functioning do not really help and may even potentially harm the persons with whom they work. The study used Carkhuff's Empathy Scale, omitting level five, which exists in intense relationships (Gazda et al., (1973). 
TABLE 11

MEAN HELPING SCORES OF TWENTY-FOUR REGISTERED
NURSES PRETESTED IN GROUP I AND GROUP II

\begin{tabular}{|c|c|c|}
\hline & $\frac{\text { GROUP I }}{\overline{\bar{x}}}$ & $\frac{\text { GROUP II }}{\overline{\bar{x}}}$ \\
\hline & 1.70 & 1.73 \\
\hline & 1.70 & 1.68 \\
\hline & 1.64 & 1.65 \\
\hline & 1.61 & 1.61 \\
\hline & 1.56 & 1.54 \\
\hline & 1.48 & 1.51 \\
\hline & 1.43 & 1.39 \\
\hline & 1.38 & 1.38 \\
\hline & 1.35 & 1.38 \\
\hline & 1.35 & 1.36 \\
\hline & 1.26 & 1.35 \\
\hline & 1.23 & 1.31 \\
\hline Group $\bar{x}$ & 1.47 & Group $\bar{x}$ \\
\hline Median & 1.45 & Median \\
\hline
\end{tabular}

The data obtained in the investigation clearly pointed out that the nurses tested in the study had an extremely low level-of-functioning. The scores ranged from 1.23 to 1.73 for the two groups, with the mean at 1.48 and the median at 1.45. The level of 1.00 on 
Carkhuff's Empathy Scale represented irrelevant or hurtful responses, whereas the level of 2.00 represented responses only partially communicating an awareness of the surface feelings of the helpee (Carkhuff, 1969d). The nurses' scores lie almost at the midpoint between hurting another person and only partially responding to superficially expressed feelings. The researcher believed these results to be most serious, inasmuch as all nurses are in positions that demand effective helping skills. Due to the low helping scores, no one was eliminated from the training program.

In the second hypothesis, the posttest scores of Group I, the experimental group, and the posttest scores of Group II and Group III, the control groups, were analyzed for variance. The reader is reminded that only Group I had participated in the Staff Development Program. Table 12 lists the mean helping scores of the posttests from the three groups in rank order.

The results of the analysis of variance showed that there was a genuine population difference between the three groups at greater than alpha $=.001$. The mean score of Group I rose from 1.47 to 2.58 following participation in the Staff Development Program; that of Group II, from 1.49 to 1.66 .

Hypothesis III was formulated to test for the place of the variance if Hypothesis II was rejected. Analysis 
TABLE 12

MEAN HELPING SCORES OF THIRTY-NINE REGISTERED NURSES POSTTESTED IN GROUP I, GROUP II, AND GROUP III

\begin{tabular}{|c|c|c|c|}
\hline & GROUP I & GROUP II & GROUP III \\
\hline & 3.38 & 2.20 & 2.23 \\
\hline & 3.24 & 1.88 & 2.14 \\
\hline & 3.14 & 1.80 & 2.10 \\
\hline & 2.74 & 1.66 & 1.86 \\
\hline & 2.71 & 1.64 & 1.84 \\
\hline & 2.68 & 1.63 & 1.71 \\
\hline & 2.39 & 1.61 & 1.64 \\
\hline & 2.38 & 1.58 & 1.60 \\
\hline & 2.21 & 1.56 & 1.60 \\
\hline & 2.19 & 1.49 & 1.56 \\
\hline & 2.16 & 1.48 & 1.53 \\
\hline \multirow{4}{*}{\multicolumn{2}{|c|}{1.78}} & 1.45 & 1.45 \\
\hline & & & 1.35 \\
\hline & & & 1.35 \\
\hline & & & 1.23 \\
\hline Group $\bar{x}:$ & 2.58 & 1.66 & 1.67 \\
\hline Median: & 2.53 & 1.62 & 1.60 \\
\hline
\end{tabular}

of Hypothesis III clearly placed the variance in Group I at greater than alpha $=.002$. Groups II and III showed no significant differences in scores. 
The data substantiated the effectiveness of the Staff Development Program in raising a helper's ability to perceive and respond with empathy. Related research has also reinforced the knowledge that human-relations modeled training programs integrating didactic and experiential approaches to training have been most successful in raising a helper's level-of-functioning in the core dimensions of helping (Berenson, Carkhuff \& Myrus, 1966; Carkhuff, 1969f; Carkhuff \& Banks, 1970; Carkhuff \& Bierman, 1970; Carkhuff \& Truax, 1965b; Foulds, 1969; Martin \& Carkhuff, 1968; Truax, Silbur \& Wargo, 1966; Vitalo, 1971).

The Staff Development Program in the investigation was a ten-and-three-quarter-hour program spread over seven weeks. Other studies of short-term programs, ranging from 10 to 30 hours, were also successful (Berenson, Carkhuff \& Myrus, 1966; Carkhuff \& Truax, 1965a; Collingwood, 1969; Pierce \& Drasgrow, 1969; Pierce, Carkhuff \& Berenson, 1967).

In order to provide further clarification, Table 13 presents a comparison of the mean pretest and posttest helping scores of the members of Group $I$, the experimental group. In the study, helper growth is defined as the difference between the pretest and the posttest scores. The growth observed in the participants' helping scores ranged from an increase of .43 to 1.68 , with the 
TABLE 13

COMPARISON OF THE MEAN PRETEST AND POSTTEST

HELPING SCORES: GROUP I

\begin{tabular}{|c|c|c|c|c|}
\hline \multicolumn{2}{|c|}{ PRETEST SCORES } & \multirow{2}{*}{$\begin{array}{l}\text { POSTTEST } \\
\text { Number }\end{array}$} & \multirow{2}{*}{$\begin{array}{c}\text { SCORES } \\
\overline{\mathrm{x}}\end{array}$} & \multirow[t]{2}{*}{ HELPER GROWTH } \\
\hline Number & $\overline{\mathrm{x}}$ & & & \\
\hline (1) & 1.23 & (1) & 2.19 & .96 \\
\hline (2) & 1.56 & (2) & 2.74 & 1.18 \\
\hline (3) & 1.26 & (3) & 2.39 & 1.13 \\
\hline (4) & 1.35 & (4) & 1.78 & .43 \\
\hline (5) & 1.48 & (5) & 2.68 & 1.20 \\
\hline (6) & 1.35 & (6) & 2.21 & .86 \\
\hline (7) & 1.38 & (7) & 2.38 & 1.00 \\
\hline (8) & 1.43 & (8) & 2.16 & .73 \\
\hline (9) & 1.61 & (9) & 3.14 & 1.53 \\
\hline$(10)$ & 1.70 & $(10)$ & 3.38 & 1.68 \\
\hline (11) & 1.64 & (11) & 2.71 & 1.07 \\
\hline (12) & 1.70 & (12) & 3.24 & 1.54 \\
\hline Group $\bar{x}$ : & 1.47 & Group $\overline{\mathrm{x}}$ : & 2.58 & Group Growth: \\
\hline Median: & 1.45 & Median: & 2.53 & 1.11 \\
\hline
\end{tabular}

mean at 1.11. It should be noted that eight of the twelve participants raised their levels of empathy by at least one point.

According to Carkhuff's helping model, the minimal level-of-functioning for helpers should be at 3.0. Even 
though the results of the study are significant at greater than alpha $=.001$, only three subjects reached a minimal level-of-functioning after the training program. The 3.0 level represented a response that conveyed the helpee is understood at the level at which he is expressing himself (Carkhuff, 1969d). Eight subjects were in the 2.0 to 3.0 range, which encompasses partial to complete awareness of what a helper expresses (Carkhuff, 1969d). One subject still remained in the 1.0 to 2.0 range that proceeds from a hurtful response to only superficial awareness of what is expressed (Carkhuff, 1969d).

In general terms, the data from the study suggest that Registered Nurses as a group possess extremely low levels of empathy. A training program will significantly raise helper's levels of empathy. These data provide rich implications for future training programs and will be discussed in Chapter $\mathrm{V}$.

\section{Evaluation of the Staff Development Program}

This section presents the subjective evaluations and reactions of the Staff Development Program by the trainer/ investigator and the trainees. The results of these evaluations will be included in the implications of the study, Chapter V. 
The trainer in the Staff Development Program was also the investigator of the project. She kept a weekly journal on reactions of both the participants and herself as well as of the flow of the program. This will be presented first.

The trainer personally invited Registered Nurses to participate in the program after an announcement had been distributed to all nurses by the Director of Nursing, Wesson Memorial Hospital (Appendix E). Thirty-six Registered Nurses agreed to take part; only 28 came to the first session. Of these 28,15 by self-selection chose to share in the Staff Development Program. The trainer did not exclude anyone from the program who did not meet the specifications of the sample; they were later excluded in the data analyses. It was felt by the trainer that an interest in learning should be positively reinforced. The remaining 13 people agreed to be in either Group II or Group III. The trainer had to solicit more participants for Groups II and III and found most of these willing to respond to the Index of Communication. Six of Group III, the one responding to the questionnaire once, refused to identify themselves by name on the Personal Data Sheet.

There was no attrition in the staff Development, but one member dropped out of Group II. This was felt 
to be extremely positive in terms of the process of investigation and the significance of the results.

The trainer felt that initially subjects were overly concerned with perceiving and responding with trite statements. By the sixth week, they seemed to have grasped what it means to be empathic and were responding at high levels.

The group was composed of nurses whose ages spanned the limits proposed in the sample, 21 to 45 . This factor appeared to increase discussion and thereby elicited different opinions and responses based on varied experiences, environmental and contextual variables.

The same sessions were held twice a week, and subjects attended at the most convenient time for their schedules. The groups remained fairly consistent and small, however, seven to eight, which seemed to have been ideal.

The trainer found herself being steadily didactic, as well as participating in the group experience and clarifying as necessary. This process flowed comfortably and effectively.

Nursing content was integrated throughout the entire program as participants constantly drew references from their nursing backgrounds. They explicated the usefulness of receiving varied frames of reference from other group members. They shared experiences freely and supported each other. 
The group favored role-modeling situations; they freely discussed their responses, perceptions and feelings during this process. They were almost surprised to realize how easily little distractions and the very tones of their voices could change the meanings of their responses.

Throughout the seven weeks, it was apparent that the group was becoming more comfortable with one another and the trainer, as well as more supportive and direct. In the third week, one of the subjects asked the trainer to be more specific in clarifying high-level perceptions and responses. She felt the trainer was trying to be "too nice." This was echoed by the entire group. The trainer expressed her hesitancy in being too blunt but recognized that the group was not satisfied at that time with her level of confrontation. This incident appeared to be a bridge to the faster, more direct learning and training which followed.

During the fourth week, members pleaded that they needed more time for every session because they felt they were at their greatest intensity just when it was time to stop. Following discussion, group members decided that they would commit themselves to a minimum of one-and-a-half hours per week. This schedule then continued till the end of the program, with sessions lasting from one-and-a-half to two hours. 
Members reacted to the fact that the majority of situations and responses in the design were negative or unhappy. The discussion that followed stressed the realization that they had difficulty working with situations that contained positive or happy feelings; that it was always easier to respond to unhappiness. This conclusion seemed to be extremely pertinent and meaningful to every group member.

The application to nursing during the seventh week flowed continuously. Members seemed very much more aware of the cliches with which they often responded and were more able to listen and respond with pertinence and empathy to the other person.

In summary, the trainer felt that the Staff Development Program was an effective experience for all group members. The learnings derived from this evaluation will be discussed in Chapter $\mathrm{V}$ in the section addressing the implications of the study.

The reactions and evaluations of the trainer/investigator were previously covered. It included reactions from the participants during the Staff Development Program. At the conclusion of the program, subjects were requested to write a written evaluation of the experience (Appendix K). This evaluation was designed by the investigator for the purpose of the study. The results of these evaluations are presented in the following paragraphs. 
Discussing the content of the Staff Development Program, participants generally felt it to be pertinent to achieving more accurate perceptions and responses to people in need, as well as acquiring a greater awareness of the helpee's individuality and world. Subjects generally commented that the content gave them much to ponder; they had never really been aware of how easy it was to alienate another person without meaning to. The movement from perceiving and responding broadly to more specificity was also positive. Some members felt that the content reviewed what they had learned during their psychiatric affiliation in school, but the experiences, situations and group discussion enabled them to comprehend it much better. A few members wished the program had had more emphasis on nonverbal communication and the theory of Carkhuff's model for helping.

The content was presented using a human relations model with didactic, experiential and interpersonal approaches. This was unanimously well received. The nurses felt that they were able to communicate freely without fear of being "turned off" or giving the wrong response. The role-playing seemed to have the greatest impact. Three members felt the time commitments imposed the only block to total effectiveness in the program. The applications to nursing were without question. Members resolved that henceforth they would certainly 
listen to their patients with a sharper ear. They felt that often they had seemed to lack time to listen and respond to their patients; but now they saw the need to perceive and respond with empathy as a much greater force. They recognized that patients' needs for understanding were just as necessary and important as medications and treatments; that both could possibly be accomplished concurrently. The subjects carried the knowledge and experiences back to their personal environments, saying that they would hereafter listen and respond, not only to patients, but to everyone with whom they came in contact. One participant expressed how she always had empathized with her patients, but had not felt it was important or appropriate to verbalize her feelings before this instruction.

In discussing the technique and tenderness of the trainer, the participants generally felt the trainer's relaxed, informal, helpful, straight-forward style was highly beneficial to their learning. They felt her explanations and suggestions provided a most interesting learning experience. At times, however, they thought the trainer could have provided more of her own knowledge. Participants expressed their appreciation of the fact that the trainer was able to show which perceptions and responses were helpful without pushing her own feelings on anyone or making anyone uncomfortable. Several members 
found that the trainer exemplified the helping model herself by showing much empathy for her trainees. They appreciated the feelings of total community within the group and credited this to the trainer's inclusion of everyone in the experience. One member reacted to the trainer's tendency to "put her on the spot," yet conceded that she was not pushed to react if she did not desire to.

This section has covered the trainer's and trainees' reactions and evaluations of the Staff Development Program. The implications of this will be covered in Chapter $V$, which will provide a discussion of the results of the study in terms of significance, implications, limitations, and suggestions for further research. 


\author{
$\begin{array}{llllllllllllllll}C & H & A & P & T & E & R & V\end{array}$ \\ SUMMARY, LIMITATIONS, IMPLICATIONS \\ AND RECOMMENDATIONS
}

\title{
$\underline{\text { Introduction }}$
}

Chapter $\mathrm{V}$ begins with a brief summary of the results of the investigation based on the data presented in Chapter IV. Limitations of the study follows, including those suggested by data analyses and related research. The chapter ends with a broad discussion of the implications of the results and specific suggestions for further research. The reader should be aware that the use of the pronoun "she" when describing the Staff Development Program and the results of the program do not imply a sexist bias. It related to the fact that the population in the research was all female.

\section{Summary of the Results}

The helping score of the trainer/investigator was 3.94 on a four-point scale. Carkhuff and Berenson (1967) defined the minimal level-of-functioning to be 3.0 on a five-point scale. The level is required to insure that helpers possess the skills necessary to truly help or train another person. Rater reliability was established at .83 , which showed a high degree of agreement between two raters. 
A Mann-Whitney U Test was performed on the data from the pretest scores of Groups I and II to establish whether or not the two independent groups had been drawn from the same population. A U value of equal or less than 37 would have shown a significant difference in the population for a two-tailed test at alpha $=.05$ (Siegel, 1956). In the investigation a $U$ value in Hypothesis I of 66.5 was obtained. This revealed that there was no significant difference in the pretest scores of Groups I and II, representing a distribution in the two groups which had underlying continuity. Hypothesis I failed to be rejected.

A Kruskal-Wallis one-way analysis of variance by ranks was used to test Hypothesis II (Siegel, 1956). This determined whether the differences in the posttest scores signified genuine population differences or were chance variations. The statistic used in the KruskalWallis Test, and defined by its formula, tests for the value of $\mathrm{H}$. It is distributed as chi square with $\mathrm{df}=\mathrm{k}-1$. An $\mathrm{H}$ value of equal or greater than 13.82 would have shown that the three groups came from the same population with respect to averages at alpha $=.001$ (Siegel, 1956). In the investigation, an $\mathrm{H}$ value of 20.5641, corrected for ties, was obtained. This showed that there was a significant variance in the three groups at greater than alpha $=.001$. Consequently, 
Hypothesis II was rejected and Hypothesis III tested.

To discover the place of the variance in the posttest scores, the Mann-Whitney U Test was used on the scores between Groups I and II, I and III, and II and III. Testing on Groups I and II obtained a $U$ value of 5 . A $\mathrm{U}$ value of equal or less than 20 would have shown a significant difference in the population for a two-tailed test at alpha $=.002$ (Siegel, 1956). Testing on Groups $I$ and III found a $U$ value of 8 . A $U$ value of 28 would have documented a significant difference in the population for a two-tailed test at alpha $=.002$ (Siegel, 1956). There were significant population differences revealed in both tests at levels greater than alpha $=.002$. Hypothesis IIIA was rejected.

As a result of the testing of Groups II and III, a $U$ value of 87.5 was obtained. A U value of equal or less than 49 would have documented a significant difference in the population for a two-tailed test at alpha $=.05($ Siegel, 1956). Hypothesis IIIB failed to be rejected.

When the pretest helping scores were analyzed, it was established that the samples in Groups I and II were drawn from the same population. The analysis of variance of the posttest helping scores from Groups I, II and III showed that a variance in the scores existed. Further statistical analysis revealed that the only essential 
variance was between Groups I and II, and I and III.

This suggested that: (1) The experimental program was effective in increasing the subjects' abilities to perceive and respond with empathy: (2) the pretesting had little effect on the posttesting scores; and (3) the time lapse between onset and conclusion of the experiment was not a significant variable.

\section{Limitations of the study}

This section includes explanations of the factors which limit the meaning of the results of the study. Chapter I also contained a section that discussed the limitations of the study; overlap does exist. The difference between the two discussions, however, is that the earlier commented on anticipated limitations which could occur as a result of the design of the study; the comments here are based on the actual experience of conducting the study.

The dependence on one standardized instrument may be a basic limitation of the study. Although Carkhuff (1969d) has done extensive work in creating the standardized and valid Index of Communication and the Empathy scale, the reader is reminded that the helping scores represent data from one single instrument. The theoretical framework reflected in Carkhuff's work has been widely 
but not universally accepted. Further, errors of interpretation in the use of Carkhuff's instrument could have influenced the results. Even though the selection and training of the raters was an important facet of the study, any misuse of the instrument and rating scale could affect the results.

Another limitation is suggested by the nature of the sample. It is difficult to generalize the findings to the nursing population as a whole because of the small number of subjects, even though the sample represented varied backgrounds, ages and experiences as defined in the specifications.

The study used educational examples as a basis for the Staff Development Program. Despite the theoretical basis of this design, the relevance of problems specific to the nursing profession was not investigated.

The research did not test whether an increase in empathy skills produced an increase in the level-offunctioning in the clinical setting. Research has proven, however, that transfer does take place (Carkhuff, 1969e; Martin \& Carkhuff, 1968; Paul, 1967; Truax \& Carkhuff, 1966).

Another limitation may be in assessing the longterm effects of a short-term program. Trainees occasionally return to environments that do not support or reinforce their activities or learning (Meadow \& Tillem, 1963; 
Munger, Myers \& Brown, 1963). This was not investigated in the study.

Finally, differences in the administration of the instrument could have effects on the results. While attempts were made to standardize the administration of the instrument, most subjects taking the posttest in Group II and those being tested in Group III completed the instrument at their leisure, whereas subjects pretested in Groups I and II and posttested in Group I completed the Index of Communication in a formal group setting. This occurred due to inability to arrange a convenient time when administration of the instrument could be accomplished fully and simultaneously. This uneven administration of the instrument may have elicited more or less thoughtful responses from individuals.

All of these limitations could be addressed by additional follow-up and research efforts. They do not suggest, however, that serious attention should not be given the implications of this study, nor should they prevent people from immediately beginning to develop further research and training programs specific to their environments. 


\section{Implications of the Study}

This section provides for a discussion of the implications of the study as based on the results of the investigation.

The fact that the nurses pretested in Groups I and II achieved such low helping scores has definite implications for nurses from Wesson Memorial Hospital, as well as for those in other institutions. While Wesson Memorial Hospital and its staff of nurses share many of the same characteristics with other institutions, however, no link has been established between nurses' helping skills at Wesson Memorial Hospital and elsewhere. Further research is needed before generalizations can be confidently made about the levels of helping skills of nurses in other hospital communities. A replication of the study with subjects from other institutions would be a helpful step in establishing these connections.

Since the study documented that the designed Staff Development Program did raise a helper's ability to perceive and respond with greater empathy, a program could be incorporated into nursing inservice programs that would provide this theory and experience. This could be a mode of reaching the vast numbers of practicing nurses who have no desire or opportunity to return to formalized educational programs. Another possibility is to incor- 
porate this knowledge and experience into evening extension courses sponsored by universities, community colleges and hospitals. An external motivating force, such as requiring nurses to continue their education in order to grow within their practice and position, might be applied.

An outstanding implication would be to test whether student nurses prior to graduation, in fact, receive this knowledge and experience in helping skills. If they do not, it should become a necessary part of nursing curricula. If they are taught this and measure high in helping scores upon their graduation, studies should subsequently be made about the environments in which they work that may effect a lowering of their helping scores. Changes in the hospital milieu should be proposed accordingly. Since the most important aspect in training is the level-offunctioning of the helpers, educators in nursing schools should also be tested and the results studied, with changes or education being required as research implies.

While the findings of the investigation suggest further research outside the Wesson Memorial Hospital community, the major implication is a need for immediate and extensive action. All of the subjects tested possessed dangerously low levels of empathy and all are cast in helping roles, occupying positions where helping skills are most necessary. The implications of these data seem clear. If the staff of Wesson Memorial 
Hospital and other related institutions want to influence the growth, care and rehabilitation of their patients, a means of improving the helping skills of a large number of people needs to be found in a limited amount of time. With reference to the Staff Development Program tested in the investigation, it is clear that the program significantly increased the subjects' abilities to perceive and respond with empathy. In order to bring the subjects' mean levels of functioning from 1.47 to a minimally facilitative level, however, much more intensive training is needed. The Staff Development Program raised only three of the twelve participants to a helping score equal to or above the minimal facilitative level, even though the significance of the research was at greater than alpha $=.001$. Obviously, this is not sufficient! Further studies should attempt to intensify the basic outline. The program should include an expansion of the didactic and experiential components incorporated in the study. Carkhuff (1969d, 1969e), Ivey (1971) and Haase and Di Mattia (1970) provide specific help in suggesting training-program designs that may broaden the model used in the study.

Retraining that enables nurses to maintain their peak post-training levels should also be instituted. Research studies have documented that periodic refresher courses are needed in order for professionals to main- 
tain a peak level-of-functioning (Anthony, 1968; Bellak

\& Small, 1967; Carkhuff, 1968a, 1968b; Collingwood, 1971; Glasser, 1965; Holder, 1969; MC Geoch \& Irion, 1952).

Further research should also emphasize the carryover of learned theory and experiences into clinical practice. This could be accomplished by taping subjects' interviews and conversations with patients at three and six-month intervals and evaluating the effectiveness of their responses at such periods after formal training. Kalisch (197la) reported results similar to the study of the low levels of empathy in nursing students. Since these are still in the process of formally learning to perceive and respond with empathy, and all nurses pass through this educational process, the implications lie with the levels of functioning of the faculty members. Only those persons who possess high levels of functioning can provide for constructive growth of their trainees (Carkhuff, 1969d). This area is another aspect which needs further investigation for trainers/educators in terms of actual testing, carryover in teaching and retraining.

Implications that resulted from subjective evaluations of the staff Development Program showed that the nurse-participants had never before realized the impact and need to perceive and respond with empathy. They were 
more than willing to learn and study, but the program had to be convenient. On the whole, they hesitated when faced with returning to the hospital at night. They generally showed fear of being put "on the spot." The implication is to provide a program that is a necessary part of their work, one in which threatening situations are reduced as much as feasible until the group builds its own support system. This would be paramount to effective learning.

In the final analysis, hospitals should incorporate strong, intense, human relations modeled inservice programs that offer the highest probability of significantly affecting the level of helping skills of their nurses. These should include an intense and broad didactic and experiential component, a clinical component and three and six-month follow-up training sessions. Educational settings should formally integrate theory and experience in teaching helping skills into their curricula. Varieties of programs focusing on this content should be provided through educational institutions, hospitals and all related facilities, to embrace the thousands of nurses practicing in the helping profession. This need is intense! The research not only documents that nurses are practicing with dangerously low levels of empathy, but that with relatively short-term, inexpensive training efforts, their levels can be significantly increased. 
This small effort by Nursing Educators and Administrators would inevitably result in better patient care. Finally, any training program should systematically encompass didactic and experiential bases; they should be given only under the leadership of individuals who have themselves demonstrated high levels of helping skills and who consistently enmesh themselves in maintaining peak post-training levels of functioning.

\section{Suggestions for Further Research}

Several suggestions can be made concerning further investigations implied by the results of the investigation.

The study can be repeated with similar populations from other medium-sized, urban hospitals to enable trustworthy generalizations to be deduced from the specific needs of practicing professional nurses today, together with a training-program design that best meets those needs.

The same study may also be used with smaller, rural hospital communities and larger, urban ones, to discover whether or not environmental and contextual variables have positive or negative effects on nurses' helping skills.

The investigation can be utilized with persons on all levels of the organizational structure to discover 
their individual quality of communication. The implications of the results of such a study may be woven around each person's leadership style and its effectiveness. This may provide the bridge to understanding and change when a person's attitudes or predispositions are in contrast to intended behavior perceived by others (Hersey \& Blanchard, 1972).

Carkhuff (1969e) insisted that at least a minimal facilitative level-of-functioning of the trainer/helper is paramount to constructive growth of the trainee/helpee. Further research then can give attention to similar studies with educators who are theoretically and clinically purporting to educate nurses and all helping professionals. Ultimately, the responsibility begins in formalized educational systems. Concomitantly, student nurses and students in all helping professions should be investigated to determine their levels of functioning in communication skills. As a result of both types of investigations, educators may need training and retraining and/or changes and additions in course content may become necessary. Assuming that student helping-professionals score above the minimal facilitative levels, and practicing professionals score below the minimal facilitative levels, then the environments in which helping professionals practice should be investigated to discover the environmental and organizational reasons for deterioration of helping skills. 
Further investigations should broaden the design of the Staff Development Program with the intention of raising all, or a much greater portion of the subjects' helping scores, to at least a minimal facilitative level. The reader is reminded that even though the significance of the study was greater than alpha $=.001$, only three of the subjects attained above the minimal facilitative level of functioning: 3.0 on a five-point scale (Carkhuff \& Berenson, 1967). Suggestions for extending the foundation of the Staff Development Program include increasing the didactic and experiential components incorporated in the design, and making the program longer in hours with more intensity. The program design can include and test the effectiveness of carryover of learned theory and experiences into clinical practice. This can be done as part of the basic training. Further investigation would then need to be made at three-month, six-month and one-year intervals to reinforce the long-term effects of the training program. Following analysis of the data obtained from such investigations, generalizations may be made concerning the retraining that would become necessary to insure that helpers maintain their maximum post-training levels of functioning.

Research can be done that investigates the effectiveness or ineffectiveness of using situational materials specific to the helping profession being trained, versus 
educational media used in the study with nurses.

The paramount suggestion for further research is grounded on the urgent need for similar studies to be done in order to record the need, provide training and insure that helping professionals in education and practice are meeting their responsibilities by truly helping . 
C H A P T E R

PUBLICATION

\section{Empathy Training as the Major Thrust of a Staff Development Program}

\section{Abstract}

The purpose of the study was to obtain an objective measure of the level-of-empathy of professional nurses practicing in an acute-and-chronic-care hospital facility. For those nurses who scored low in empathy, a short-term, human-relations modeled Staff Development Program was designed specifically to train those helping professionals to increase their abilities to perceive and respond with greater empathy. The results of the study indicated that all of the nurses tested possessed an extremely low levelof-empathy, that the Staff Development Program significantly raised their levels of empathy, but more training is needed to enable all or the majority of subjects to at least reach the minimal facilitative level necessary to truly help another person.

This work is part of the dissertation submitted by Elaine Lynne La Monica for the Ed. D. degree under the direction of Dr. Donald K. Carew at the University of Massachusetts, Amherst. It represents an attempt to present a publishable article as an outcome of the research project. 


\section{$\underline{\text { Introduction }}$}

Nursing by definition is considered a helping profession (Henderson, 1966). Even though it's goal is one of providing growth-facilitating support and assistance, there is quantitative and qualitative evidence that the transactions between these helpers and their clients often do not prove beneficial. Research by Anthony (1971), Berenson, Mitchell and Laney (1968), Berenson, Mitchell and Moravec (1968), Carkhuff (1969b) and Carkhuff and Burstein (1970) on helping conditions indicated that, in fact, the helping process can be destructive to growth rather than enhancing, depending on the level of facilitative skills of the helper. It then is critical that nursing educators and administrators concern themselves with the helping skills of their students and employees. The major focus of this study was to provide a setting and a program enabling people in the helping professions to increase their awareness and ability to be supportive to other human beings. It was broadly based on the knowledge that the world one creates is composed of what is taken and received from others and the environment (Gazda, Asbury, Balzer, Childers, Desselle \& Walters, 1973).

The primary conditions for helping are: empathy, respect, warmth, genuineness, self-disclosure, concrete- 
ness, confrontation and immediacy of relationship (Carkhuff, 1969b). The major condition considered in the study was empathy. Empathy has been found to be the primary ingredient in any helping relationship (Carkhuff, 1969b; Combs, Avila \& Purkey, 1973; Gazda et al., 1973; Pierce \& Zarle, 1972; Rogers, 1961; Truax \& Carkhuff, 1967; Truax \& Wittmer, 1971; Truax, Wittmer \& Wargo, 1971). Further research supported the concept that if a helper could perceive and respond with empathy accurately, the remaining dimensions of the helping relationship could then be discriminated rather easily (Carkhuff, 1969b; Carkhuff \& Berenson, 1967; Carkhuff, Kratochvil \& Friel, 1968; Truax \& Carkhuff, 1967). Carkhuff (1969b) also stated that the helper level-of-functioning is directly related to his effectiveness in a relationship. If he does not possess the quality of empathy, the results to the helpee may be detrimental, actually causing more harm than good.

The purpose of the study was to obtain an objective measure of the level-of-empathy, using Carkhuff's Index of Communication (1969b), of professional nurses practicing in an acute-and-chronic-care hospital facility. For those nurses who scored low on the Index of Communication, 1.0 or below, a human-relations-modeled Staff Development Program was designed specifically to train those professionals to increase their abilities to 
perceive and respond with greater empathy. The effectiveness of the Staff Development Program in accomplishing this goal was statistically tested.

Given that there were nurses who had low levels of empathy and that those same nurses participated in a Staff Development Program, the following null hypotheses were tested in the research. The rejection level for each hypothesis was at the .05 level of significance.

(1) There is no significant difference of mean scores on Carkhuff's Index of Communication between practicing nurses pretested in Group $I$, the experimental group, and Group II, the control group.

(2) There is no significant difference of mean scores on Carkhuff's Index of Communication between the posttest scores of Group I, the experimental group, and the posttest scores of Groups II and III, the control groups.

(3) Upon rejection of Hypothesis II, the following two hypotheses were to be tested: (A) There is no significant difference between posttest scores of Group I and Group II, and Group I and Group III; (B) there is no significant difference between posttest scores from Group II and Group III. 


\section{Method}

The Staff Development Program was designed around a human-relations model based on the previously documented effectiveness of this type of training model (Appley \& Winder, 1973; Berenson, Carkhuff \& Myrus, 1966; Foulds, 1969; Martin \& Carkhuff, 1968; Truax, Silbur \& Wargo, 1966; Vitalo, 1971). It was designed to be applicable for use with all helping professions. The core condition of empathy was divided into training in perceiving and training in responding with empathy. Specific areas of foci within these divisions included nonverbal behavior, ineffective communication styles and application into the helping profession specified by the sample. The program was spread over seven weeks with sessions held once a week. The length of the program was approximately eleven hours.

The sample employed in the study consisted of 39 employed, female, Registered Nurses from a mediumsized, urban, acute-and-chronic-care hospital facility. The Registered Nurses participating had all obtained their education in either a Diploma school of Nursing or an Associate Degree Program. In an effort to eliminate the variable of added education in the applied behavioral sciences, nurses educated in a Baccalaureate Program were excluded from the sample. The ages 
ranged from 21 to 45 years. The participants had worked actively as nurses for a minimum of six months preceding the investigation. The positions in the hospital included Staff Nurses, Assistant Head Nurses and Head Nurses. They were continuously employed during the study.

Thirty-nine nurses volunteered and were eligible to participate. Twenty-four were pretested and scored less than 2.0 on Carkhuff's Index of Communication. These were divided into two groups: Groups I and II. Group I, the experimental group, received the pretest, staff Development Program and posttest. Group II, controlling the effectiveness of the training program, received only the pretest and posttest. The remaining fifteen were in Group III which controlled the test-retest variable and the effects of time in the investigation. Group III only received the posttest.

There were two major areas in which instruments were used for data analyses: Those to assess the Staff Development Program and the ones used to assess the raters' reliability. Carkhuff's (1969b) Index of Communication was the primary instrument used to assess the staff Development Program and was given to all subjects as well as the trainer/investigator. The second instrument used in assessing the Staff Development Program was Carkhuff's (1969b) Empathy Scale, which measures empathic understanding in interpersonal processes. Carkhuff's 
original scale was modified by omitting level five, which exists only in intense relationships (Gazda et al., 1973). The key to the empathy rating was the proximity of the helper's response to the helpee's expression in relation to the helpee's expressed affect and content. The last instrument used to assess the Staff Development Program was a Personal Data Sheet. This was designed to obtain the necessary information from each subject to insure her eligibility in the sample.

The instrument used to assess rater reliability was composed to 20 responses from three situations taken from Gazda's et al., (1973) training situations in perceiving empathy. Following training on Carkhuff's model for helping, each rater independently scored the 20 responses using Carkhuff's (1969b) Empathy Scale. Reliability of the raters was determined by use of the Kendall rank correlation coefficient (Siegel, 1956).

The Indexes of Communication were all rated on Carkhuff's (1969b) Empathy Scale by two, independent, reliable raters and the mean of these scores was used in the data analyses.

The pretest helping scores from Group I and Group II were compared by the Mann-Whitney U Test (Siegel, 1956). This measured whether the two groups came from the same population. It tested the first hypothesis stating that there is no significant difference between Group I 
and Group II on the pretest. The posttest helping scores from all three groups were analyzed by use of the KruskalWallis one-way analysis of variance by ranks (Siegel, 1956).

This tested Hypothesis II. Upon rejection of Hypothesis II, the Mann-Whitney U Test (Siegel, 1956) would be used to evaluate where the difference in scores lay. This tested Hypothesis III.

\section{$\underline{\text { Results }}$}

The helping score of the trainer/investigator was 3.94 on a four-point scale. Carkhuff and Berenson (1967) defined the minimal level-of-functioning to be 3.0 on a five-point scale. The level is required to insure that helpers possess the skills necessary to truly help or train another person. Rater reliability was established at .83, which showed a high degree of agreement between two raters.

A Mann-Whitney U Test was performed on the data from the pretest scores of Group I and Group II to establish whether or not the two independent groups had been drawn from the same population. A U value of equal or less then 37 would have shown a significant difference in the population for a two-tailed test at alpha $=.05$ (Siegel, 1956). In the investigation a $U$ value in Hypothesis I of 66.5 was obtained. This revealed that 
there was no significant difference in the pretest scores of Groups I and II, representing a distribution in the two groups which had underlying continuity. Hypothesis I failed to be rejected. Table 1 lists the mean helping scores for the subjects pretested in Groups I and II. Table 2 provides the measures of central tendency and variability for the pretest helping scores.

Insert Table 1 about here

Insert Table 2 about here

A Kruskal-Wallis one-way analysis of variance by ranks was used to test Hypothesis II (Siegel, 1956). This determined whether the differences in the posttest scores signified genuine population differences or were merely chance variations. The statistic used in the Kruskal-Wallis Test, and defined by its formula, tests for the value of $\mathrm{H}$. It is distributed as chi square with $d f=k-1$. An $H$ value of equal or greater than 13.82 would have shown that the three groups came from the same population with respect to averages at alpha $=.001$ (Siegel, 1956). In the investigation, an 
H value of 20.5641 , corrected for ties, was obtained. This showed that there was a significant variance in the three groups at greater than alpha $=.001$. Consequently, Hypothesis II was rejected and Hypothesis III tested. Table 3 shows the posttest scores of Groups I, II and III. Table 4 provides the measures of central tendency and variability for the posttest helping scores.

Insert Table 3 about here

Insert Table 4 about here

To discover the place of the variance in the posttest scores, the Mann-Whitney $U$ Test was used on the scores between Groups I and II, I and III, and II and III. Testing on Groups I and II obtained a U value of 5. A $U$ value of equal or less than 20 would have shown a significant difference in the population for a twotailed test at alpha $=.002$ (Siegel, 1956). Testing on Groups I and III found a $U$ value of 8 . A $U$ value of equal or less than 28 would have documented a significant difference in the population for a two-tailed test at alpha $=.002$ (Siegel). There were significant population 
differences revealed in both tests at levels greater than alpha $=.002$. Hypothesis IIIA was rejected.

As a result of the testing of Groups II and III, a $\mathrm{U}$ value of 87.5 was obtained. A U value of equal or less than 49 would have documented a significant variation in the population for a two-tailed test at alpha $=.05$ (Siegel, 1956). Hypothesis IIIB failed to be rejected.

When the pretest helping scores were analyzed, it was established that the samples in Groups I and II were drawn from the same population. The analysis of variance of the posttest helping scores from Groups I, II and III showed that a variance in the scores existed. Further statistical analysis revealed that the only essential variance was between Groups I and II, and I and III. This suggested that: (1) The experimental program was effective in increasing the subjects' abilities to perceive and respond with empathy; (2) the pretesting had little effect on the posttesting scores; and (3) the time lapse between onset and conclusion of the experiment was not a significant variable.

\section{Discussion}

The data obtained in the investigation clearly pointed out that the nurses tested in the study had extremely low levels of empathy. The scores ranged 
from 1.23 to 1.73 for the two groups with the mean at 1.48 and the median at 1.45. The level of 1.00 on Carkhuff's Empathy Scale represented irrelevant or hurtful responses while the level of 2.00 represented responses only partially communicating an awareness of the surface feelings of the helpee (Carkhuff, 1969b). The subjects' scores lie almost at the midpoint between hurting another person and only partially responding to superficially expressed feelings. These results are most serious due to the fact that all nurses are in positions that require effective helping skills. Implications and actions begin and rest most heavily with nursing educators and administrators and then filter to all practicing professional nurses who present themselves as educated in the helping process.

The data documented the effectiveness of the Staff Development Program in raising a helper's ability to perceive and respond with empathy. Related research has also documented that human-relations-modeled training programs integrating didactic and experiential approaches to training have been most successful in raising a helper's level-of-functioning in the core dimensions of helping (Berenson et al., 1966; Carkhuff, 1969a; Carkhuff \& Banks, 1970; Carkhuff \& Bierman, 1970; Carkhuff \& Truax, 1965b; Foulds, 1969; Martin \& Carkhuff, 1968; Truax et al., 1966; Vitalo, 1971). 
The Staff Development Program in the investigation included approximately eleven hours and was spread over seven weeks. Success has been documented in other studies of short-term programs ranging from ten to thirty hours (Berenson et al., 1966; Carkhuff \& Truax, 1965a; Collingwood, 1969; Pierce \& Drasgrow, 1969; Pierce, Carkhuff \& Berenson, 1967).

According to Carkhuff's helping model, the minimal level-of-empathy for helpers should be at the 3.0 level on a five-point scale. Even though the results of the study are significant at greater than alpha $=.001$, only three subjects reached a minimal level-of-empathy after the training program. The 3.0 level represented a response that conveyed the helpee is understood at the level he is expressing himself (Carkhuff, 1969b). Eight subjects were in the 2.0 to 3.0 range. This range encompasses partial to complete awareness of what a helper expresses (Carkhuff, 1969b). One subject still remained in the 1.0 to 2.0 range which proceeds from a hurtful response to superficial awareness of what is expressed (Carkhuff, 1969b). These results have implications for future training programs and research and provide foundations for nursing leaders with which they can build future programs.

In final analysis, hospital and nursing administrators should incorporate strong, intense human-relations 
modeled inservice programs that offer the highest probability of significantly affecting the level of helping skills of their nurses. The data imply the need for professional nurses to become involved in longer, more intense programs that will insure that their empathy skills reach a minimal facilitative plateau. These should include an intense and broad didactic and experiential component, a clinical component and three and six-month follow-up training sessions. Nursing educators should formally integrate theory and experience in learning helping skills into their curricula. Varieties of programs focusing on this content should be provided through educational institutions, hospitals and all related facilities, to embrace the thousands of nurses practicing in the helping profession. This need is intense! The research not only documents that nurses are practicing with dangerously low levels of empathy, but that with relatively short-term, inexpensive training efforts, their levels can be significantly increased. This small effort by nursing administrators and educators would inevitably result in better patient care. Finally, any training program should systematically encompass didactic and experiential bases; they should be given only under the leadership of individuals who have themselves demonstrated high levels of helping skills and who consistently enmesh themselves in maintaining 
peak post-training levels of functioning.

Based on the experience of conducting the study, there are several limitations that must be considered in evaluating the implications of the investigation.

The investigation depended heavily on one standardized instrument and rating scale. Even though the selection and training of the raters was an important facet of the study, any misuse of the instrument and rating scale could effect the results.

Another limitation is suggested by the nature of the sample. It is difficult to generalize the findings to the nursing population as a whole because of the small number of subjects, even though the sample represented varied backgrounds, ages and experiences as defined in the specifications.

The study used educational examples as a basis for the Staff Development Program. Despite the theoretical basis of this design, the relevance of problems specific to the nursing profession was not investigated.

The research did not test whether an increase in empathy skills produced an increase in the level-offunctioning in the clinical setting. Research has proven, however, that transfer does take place (Carkhuff, 1969c; Martin \& Carkhuff, 1968; Paul, 1967; Truax \& Carkhuff, 1966). 
Finally, another limitation may be in assessing the long-term effects of a short-term program. Trainees occasionally return to environments that do not support or reinforce their activities or learning (Meadow \& Tillem, 1963; Munger, Myers \& Brown, 1963). This effect was not investigated in the study.

All of these limitations could be addressed by additional follow-up and research efforts. They do not suggest, however, that serious attention should not be given the implications of this study, nor should they prevent people from immediately beginning to develop further research and training programs specific to their environments.

\section{Conclusions}

The investigation addressed the problem of testing the effectiveness of a relatively short training program based on Carkhuff's model for helping with the key focus being on the core dimension of empathy. The staff Development Program was designed to relate to any of the helping professions. The sample chosen for investigation in the study was nurses. Research has shown that little emphasis has been placed on directly developing within nurses the abilities to perceive and respond with empathy • 
The results of the study suggest that Registered Nurses as a group possess extremely low levels of empathy. The training program significantly raised their levels of empathy, but more intensity, theory and clinical applications are needed to enable all of the nurses to at least function at the minimal facilitative helping level. 
TABLE 1

MEAN HELPING SCORES FOR SUBJECTS PRETESTED IN GROUP I AND GROUP II

\begin{tabular}{cccc}
\hline \multicolumn{2}{c}{ GROUP } & \multicolumn{2}{c}{ GROUP } \\
\hline Number & $\overline{\mathrm{X}}$ & Number & $\overline{\mathrm{X}}$ \\
\hline$(1)$ & 1.23 & $(1)$ & 1.38 \\
$(2)$ & 1.56 & $(2)$ & 1.36 \\
$(3)$ & 1.26 & $(3)$ & 1.51 \\
$(4)$ & 1.35 & $(4)$ & 1.38 \\
$(5)$ & 1.48 & $(5)$ & 1.35 \\
$(6)$ & 1.35 & $(6)$ & 1.39 \\
$(7)$ & 1.38 & $(7)$ & 1.68 \\
$(8)$ & 1.43 & $(8)$ & 1.54 \\
$(9)$ & 1.61 & $(9)$ & 1.61 \\
$(10)$ & 1.70 & $(10)$ & 1.31 \\
$(11)$ & 1.64 & $(11)$ & 1.65 \\
$(12)$ & 1.70 & $(12)$ & 1.73 \\
& & &
\end{tabular}




\section{TABLE 2}

MEASURES OF CENTRAL TENDENCY AND VARIABILITY:

PRETEST SCORES IN GROUP I AND GROUP II

\begin{tabular}{lcc}
\hline ITEM & GROUP I & GROUP II \\
\hline $\mathrm{N}$ & 12 & 12 \\
$\overline{\mathrm{X}}$ & 1.47 & 1.49 \\
Median & 1.45 & 1.45 \\
Q & .135 & .13 \\
Range & .47 & .42 \\
\hline
\end{tabular}


TABLE 3

MEAN HELPING SCORES FOR SUBJECTS POSTTESTED IN GROUPS I, II AND III

\begin{tabular}{|c|c|c|c|c|c|}
\hline GROUP & I & GROUP & II & GROUP & III \\
\hline Number & $\overline{\mathrm{x}}$ & Number & $\overline{\mathrm{x}}$ & Number & $\overline{\mathrm{x}}$ \\
\hline (1) & 2.19 & (1) & 2.20 & (1) & 1.64 \\
\hline (2) & 2.74 & (2) & 1.49 & (2) & 1.60 \\
\hline (3) & 2.39 & (3) & 1.80 & (3) & 1.56 \\
\hline (4) & 1.78 & (4) & 1.61 & (4) & 1.53 \\
\hline (5) & 2.68 & (5) & 1.64 & (5) & 1.86 \\
\hline (6) & 2.21 & (6) & 1.63 & (6) & 1.23 \\
\hline (7) & 2.38 & (7) & 1.58 & (7) & 2.10 \\
\hline (8) & 2.16 & (8) & 1.45 & (8) & 1.45 \\
\hline (9) & 3.14 & (9) & 1.48 & (9) & 1.84 \\
\hline (10) & 3.38 & (10) & 1.66 & (10) & 2.14 \\
\hline (11) & 2.71 & (11) & 1.56 & (11) & 1.60 \\
\hline (12) & 3.24 & (12) & 1.88 & (12) & 1.35 \\
\hline & & & & (13) & 1.35 \\
\hline & & & & (14) & 2.23 \\
\hline & & & & (15) & 1.71 \\
\hline
\end{tabular}


TABLE 4

MEASURES OF CENTRAL TENDENCY AND VARIABILITY: POSTTEST SCORES IN GROUPS I, II AND III

\begin{tabular}{lccc}
\hline \hline ITEM & GROUP I & GROUP II & GROUP III \\
\hline $\mathrm{N}$ & 12 & 12 & 15 \\
$\overline{\mathrm{X}}$ & 2.58 & 1.66 & 1.67 \\
Median & 2.53 & 1.62 & 1.60 \\
$\mathrm{Q}$ & .37 & .105 & .315 \\
Range & 1.60 & .75 & 1.00 \\
\hline
\end{tabular}


REFERENCES

Anthony, W. A methodological investigation of the minimally facilitative level of interpersonal functioning. Journal of Clinical Psychology,

Appley, D. and Winder, A. T-Groups and therapy groups in a changing society. San Francisco: Jossey-Bass,

Berenson, B., Carkhuff, R. and Myrus, P. The interpersonal functioning and training of college students. Journal of Counseling Psychology,

Berenson, B., Mitchell, K. and Laney, R. Level of therapist functioning, types of confrontation and type of patient. Journal of Clinical Psychology, $1968,24,111-113$.

Berenson, B., Mitchell, K. and Moravec, J. Level of therapist functioning, patient depth of selfexploration and type of confrontation. Journal of Counseling Psychology, 1968, 15, 136-139.

Carkhuff, R. Critical variables in group therapeutic processes. In J. Hansen and S. Cramer (Eds.), Group counseling. New York: Appleton-CenturyCrofts, 1969. (a)

Carkhuff, R. Helping and human relations: A primer for lay and professional helpers. Vol. I. New York: Holt, Rinehart \& Winston, 1969. (b)

Carkhuff, R. Helping and human relations: A primer for lay and professional helpers. Vol. II. New York: Holt, Rinehart \& Winston, 1969. (c)

Carkhuff, R. and Banks, G. Training as a preferred mode of facilitating relations between races and generations. Journal of Counseling Psychology, $1970,17,413-\overline{418}$.

Carkhuff, R. and Berenson, B. Beyond counseling and therapy. New York: Holt, Rinehart \& Winston, 1967. 
Carkhuff, R. and Bierman, R. Training as a preferred mode of treatment of parents of emotionally disturbed children. Journal of Counseling Psychology, 1970, 17, 157-161.

Carkhuff, R. and Burstein, J. Objective therapist and client ratings of therapist-offered facilitative conditions of moderate to low functioning therapists. Journal of Clinical Psychology, 1970, $26,394-395$.

Carkhuff, R. and Truax, C. Lay mental health counseling: The effectiveness of lay group counseling. Journal of Consulting Psychology, 1965, 29, 426-431. (a)

Carkhuff, R. and Truax, C. Training in counseling and psychotherapy: An evaluation of an integrated didactic and experiential approach. Journal of Consulting Psychology, $1965,29,333-\overline{336}$. (b)

Carkhuff, R., Kratochvil, D. and Friel, T. The effects of professional training: The communication and discrimination of facilitative conditions. Journal of Counseling Psychology, 1968, 15, 68-74.

Collingwood, T. The effects of large group training on facilitative interpersonal communication. Journal of Clinical Psychology, 1969, 25, 461-462.

Combs, A., Avila, D. and Purkey, W. Helping relationships: Basic concepts for the helping professions. Boston: Allyn \& Bacon, 1971.

Foulds, M. Self-Actualization and the communication of facilitative conditions during counseling. Journal of Counseling Psychology, 1969, 16, 132-136.

Gazda, G., Asbury, F., Balzer, F., Childers, W., Desselle, R. and Walters, R. Human relations development: A manual for educators. Boston: Allyn \& Bacon, 1973 .

Henderson, V. The nature of nursing. New York: The Macmillan Company, 1966.

Martin, J. and Carkhuff, R. Changes in personality and interpersonal functioning in counselors in training. Journal of Clinical Psychology, 1968, 24, 109-110. 
Meadow, L. and Tillem, K. Evaluating the effectiveness of a workshop rehabilitation program. Personnel and Guidance Journal, 1963, 42, 541-545.

Munger, P., Myers, R. and Brown, D. Guidance institutes and the persistence of attitudes. Personnel and Guidance Journal, 1963, 41, 415-419.

Paul, G. Outcome research is psychotherapy. Journal of Consulting Psychology, 1967, 31, 109-118.

Pierce, R. and Drasgrow, J. Teaching facilitative interpersonal functioning to psychiatric inpatients.

Journal of Counseling Psychology, 1969, 16, 295-298.

Pierce, R. and Zarle, T. Differential referral to significant others as a function of interpersonal effectiveness. Journal of Clinical Psychology, 1972, 28, $230-232$.

Pierce, R., Carkhuff, R. and Berenson, B. The differential effects of high and low functioning counselors upon counselors in training. Journal of Clinical Psychology, 1967, 23, 212-215.

Rogers, C. On becoming a person. Boston: Houghton Mifflin Company, 1961.

Siegel, S. Nonparametric statistics for the behavioral sciences. New York: McGraw-Hill, 1956.

Truax, C. and Carkhuff, R. Introduction to counseling and psychotherapy: Training and practice. Chicago: Aldine Publishing Company, 1966.

Truax, C. and Carkhuff, R. Toward effective counseling and psychotherapy: Training and practice. Chicago: Aldine Publishing Company, 1967.

Truax, C. and Wittmer, J. The effects of therapist focus on patient anxiety source and the interaction with therapist level of accurate empathy. Journal of Clinical Psychology, 1971, 27, 295-299.

Truax, C., Silbur, L. and Wargo, D. Training and change in psychotherapeutic skills. Mimeographed manuscript, Arkansas Rehabilitation and Research Center, University of Arkansas, 1966. 
161

Truax, C., Witter, J. and Wargo, D. Effects of the therapeutic conditions of accurate empathy, nonpossessive warmth, and genuineness on hospitalized mental patients during group therapy. Journal of Clinical Psychology, 1971, 27, 137-142.

Vitalo, R. Teaching improved interpersonal functioning as a preferred mode of treatment. Journal of Clinical Psychology, 1971, 27, 166-171. 
BIBLIOGRAPHY 
Allerand, A. Empathy in and out of psychotherapy. Unpublished manuscript, Columbia Teacher's College, 1964 .

Anderson, R. and Anderson, G. The development of an instrument for measuring rapport. Personnel and Guidance Journal, 1962, 41, 18-24.

Anthony, W. The effects of training upon discrimination, communication and attitudes of rehabilitation counselors. Unpublished doctoral dissertation, State University of New York at Buffalo, 1968.

Anthony, W. A methodological investigation of the minimally facilitative level of interpersonal functioning. Journal of Clinical Psychology, 1971,27 , 156- 157 .

Appley, D. and Winder, A. T-Groups and therapy groups in a changing society. San Francisco: Jossey-Bass, 1973 .

Arnhoff, F. Some factors influencing the unreliability of clinical judgments. Journal of Clinical Psychology, $1954,10,272-275$.

Aspy, D. and Hadlock, W. The effects of high and low functioning teachers upon student academic achievement and truancy. Unpublished research, University of Florida, Gainesville, 1969.

Bach, G. The marathon group: I. Intensive practice of intimate interaction. Psychological Reports, 1966, $18,995-1002$.

Baldwin, A., Kalhorn, J. and Breese, F. Patterns of parent behavior. Psychological Monographs, 1945, $58,1-75$.

Banks, W. The differential effects of race and social class in helping. Journal of Clinical Psychology, 1972 , 28, 90-92.

Banks, G., Berenson, B. and Carkhuff, R. The effects of counselor race and training upon counseling process with negro clients in initial interviews. Journal of Clinical Psychology, 1967, 23, 70-72. 
Beck, C. Philosophical foundations of guidance. Englewood Cliffs, New Jersey: Prentice-Hall, 1963.

Bellak, J. and Small, L. Emergency psychotherapy and brief psychotherapy. New York: Holt, Rinehart \& Winston, 1967 .

Benne, K. The self, the group or the task? Differences among growth groups. Paper presented, The growth groups: Encounter, marathon, sensitivity and "T", Ninth Annual Conference, Personality, Theory and Counseling Practice, University of Florida, Gainesville, January, 1969.

Berenson, B. The effects of systematic human relations training upon the classroom performance of elementary school teachers. Journal of Research and Development in Education, 1971, 4, 70-85.

Berenson, B. and Carkhuff, R. Sources of gain in counseling and psychotherapy. New York: Holt, Rinehart \& Winston, 1967.

Berenson, B. and Mitchell, K. Confrontation in counseling and life. Mimeographed manuscript, American International College, Springfield, Massachusetts, 1968. (a)

Berenson, B. and Mitchell, K. Therapeutic conditions after therapist-initiated confrontation. Journal of Clinical Psychology, $1968,24,363-364$. (b)

Berenson, B., Carkhuff, R. and Myrus, P. The interpersonal functioning and training of college students. Journal of Counseling Psychology, 1966, 13, 441-446.

Berenson, B., Mitchell, K. and Laney, R. Level of therapist functioning, types of confrontation and type of patient. Journal of Clinical Psychology, $1968,24,111-113$.

Berenson, B., Mitchell, K. and Moravec, J. Level of therapist functioning, patient depth of selfexploration and type of confrontation. Journal of Counseling Psychology, 1968, 15, 136- 139 .

Berenson, B., Carkhuff, R., Friel, T. and Leitner, I. systematic training in written communication and discrimination in large groups. Unpublished research, State University of New York at Buffalo, 1968 . 
Bergin, A. and Soloman, S. Correlates of empathic ability in psychotherapy. American Psychologist,

Berne, E. Games people play: The psychology of human relationships. New York: Grove Press, 1964 .

Berzon, B. and Soloman, L. Research frontiers: The self-directed therapeutic group. Journal of Counseling Psychology, 1966, 13, 491-497.

Blanchard, K. Observation exercise. Unpublished material, University of Massachusetts, Amherst, 1973.

Blocher, D. Developmental counseling. New York: The Ronald press, 1966.

Bordin, E. Ambiguity as a therapeutic variable. Journal of Consulting Psychology, 1955, 19, 9-15.

Bradford, P., Gibb, J. and Benne, K. (Eds.) T-Group theory and laboratory method: An innovation in re-education. New York: John Wiley \& Sons, 1964.

Buchheimer, A. The development of ideas about empathy. Journal of Counseling Psychology, 1963, 10, 61-71.

Cannon, J. and Pierce, R. Order effects in the experimental manipulation of therapeutic conditions. Journal of Clinical Psychology, 1968, 24, 242-244.

Carkhuff, R. Counseling research, theory and practice. Journal of Counseling Psychology, 1966, 13, 467-480.

Carkhuff, R. The differential functioning of lay and professional helpers. Journal of Counseling Psychology, 1968, 15, 117-126. (a)

Carkhuff, R. The effects of training on the communication of teacher-counselors. Unpublished research, State University of New York at Buffalo, 1968. (b)

Carkhuff, R. Critical perspectives on group processes. Address, The growth groups: Encounter, marathon, sensitivity and " $T$ ", Ninth Annual Conference, Personality Theory and Counseling Practice, University of Florida, Gainesville, January, 1969. (a) 
Carkhuff, R. Critical variables in effective counselor training. Journal of Counseling Psychology, 1969 $16,238-245$. (b)

Carkhuff, R. Critical variables in group therapeutic processes. In J. Hansen and S. Cramer (Eds.), Group counseling. New York: Appleton-CenturyCrofts, 1969. (c)

Carkhuff, R. Helping and human relations: A primer for lay and professional helpers. Vol. I. New York: Holt, Rinehart \& Winston, 1969. (d)

Carkhuff, R. Helping and human relations: A primer for lay and professional helpers. Vol. II. New York: Holt, Rinehart \& Winston, 1969. (e)

Carkhuff, R. The prediction of the effects of didactic training in discrimination. Journal of Clinical Psychology, 1969, 25, 460-461. (f)

Carkhuff, R. The development of effective courses of action for ghetto school children. Psychology in the Schools, 1970, 7, 272-274.

Carkhuff, R. The art of helping. Amherst, Massachusetts: Human Resource Development Press, 1973.

Carkhuff, R. and Banks, G. Training as a preferred mode of facilitating relations between races and generations. Journal of Counseling Psychology, 1970, $17,413-418$.

Carkhuff, R. and Berenson, B. Beyond counseling and therapy. New York: Holt, Rinehart \& Winston, 1967.

Carkhuff, R. and Bierman, R. Training as a preferred mode of treatment of parents of emotionally disturbed children. Journal of Counseling Psychology, 1970,17 , 157-161.

Carkhuff, R. and Burstein, J. Objective therapist and client ratings of therapist-offered facilitative conditions of moderate to low functioning therapists. Journal of Clinical Psychology, 1970, 26, 394-395.

Carkhuff, R. and Pierce, R. The differential effects of therapist race and social class upon patient depth of self-exploration in the initial clinical interview. Journal of Consulting Psychology, 1967, 31, 632-634. 
Carkhuff, R. and Truax, C. Lay mental health counseling: The effectiveness of lay group counseling. Journal of Consulting Psychology, 1965, 29, 426-431. $\frac{\text { (a) }}{(a)}$

Carkhuff, R. and Truax, C. Training in counseling and psychotherapy: An evaluation of an integrated didactic and experiential approach. Journal of Consulting Psychology, 1965, 29, 333-336. (b)

Carkhuff, R., Collingwood, T. and Renz, L. The effects of didactic training upon trainee levels of discrimination and communication. Journal of Clinical Psychology, 1969, 25, 460-461.

Carkhuff, R., Kratochvil, D. and Friel, T. The effects of professional training: The communication and discrimination of facilitative conditions. Journal of Counseling Psychology, 1968, 15, 68-74.

Carlton, S. Counselor empathy: In R. Carkhuff (Ed.), The counselor's contribution to facilitative processes. Urbana, Illinois: Parkinson, 1967.

Cartwright, R. and Lerner, B. Empathy, need to change and improvement with psychotherapy. Journal of Consulting Psychology, 1963, 27, 138-144.

Chance, J. and Meaders, W. Needs and interpersonal perception. Journal of Personality, 1960, 28, 200-210.

Collingwood, T. The effects of large group training on facilitative interpersonal communication. Journal of Clinical Psychology, 1969, 25, 461-462.

Collingwood, T. Retention and retraining of interpersonal communication skills. Journal of Clinical Psychology, $1971,27,294-296$.

Collingwood, T. and Renz, L. The effects of client confrontations upon levels of immediacy offered by high and low functioning counselors. Journal of Clinical Psychology, 1969, 25, 224-226.

Combs, A. and Snygg, D. Individual behavior. New York: Harper \& Row, 1959.

Combs, A., Avila, D. and Purkey, W. Helping relationships: Basic concepts for the helping professions. Boston: Allyn \& Bacon, 1971. 
Correll, P. Factors influencing communication in counseling. Doctoral Dissertation, University of Missouri, 1955.

Duff, R. and Hollingshead, A. Sickness and society. New York: Harper \& Row, 1968, pp. 225-240.

Dugdale, K. A manual of form for theses and term reports. Bloomington, Indiana: Indiana University, 1972 .

Duncan, S. Nonverbal communication. Psychological Bulletin, 1969, 79, 118-137.

Eckelberry, G. Administration of comprehensive nursing care. New York: Appleton-Century-Crofts, 1971.

Eisenman, R. Creativity change in student nurses: A cross-sectional and longitudinal study. Developmental Psychology, $1970,3,320-325$.

Eisenman, R. Creativity in student nurses and their attitudes toward mental illness and physical

disability. Journal of Clinical Psychology, 1972, $28,218-219$.

Ekman, P. and Friesan, W. Nonverbal behaviour in psychotherapy research. In J. Schlien (Ed.), Research in psychotherapy. Washington, D. C.: American Psychological Association, 1968, 3, pp. 179-215.

Ellsworth, P. and Ludwig, L. Visual behaviour in social interaction. Journal of Communication, 1972, 22, $375-403$.

Farson, R. The counselor is a woman. Journal of Counseling Psychology, 1954, 1, 221-223.

Fiedler, F. Quantitative studies on the role of the therapists' feelings toward their patients. In O. H. Mowrer (Ed.), Psychotherapy: Theory and research. New York: Ronald Press, 1953, Chapter 12.

Flores, F. Role of the graduate nurse today. New England Journal of Medicine, 1962, 267, 487.

Foote, N. and cottrell, L. Identity and interpersonal competence. Chicago: University of Chicago Press, 1955 . 
Foulds, M. Self-actualization and the communication of facilitative conditions during counseling. Journal of Counseling Psychology, 1969, 16, 132-136.

Fox, R. and Goldin, P. The empathic process in psychotherapy: A survey of theory and research. Journal of Nervous and Mental Diseases, 1964, 4, 138 .

Friel, T., Berenson, B. and Mitchell, K. Factor analysis of therapeutic conditions for high and low functioning therapists. Journal of Clinical Psychology, 1971, $27,291-293$.

Gardner, W. The differential effects of race, education and experience in helping. Journal of Clinical Psychology, 1972, 28, 87-89.

Gazda, G. Innovations in group psychotherapy. Springfield, Illinois: Charles C. Thomas, 1969.

Gazda, G. Systematic human relations training in teacher preparation and in-service education. Journal of Research and Development in Education, 1971, 4, 47-51.

Gazda, G. , Asbury, F., Balzer, F., Childers, W., Desselle, R. and Walters, R. Human relations development: A manual for educators. Boston: Allyn \& Bacon, 1973.

Gibb, J. The effects of human relations training. In A. Bergin and S. Garfield (Eds.), Handbook of psychotherapy and behavior change. New York: John Wiley \& Sons, 1971, pp. 829-862.

Glasser, W. Reality therapy. New York: Harper \& Row, 1965.

Goffman, E. The presentation of self in everyday life. Edinburgh: University of Edinburgh Social Sciences Research Centre, 1956. Goffman, E. Encounters: Two studies in the sociology of
interaction. New York: Bobbs-Merrill Company, 1961.

Greenberg, B. The differential ratings of counselor responses to client expressions in a written, audio and real life form. Unpublished research, State University of New York at Buffalo, 1968. Cited by R. Carkhuff, Helping and human relations, Vols. I 
Haase, R. and Di Mattia, D. The application of the microcounseling paradigm to the training of support personnel in counseling. Counselor Education and Supervision, $1970,10,16-22$.

Halkides, G. An experimental study of four conditions necessary for therapeutic change. Unpublished doctoral dissertation, University of Chicago, 1958.

Harrison, R. and Lubin, B. Personal style, group composition and learning. Journal of Applied Behavioral Science, $1965,3,286-301$.

Hefele, T. The effects of systematic human relations training upon student achievement. Journal of Research and Development in Education, 1971, 4, 52-69.

Heine, R. A comparison of patients' reports on psychotherapeutic experience with psychoanalytic, nondirective, and Adlerian therapists. Unpublished doctoral dissertation, University of Chicago, 1950.

Henderson, V. The nature of nursing. New York: The Macmillan Company, 1966.

Hersey, P. and Blanchard, K. Management of organizational behavior: Utilizing human resources. Englewood Cliffs, New Jersey: Prentice-Hall, 1972.

Hinchliffe, M., Lancashire, M. and Roberts, F. Study of eye contact in depressed and recovered patients. British Journal of Psychiatry, 1971, 119, 213-215.

Hirshberg, F., Carkhuff, R. and Berenson, B. The differential effectiveness of counselors and therapists with inpatient schizophrenics and counseling center clients. Unpublished research, University of Massachusetts, Amherst, 1967.

Holder, B. Post-training retention effects as a function of training exposure. Doctoral dissertation, State University of New York at Buffalo, 1969.

Holder, B., Carkhuff, R. and Berenson, B. The differential effects of the manipulation of therapeutic conditions upon high and low functioning clients. Journal of Counseling Psychology, 1967, 14, 63-66.

Hollingshead, A. and Redlich, F. Social class and mental illness. New York: John Wiley \& Sons, 1958. 
Ivey, A. Microcounseling: Innovations in interviewing training. Springfield, Illinois: Charles C. Thomas, 1971 .

Jones, M. The therapeutic community. New York: Basic

Jourard, S. The transparent self. New York: Van Nostrand Reinhold Company, 1971.

Kalisch, B. An experiment in the development of empathy in nursing students. Nursing Research, 1971, 20, 202-211. (a)

Kalisch, B. Strategies for developing nurse empathy. Nursing Outlook, 1971, 19,714-718. (b)

Katz, R. Empathy: Its nature and uses. New York: Free Press, 1963.

Kratochvil, D., Aspy, D. and Carkhuff, R. The differential effects of absolute level and direction of growth in counselor functioning upon client functioning. Journal of Clinical Psychology, 1967, 23, 216-218.

Kreuter, F. What is good nursing care? Nursing outlook, $1957,5,302$.

La Monica, E. Nonverbal feedback. Unpublished material, University of Massachusetts, Amherst, 1974.

Lieberman, M., Yalom, I. and Miles, M. Encounter groups: First facts. New York: Basic Books, 1973 .

Lubin, B. and Lubin, A. Group psychotherapy: A bibliography of the literature from 1956 to 1964 . East Lansing, Michigan: Michigan State University Press, 1967 .

Martin, J. and Carkhuff, R. Changes in personality and interpersonal functioning in counselors in training. Journal of Clinical Psychology, 1968, 24, 109-110.

Maslow, A. Toward a psychology of being. New York: Van Nostrand Company, 1968.

Matarazzo, J. Psychotherapeutic processes. Annual Review of Psychology, Palo Alto, California, $19 \overline{65}, 16$, 181-219. 
McClain, E. Is the counselor a women? personnel and Guidance Journal, 1968,46,444-448.

Mc Geoch, J. and Irion, A. The psychology of human learning. New York: Longmans, Green, 1952.

Mc Gowan, J. and Schmidt, L. (Eds.) Counseling: Readings in theory and practice. New York: Holt, Rinehart \& Winston, 1962 .

Meadow, L. and Tillem, K. Evaluating the effectiveness of a workshop rehabilitation program. Personnel and Guidance Journal, 1963, 42, 541-545.

Melloh, R. Accurate empathy and counselor effectiveness. Unpublished doctoral dissertation, University of Florida, Gainesville, 1964.

Miles, M. Changes during and following laboratory training: A clinical experimental study. Journal of Applied Behavioral Science, 1965, 1, 215-242.

Mitchell, K., Mitchell, R. and Berenson, B. Therapist focus on clients' significant others in psychotherapy. Journal of Clinical Psychology, 1970, $26,533-536$.

Moustakas, C. The authentic teacher: Sensitivity and awareness in the classroom. Cambridge, Massachusetts: Howard A. Doyle, 1972 .

Muehlberg, N., Pierce, R. and Drasgrow, J. A factor analysis of therapeutically facilitative conditions. Journal of Clinical Psychology, 1969, 25, 93-95.

Munger, P., Myers, R. and Brown, D. Guidance institutes and the persistence of attitudes. Personnel and Guidance Journal, 1963, 41, 415-419.

Murphy, M. The growth center phenomenon. Address, The growth groups: Encounter, marathon, sensitivity and "T", Ninth Annual Conference, Personality, Theory and Counseling Practice, University of Florida, Gainesville, January, 1969.

Orlando, I. The dynamic nurse-patient relationship. New York: G. P. Putnam's Sons, 1961.

Otto, H. Group methods to actualize human potential: A handbook. Beverly Hills, California: Holistic Press, 1970 . 
Pagell, W., Carkhuff, R. and Berenson, B. The predicted differential effects of the level of counselor functioning upon the level of functioning of outpatients. Journal of Clinical Psychology, 1967, $23,510-512$.

Patterson, C. The selection of counselors. Paper presented at the Conference on Research Problems in Counseling, Washington University, St. Louis, Missouri, 1967.

Paul, G. Outcome research in psychotherapy. Journal of Consulting Psychology, 1967, 31, 109-118.

Perls, F. Gestalt therapy verbatim. Lafayette, California: Real People Press, 1969.

Pfeiffer, J. and Jones, J. Structured experiences for human relations training. Vols. I, II, III, \& IV. Iowa City, Iowa: University Associates Press, 1972-1973.

Piaget, G., Berenson, B. and Carkhuff, R. The differential effects of the manipulation of therapeutic conditions by high and low functioning counselors upon high and low functioning clients. Journal of Consulting Psychology, $1967,31,481-486$.

Pierce, R. and Drasgrow, J. Teaching facilitative interpersonal functioning to psychiatric inpatients. Journal of Counseling Psychology, 1969, 16, 295-298.

Pierce, R. and Zarle, T. Differential referral to significant others as a function of interpersonal effectiveness. Journal of Clinical Psychology, $1972,28,230-23 \overline{2}$.

Pierce, R., Carkhuff, R. and Berenson, B. The differential effects of high and low functioning counselors upon counselors in training. Journal of Clinical Psychology, $1967,23,212-215$

Publication Manual of the American Psychological Association, Washington, D. C.: American Psychological Association, 1967 .

Rapaport, R. The community as a doctor. Chicago: Charles C. Thomas, 1960 . 
Rogers, C. On becoming a person. Boston: Houghton Mifflin Company, 1961 .

Rogers, C. Client-centered therapy. Boston: Houghton Mifflin Company, 1965.

Rogers, C. A plan for self-directed change in an educational system. Educational Leadership, 1967, $24,717-731$.

Rogers, C., Gendlin, E., Kiesler, D. and Truax, C. (Eds.) The therapeutic relationship and its impact: A study of psychotherapy with schizophrenics. Madison, Wisconsin: University of Wisconsin Press, 1967.

Scheff, T. Being mentally ill: A sociological theory. Chicago: Aldine Publishing Company, 1966.

Scheff, T. Mental illness and social processes. New York: Harper \& Row, 1967.

Schein, E. and Bennis, w. (Eds.) Personal and organizational change through group methods: The laboratory approach. New York: John Wiley \& Sons, 1965 .

Schutz, w. Joy: Expanding human awareness. New York: Grove Press, 1967.

Seashore, C. What is sensitivity training. In R. Golembiewski and A. Blumberg (Eds.), Sensitivity training and the laboratory approach: Readings about concepts and applications. Itasca, Illinois: F. E. Peacock, 1970 .

Seeman, J. Counselor judgments of therapeutic process and outcome. In C. Rogers and R. Dymond (Eds.), Psychotherapy and personality change. Chicago: University of Chicago Press, 1954, Chapter 7.

Shibutani, T. Society and personality: An interactional approach to social psychology. Englewood Cliffs, New Jersey: Prentice-Hall, 1961.

Siegel, S. Nonparametric statistics for the behavioral sciences. New York: McGraw-Hill, 1956.

Smelser, N. and Smelser, W. (Eds.) Personality and social systems. New York: John Wiley \& Sons, 1963. 
Smith, D. Myth and method in nursing practice. American Journal of Nursing, $1964,64,68$. Smith, H. Sensitivity to people. New York: McGraw-Hill,

Spiegel, P. and Spiegel, D. Perceived helpfulness of others as a function of compatible intelligence. Journal of Counseling Psychology, 1967, 14, 61-62. Stoller, F. The long weekend. Psychology Today, 1967,
$1,28-33$.

Taft, E. Ability to judge people. Psychological Bulletin, $1955,52,1-23$.

Thorne, F. The etiological equation. In R. Carkhuff and

B. Berenson, Beyond counseling and therapy.

New York: Holt, Rinehart \& Winston, 1967, Appendix A.

Truax, C. Length of therapist response, accurate empathy and patient improvement. Journal of Clinical

Psychology, $1970,26,539-\overline{541 . \quad(a)}$

Truax, C. Therapists' evaluative statements and patient outcome in psychotherapy. Journal of Clinical

Psychology, $1970,26,536-5 \overline{38 \text {. (b) }}$

Truax, C. and Carkhuff, R. For better or for worse:

The process of psychotherapeutic personality change.

In Recent advances in the study of behavioral change.

Montreal: McGill University, 1963.

Truax, C. and Carkhuff, R. Significant developments in psychotherapy research. In progress in clinical psychology. New York: Grune \& Stratton, 1964.

Truax, C. and Carkhuff, R. The experimental manipulation of therapeutic conditions. Journal of Consulting Psychology, $1965,29,119-12 \overline{4}$

Truax, C. and Carkhuff, R. Introduction to counseling and psychotherapy: Training and practice. Chicago: Aldine Publishing Company, 1966.

Truax, C. and Carkhuff, R. Toward effective counseling and psychotherapy: Training and practice. Chicago: Aldine Publishing Company, 1967. 
Truax, C. and Wittmer, J. The effects of therapist focus on patient anxiety source and the interaction with therapist level of accurate empathy. Journal of Clinical Psychology, 1971, 27, 295-299.

Truax, C., Silbur, L. and Wargo, D. Training and change in psychotherapeutic skills. Mimeographed manuscript, Arkansas Rehabilitation and Research Center, University of Arkansas, 1966.

Truax, C., Wittmer, J. and Wargo, D. Effects of the therapeutic conditions of accurate empathy, nonpossessive warmth, and genuineness on hospitalized mental patients during group therapy. Journal of Clinical Psychology, 1971, 27, 137-142.

Vitalo, R. Teaching improved interpersonal functioning as a preferred mode of treatment. Journal of Clinical Psychology, 1971, 27, 166-171.

Webster's Third International Dictionary. Springfield, Massachusetts: G\& C Merriam Company, 1969.

Weigand, J. (Ed.) Developing teacher competencies. Englewood Cliffs, New Jersey: Prentice-Hall, 1971.

Weiner, F. Professional consequences of the nurse's occupational status. American Journal of Nursing, $1951,51,614$.

Weiss, J. Effect of professional training and amount and accuracy of information on behavioral prediction. Journal of Consulting Psychology, 1963, 27, 257-262.

Wesseu, A. The psychiatric hospital as a social system. Chicago: Charles C. Thomas, 1964.

Whitehorn, J. and Betz, B. A study of psychotherapeutic relationships between physicians and schizophrenic patients. American Journal of Psychiatry, 1954, 111, 321-331.

Winder, A. and Hersko, M. The effect of social class on the length and type of psychotherapy in a V. A. Mental Hygiene Clinic. Journal of Clinical Psychology, 1955, 11, 77-79. 
APPENDIX 
A $\quad$ P

APPENDIX A

CARKHUFF'S INDEX OF COMMUNICATION

Introduction and Instructions

The following excerpts represent 16 helpee stimulus expressions; that is, expressions by a helpee of feeling and content in different problem areas. In this case the same helpee is involved in all instances.

You may conceive of this helpee not necessarily as a formal client but simply as a person who has come to you in a time of need. The helpee, for example, may be a student from one of your classes. We would like you to respond as you would if someone came to you seeking assistance in a time of distress. In formulating your responses keep in mind those that the helpee can use effectively in his own life.

In summary, formulate responses to the person who has come to you for help. The following range of helpee expressions can easily come in the first contact or first few contacts; however, do not attempt to relate any one expression to a previous expression. Simply try to formulate a meaningful response to the helpee's immediate expression.

EXCERPT 1

Helpee: I don't know if I am right or wrong feeling the way I do. But I find myself withdrawing from people. I don't seem to socialize and play their stupid little games any more. I get upset and come home depressed and have headaches. It seems all so superficial. There was a time when I used to get along with everybody. Everybody said, "Isn't she wonderful. She gets along with everybody. Everybody likes her." I used to think that was something to be really proud of, but that was who I was at that time. I had no depth. I was what the crowd wanted me to be--the particular group I was with. 
EXCERPT 2

Helpee:

I love my children and my husband and I like doing most household things. They get boring at times but on the whole I think it can be a very rewarding thing at times. I don't miss working, going to the office every day. Most women complain of being just a housewife and just a mother. But then, again, I wonder if there is more for me. Others say there has to be. I really don't know.

Response:

EXCERPT 3

Helpee: Sometimes I question my adequacy of raising three boys, especially the baby. I call him the baby--well, he is the last. I can't have any more. So I know I kept him a baby longer than the others. He won't let anyone else do things for him. If someone else opens the door he says he wants Mommy to do it. If he closes the door, I have to open it. I encourage this. I do it. I don't know if this is right or wrong. He insists on sleeping with me every night and I allow it. And he says when he grows up he won't do it any more. Right now he is my baby and I don't discourage this much. I don't know if this comes out of my needs or if I'm making too much out of the situation or if this will handicap him when he goes to school--breaking away from Mamma. Is it something I'm creating for him? I do worry more about my children than I think most mothers do.

Response: 
EXCERPT 4

Helpee:

It's not an easy thing to talk about. I guess the heart of the problem is sort of a sexual problem. I never thought I would have this sort of problem. But I find myself not getting the fulfillment I used to. It's not as enjoyable-for my husband either, although we don't discuss it. I used to enjoy and look forward to making love. I used to have an orgasm but I don't any more. I can't remember the last time I was satisfied. I find myself being attracted to other men and wondering what it would be like to go to bed with them. I don't know what this means. Is this symptomatic of our whole relationship as a marriage? Is something wrong with me or us?

\section{Response:}

\section{EXCERPT 5}

\section{Helpee:}

Gee, those people! Who do they think they are? I just can't stand interacting with them any more. Just a bunch of phonies. They leave me so frustrated. They make me so anxious. I get angry at myself. I don't even want to be bothered with them any more. I just wish I could be honest with them and tell them all to go to hell! But I guess I just can't do it. 
EXCERPT 6

Helpee :

They wave that degree up like it's a pot of gold at the end of the rainbow. I used to think that, too, until I tried it. I'm happy being a housewife; I don't care to get a degree. But the people I associate with, the first thing they ask is where did you get your degree. I answer, "I don't have a degree." Christ, they look at you like you are some sort of freak, some backwoodsman your husband picked up along the way. They actually believe that people with degrees are better. In fact, I think they are worse. I've found a lot of people without degrees that are a hell of a lot smarter than these people. They think that just because they have degrees they are something special. These poor kids that think they have to go to college or they are ruined. It seems that we are trying to perpetrate a fraud on these kids. If no degree, they think they will end up digging ditches the rest of their lives. They are looked down upon. That makes me sick.

Response:

EXCERPT 7

Helpee:

I get so frustrated and furious with my daughter. I just don't know what to do with her. She is bright and sensitive, but damn, she has some characteristics that make me so on edge. I can't handle it sometimes. She just--I feel myself getting more and more angry! She won't do what you tell her to. She tests limits like mad. I scream and yell and lose control and think there is something wrong with me--I'm not an understanding mother or something. Damn! What potential! What she could do with what she has. There are times she doesn't need what she's got. She gets by too cheaply. I just don't know what to do with her. Then she can be so nice and then, boy, she can be as ornery as she can be. And then I scream and yell and I'm about ready to slam her across the room. I don't like to feel this way. I don't know what to do with it. 
EXCERPT 8

Helpee: He is ridiculous! Everything has to be done when he wants to do it. The way he wants it done. It's as if nobody else exists. It's everything he wants to do. There is a range of things I have to do. Not just be a housewife and take care of the kids. Oh no, I have to do his typing for him, errands for him. If I don't do it right away, I'm stupid--I'm not a good wife or something stupid like that. I have an identity of my own and I'm not going to have it wrapped up in him. It makes me-it infuriates me! I want to punch him right in the mouth. What am I going to do? Who does he think he is, anyway?

Response:

EXCERPT 9

Helpee: I finally found somebody I can really get along with. There is no pretentiousness about them at all. They are real and they understand me. I can be myself with them. I don't have to worry about what I say and that they might take me wrong, because I do sometimes say things that don't come out the way that I want them to. I don't have to worry that they are going to criticize me. They are just marvelous people! I just can't wait to be with them. For once I actually enjoy going out and interacting. I didn't think I could ever find people like this again. I can really be myself. It's such a wonderful feeling not to have people criticizing you for everything you say that doesn't agree with them. They are warm and understanding and I just love them! It's just marvelous.

\section{Response:}


EXCERPT 10

Helpee:

I'm really excited! We are going to california. I'm going to have a second lease on life. I found a marvelous job. It's great! It's so great. I can't believe it's true--it's so great! I have a secretarial job. I can be a mother and can have a part time job which I think I will enjoy very much. I can be home when the kids get home from school. It's too good to be true. It's so exciting. New horizons are unfolding. I just can't wait to get started. It's great!

Response:

EXCERPT 11

Helpee:

I'm so pleased with the kids. They are doing just marvelously. They have done so well at school and at home; they get along together. It's amazing. I never thought they would. They seem a little older. They play together better and they enjoy each other and I enjoy them. Life has become so much easier. It's really a joy to raise three boys. I didn't think it would be. I'm just so pleased and hopeful for the future. For them and for us. It's just great! I can't believe it. It's marvelous.

Response:

EXCERPT 12

Helpee:

I'm really excited the way things are going at home with my husband. It's just amazing. We get along great together now. Sexually, I didn't know we could be that happy. I didn't know anyone could be that happy. It's just marvelous! I'm just so pleased, I don't know what else to say. 
EXCERPT 13

Helpee:

I'm so thrilled to have found a counselor like you. I didn't know any existed. You seem to understand me so well. It's just great! I feel like I'm coming alive again. I have not felt like this in so long.

Response:

EXCERPT 14

Helpee: Silence. (Moving about in chair)

Response:

EXCERPT 15

Helpee: Gee, I'm so disappointed. I thought we could get along together and you could help me. We don't seem to be getting anywhere. You don't understand me. You don't know I'm here. I don't even think you care for me. You don't hear me when I talk. You seem to be somewhere else. Your responses are independent of anything I have to say. I don't know where to turn. I'm just so--doggone it--I don't know what I'm going to do, but I know you can't help me. There just is no hope.

Response: 
EXCERPT 16

Helpee:

Who do you think you are? You call yourself a therapist! Damn, here I am spilling my guts out and all you do is look at the clock.

You don't hear what I say. Your responses are not attuned to what I'm saying. I never heard of such therapy. You are supposed to be helping me. You are so wrapped up in your world you don't hear a thing I'm saying. You don't give me the time. The minute the hour is up you push me out the door whether I have something important to say or not. I--ah-it makes me so God damn mad!

Response:

(Carkhuff, 1969d, pp. 94-99). 


\author{
APPENDIX B \\ CARKHUFF'S EMPATHY SCALE
}

An irrelevant or hurtful response that does not

1.0 the helpee. However, in instances where content is communicated accurately, it may raise the level of the response.

1.5

A response that only partially communicates an awareness of the surface feelings of the helpee.

2.0 When content is communicated accurately it may raise the level of the response; conversely it may lower the level of the response when communicated inaccurately.

2.5

A response that conveys the helpee is understood at the level he is expressing himself; surface

3.0 feelings are accurately reflected. Content is not essential, but when included it must be accurate. If it is inaccurate, the level of the response may be lowered.

3.5

A response that conveys the helpee is understood beyond his level of immediate awareness; underlying 4.0 feelings are identified. Content is used to complement affect in adding deeper meaning. If content is inaccurate, the level of the response may be lowered.

KEY WORDS - Empathy Scale

Level 4 - underlying feelings; additive

Level 3 - surface feelings reflected

Level 2 - subtractive

Level 1 - irrelevant; hurtful

(Gazda et al., 1973, p. 71). 


\section{APPENDIX C \\ PERSONAL DATA SHEET \\ CONTRACT}

\section{Name :}

Address :

Telephone Number:

Age:

Sex :

Year of graduation from nursing school:

Educational background in nursing:

Position in hospital:

Unit assigned:

I understand that I will be involved in a training program that is to be tested statistically. Permission is granted to publish the results of this study. No one will be identified by name. I agree to attend all sessions in this program.

Date: 


\section{APPENDIX D \\ INTER-RATER RELIABILITY TEST}

Helpee Situation 1

Male: "I've been looking forward to the senior prom since I was a freshman, and now it looks like I won't be able to go. It boils down to a matter of money, since there is no way I can afford to rent a tux."

Helper Responses

1. "You've looked forward to it all these years. Are you sure you have exhausted all means of getting a tux?"

2. "You feel left out because the money problem might cause you to miss the senior prom."

3. "How unfortunate. Maybe you could borrow a tux from somebody."

4. "Why don't you talk to the manager of the tuxedo rental store and see if you could pay a little bit a week until it is all paid."

5. "The prom really means a lot to you."

6. "You are disappointed because you feel you can't afford to go to the prom."

7. "Is there some way I could help you afford this? Are you working?"

8. "What happened to all that money you made last summer?"

9. "Don't you have a friend who could lend you enough money to rent a tux until you could find work and earn enough to pay him back?"

10. "A part-time job would probably provide enough money for your needs." 
Helpee Situation 2

Tenth-grade girl to teacher: "There are times when I feel like school is not important to me. Since I'm not going to college, there isn't much use for me to
waste my time here."

Helper Responses

1. "Perhaps you could talk to the counselor about why you should stay in school."

2. "You know that the first thing an employer will want to know is if you are a high school graduate."

3. "It sounds like you are thinking about dropping out."

4. "I would be glad to sit down and discuss it with you sometime."

5. "You really don't know what to do. Perhaps you'd like to graduate, but right now you are leaning toward dropping out."

Helpee Situation 3

Tenth-grade girl to teacher: "I just hate to go home after school. If I'm not fighting with my parents, they're fighting with each other. It's always so uncomfortable at home."

\section{Helper Responses}

1. "You are dissatisfied with your home life in comparison with school."

2. "It's hard to cope with the constant fighting in your home, yet you don't know what you can do about it."

3. "Why do you have trouble with your parents?"

4. "It's upsetting not being able to feel comfortable at home with family fights every day."

5. "You really hate to go home because you feel so uncomfortable as a result of all the fighting between your parents and yourself."

(Gazda et al., 1973, pp. 73-75). 


\begin{abstract}
APPENDIX E
ANNOUNCEMENT OF A STAFF DEVELOPMENT PROGRAM
\end{abstract}

TO: ALL REGISTERED NURSES

FROM : M. B. BRIGGS

DATE : JUNE 14,1974

WOULD YOU LIKE TO BE ABLE TO ESTABLISH GOOD

RELATIONSHIPS WITH OTHER PEOPLE QUICKLY? DID YOU EVER FEEL THAT SOMEONE REALLY DID NOT UNDERSTAND WHAT YOU SAID? DO YOU EVER LEAVE SOMEONE KNOWING YOU WERE UNCOMFORTABLE WITH THE CONVERSATION YOU JUST HAD?

IF YOUR ANSWER IS "YES" TO ANY OF THE ABOVE QUESTIONS, THEN COME ON

$$
\text { MONDAY, JUNE } 24
$$

OR

WEDNESDAY， JUNE 26

$$
6: 30 \mathrm{PM}
$$

CONFERENCE ROOM A - "C" FLOOR

AND MEET WITH MS. ELAINE LA MONICA, R.N. 


\section{APPENDIX F}

\section{PERCEIVING EMPATHY}

Helpee Situation 1

Male: "I've been looking forward to the senior prom since I was a freshman, and now it looks like I won' $t$ be able to go. It boils down to a matter of money, since there is no way I can afford to rent a tux."

Helper Responses

1. "You've looked forward to it all these years. Are you sure you have exhausted all means of getting a tux?"

2. "You feel left out because the money problem might cause you to miss the senior prom."

3. "How unfortunate. Maybe you could borrow a tux from somebody."

4. "Why don't you talk to the manager of the tuxedo rental store and see if you could pay a little bit a week until it is all paid."

5. "The prom really means a lot to you."

6. "You are disappointed because you feel you can't afford to go to the prom."

7. "Is there some way I could help you afford this? Are you working?"

8. "What happened to all that money you made last summer?"

9. "Don't you have a friend who could lend you enough money to rent a tux until you could find work and earn enough to pay him back?"

10. "A part-time job would probably provide enough money for your needs."

11. "It is upsetting to think you might miss the prom this year because you don't have enough money to go."

12. "I know how you feel." 
Helpee Situation 2

Tenth-grade girl to teacher: "There are times when I feel like school is not important to me. Since I'm not going to college, there isn't much use for me to waste my time here."

Helper Responses

13. "Perhaps you could talk to the counselor about why you should stay in school."

14. "You know that the first thing an employer will want to know is if you are a high school graduate."

15. "It sounds like you are thinking about dropping out."

16. "I would be glad to sit down and discuss it with you sometime."

17. "You really don't know what to do. Perhaps you'd like to graduate, but right now you are leaning toward dropping out."

18. "It's frustrating to be caught in the middle of such a conflict."

Helpee Situation 3

Tenth-grade girl to teacher: "I just hate to go home after school. If I'm not fighting with my parents, they're fighting with each other. It's always so uncomfortable at home."

Helper Responses

19. "You are dissatisfied with your home life in comparison with school."

20. "It's hard to cope with the constant fighting in your home, yet you don't know what you can do about it."

21. "Why do you have trouble with your parents?"

22. "It's upsetting not being able to feel comfortable at home with family fights every day." 
23. "You really hate to go home because you feel so uncomfortable as a result of all the fighting between your parents and yourself."

24. "You're tired of being greeted in your home by harsh words and an unpleasant atmosphere. You'd just like to feel that you could go home and feel welcome."

25. "The situation at home makes you feel uneasy."

26. "Do you think it is something that will blow over?"

27. "Why don't you threaten to move out?"

(Gazda et al., 1973, pp. 73-75) . 


\section{APPENDIX G \\ PERCEIVING FEELINGS}

Situation 1

Teacher to teacher: "I'm so mad at myself! I was upset and tired and I blew-up at my class for no reason. I know some of them felt hurt."

Feelings present: upset, mad, angry, tired, guilty ashamed, uncomfortable.

\section{Situation 2}

Student to student: "I am so mad! It seems as if every time I have to study, these certain girls pick that time to go wild. They run up and down the hall yelling and in and out of my room asking me questions. I know I could go to the library, but I don't think it's fair for me to have to leave. What really frustrates me is that they always seem to make better grades than I do, without ever studying."

Feelings present:

\section{Situation 3}

Student to teacher: "I was over here yesterday for our conference and you weren't here. This is the second time this has happened. I don't understand why we can't get together. It makes me feel like you don't want to give me any help on this project."

Feelings present:

\section{Situation 4}

Student teacher to another student teacher: "How about this for a double standard! Today the seventh-grade teacher was talking to one of the boys about his being late to class so often. She said something about his parents and that made him mad. He used a couple of obscene words and that really set her off! She started shaking him and scratched him and he pushed her away. What really makes me furious is that he got expelled, but not a word was said to her!" 
Situation 5

Student to student: "I get so annoyed at myself when I 'chicken out' of doing something. It's so stupid to be afraid of people but $I$ am and it keeps me from doing things as simple as going into a new restaurant."

Feelings present:

\section{Situation 6}

Student teacher to another student teacher: "Today I was helping Blaine read a story. It was about a little bear that had parents that loved him. Blaine then reported to me that his parents hated him, but he was glad because he hated his parents, too. I could tell by his reactions that he was very sensitive about this so I changed the subject. There must be a way to help him, but I was so overwhelmed with his sudden remark, I just didn't know what to say."

Surface feelings:

Underlying feelings:

Situation 7

Tenth-grade girl to teacher: "I just hate to go home after school. If I'm not fighting with my parents, they're fighting with each other. It's always so uncomfortable at home."

Surface feelings:

Underlying feelings:

\section{Situation 8}

Student to teacher: "I realize I'm flunking your course, but I just want you to know that I'm actually trying very hard. It seems like the harder I try, the lower my grades get. What should I do?"

Surface feelings:

Underlying feelings: 
Situation 9

Eleventh-grader to teacher: "A lot of times I think about how nice it would be not to have to go to school And then, if I quit, I wonder how long I would be happy." Surface feelings:

Underlying feelings:

Situation 10

College freshman to dorm counselor: "I called my parents last night, and during the conversation I told them I failed a biology test. They said they weren't surprised. They pretend to care about me a lot, but it sounds like they don't have any confidence in my ability to make it in college."

Surface feelings:

Underlying feelings:

(Gazda et al., 1973, pp. 67-69). 
APPENDIX H

RESPONDING WITH EMPATHY

Helpee Situations

1. Student to student: "Since I got out of the army, school just hasn't been the same. The things I had fun doing when I was here before seem silly now."

Helper Responses

Formula: You feel

because

Natural:

2. Student to teacher after school: "We all like your class, but we seem to do the same thing every day. Class would be more interesting if you would do something besides lecturing."

Helper Responses

Formula: You feel because Natural:

3. Teacher to teacher: "At every PTA meeting, only the parents of the good kids come. The parents I really need to see are the ones who never show up."

Helper Responses

Formula: You feel because Natural:

4. Student to teacher: "I don't mind working hard in school as long as things come out all right in the end. In your class I work hard and still don't seem to do well."

Helper Responses

Formula: You feel because

Natural: 
5. Female teacher to another teacher: "I hate to be prejudiced in class, but those long-haired boys just turn me off. I'm afraid it is becoming obvious to the students."

Helper Responses

Formula: You feel

because

Natural:

6. Teacher to teacher: "I stay depressed all the time because it seems like my husband is always at work. We never have any evenings together."

Helper Responses

Formula: You feel

because

Natura1:

7. Male college student to another student: "I went through rush this year and was rejected by all the fraternities."

Helper Responses

Formula: You feel because

Natural:

8. Teacher to teacher: "I was hoping when I moved to this town I could make some new friends, but I've been home alone every night."

Helper Responses

Formula: You feel because Natural: 
9. Parent to teacher: "John's been bringing his math assignments home with him and asking me to help him. It looks like the kind of stuff I did in college, and he's only in the eighth grade. I think you're expecting too much!"

Helper Responses

Formula: You feel

because

Natural:

10. Student to student: "My roommate is driving me crazy. $\mathrm{He}$ is the most inconsiderate person I have ever met!"

Helper Responses

Formula: You feel

because

Natural:

(Gazda et al., 1973, pp. 75-77). 


\section{APPENDIX I \\ VOCABULARY OF AFFECTIVE ADJECTIVES}

This list of adjectives was developed to help the user find the most appropriate description of perceived feelings. No attempt has been made to order these words in terms of their degree of intensity.

Note that by simply preceding many of these adjectives with appropriate adverbs, you can control the intensity of your communication. For example:
You feel SOMEWHAT angry with your teacher for scolding you.
You feel QUITE angry with your teacher for scolding you. You feel VERY angry with your teacher for scolding you. You feel EXTREMELY angry with your teacher for scolding you.

Pleasant Affective States (Love, Affection, Concern)

$\begin{array}{lll}\text { admired } & \text { dedicated } & \text { just } \\ \text { adorable } & \text { devoted } & \text { kind } \\ \text { affectionate } & \text { easy-going } & \text { kindly } \\ \text { agreeable } & \text { empathic } & \text { kind-hearted } \\ \text { altruistic } & \text { fair } & \text { lenient } \\ \text { amiable } & \text { faithful } & \text { lovable } \\ \text { benevolent } & \text { forgiving } & \text { loving } \\ \text { benign } & \text { friendly } & \text { mellow } \\ \text { big-hearted } & \text { generous } & \text { mild } \\ \text { brotherly } & \text { genuine } & \text { moral } \\ \text { caring } & \text { giving } & \text { neighborly } \\ \text { charitable } & \text { good } & \text { nice } \\ \text { Christian } & \text { good-humored } & \text { obliging } \\ \text { comforting } & \text { good-natured } & \text { open } \\ \text { congenial } & \text { helpful } & \text { optimistic } \\ \text { conscientious } & \text { honest } & \text { patient } \\ \text { considerate } & \text { honorable } & \text { peaceful } \\ \text { cooperative } & \text { hospitable } & \text { pleasant } \\ \text { cordial } & \text { humane } & \text { polite } \\ \text { courteous } & \text { interested } & \text { reasonable }\end{array}$

receptive reliable respectful responsible sensitive sympathetic sweet tender thoughtful tolerant truthful trustworthy understanding unselfish warm warm-hearted well-meaning wise 
(Elation, Joy)

$\begin{array}{ll}\text { amused } & \text { exalted } \\ \text { at ease } & \text { excellent } \\ \text { blissful } & \text { excited } \\ \text { brilliant } & \text { fantastic } \\ \text { calm } & \text { fine } \\ \text { cheerful } & \text { fit } \\ \text { comical } & \text { gay } \\ \text { contented } & \text { glad } \\ \text { ecstatic } & \text { glorious } \\ \text { delighted } & \text { good } \\ \text { elated } & \text { grand } \\ \text { elevated } & \text { gratified } \\ \text { enchanted } & \text { great } \\ \text { enthusiastic } & \text { happy }\end{array}$

humorous

inspired

in high spirits splendid

jovial

joyful

jubilant

magnificent

majestic

marvelous

overjoyed

pleased

pleasant

proud

satisfied

(Potency)

$\begin{array}{lll}\text { able } & \text { durable } & \text { influential } \\ \text { adequate } & \text { dynamic } & \text { intense } \\ \text { assured } & \text { effective } & \text { lion-hearted } \\ \text { authoritative } & \text { energetic } & \text { manly } \\ \text { bold } & \text { fearless } & \text { mighty } \\ \text { brave } & \text { firm } & \text { powerful } \\ \text { capable } & \text { forceful } & \text { robust } \\ \text { competent } & \text { gallant } & \text { secure } \\ \text { confident } & \text { hardy } & \text { self-confident } \\ \text { courageous } & \text { healthy } & \text { self-reliant } \\ \text { daring } & \text { heroic } & \text { sharp } \\ \text { determined } & \text { important } & \text { skillful }\end{array}$

spirited

stable

stouthearted

strong

sure

tough

virile

well equipped

well put together

hardy

healthy

important

skillful

Unpleasant Affective States (Depression)

abandoned
alien
alienated
alone
annihilate
awful
battered
below par
blue
burned
cast off
cheapened
crushed
debased
defeated

despised
despondent
destroyed
discarded
discouraged
disfavored
dismal
done for
downcast
downhearted
downtrodden
dreadful
estranged
excluded
forlorn

horrible

humiliated

hurt

in the dumps

jilted

kaput

left out

loathed

lonely

lonesome

lousy

low

miserable

mishandled

mistreated

pathetic

pitiful

rebuked

regretful

rejected

reprimanded

rotten

ruined

run down

sad

stranded

tearful

terrible

unhappy

unloved 


$\begin{array}{llll}\text { degraded } & \text { forsaken } & \text { moody } & \text { valueless } \\ \text { dejected } & \text { gloomy } & \text { mournful } & \text { washed up } \\ \text { demolished } & \text { glum } & \text { obsolete } & \text { whipped } \\ \text { depressed } & \text { grim } & \text { ostracized } & \text { worthless } \\ \text { desolate } & \text { hated } & \text { out of sorts } & \text { wrecked } \\ \text { despair } & \text { hopeless } & \text { overlooked } & \end{array}$

\section{(Distress)}

afflicted
anguished
at the feet of
at the mercy
awkward of
baffled
bewildered
blameworthy
clumsy
confused
constrained
disgusted
disliked

(Fear, Anxiety)

\section{displeased dissatisfied \\ distrustful disturbed \\ lost \\ nauseated \\ offended \\ pained}

doubtful

foolish

futile

grief

helpless

hindered

impaired

impatient

imprisoned perplexed

puzzled

ridiculous

sickened

silly

skeptical

speechless

strained

suspicious swamped

the plaything of

the puppet of

tormented

touchy

ungainly

unlucky

unpopular

unsatisfied

unsure

$\begin{array}{ll}\text { jittery } & \text { shy } \\ \text { jumpy } & \text { strained } \\ \text { nervous } & \text { tense } \\ \text { on edge } & \text { terrified } \\ \text { overwhelmed } & \text { terror-stricken } \\ \text { panicky } & \text { timid } \\ \text { restless } & \text { uncomfortable } \\ \text { scared } & \text { uneasy } \\ \text { shaky } & \text { worrying }\end{array}$

(Belittling, Criticism, Scorn)

$\begin{array}{ll}\begin{array}{l}\text { abused } \\ \text { belittled }\end{array} & \begin{array}{l}\text { diminished } \\ \text { discredited } \\ \text { disdained }\end{array} \\ \begin{array}{l}\text { carped at } \\ \text { caviled at }\end{array} & \begin{array}{l}\text { disgraced } \\ \text { disparaged }\end{array} \\ \text { censured } & \text { humiliated } \\ \text { criticized } & \text { ignored } \\ \text { defamed } & \text { jeered } \\ \text { deflated } & \text { lampooned }\end{array}$

maligned

minimized

mocked

neglected

not taken seriously

overlooked poked fun at pooh poohed pulled to pieces scoffed at scorned shamed slammed slandered

slighted thought nothing of underestimated underrated 
deprecated depreciated derided laughed at

libeled

made light of put down

ridiculed

roasted

(Impotency, Inadequacy)

$\begin{array}{ll}\text { anemic } & \text { flimsy } \\ \text { broken } & \text { fragile } \\ \text { broken down } & \text { frail } \\ \text { chicken- } & \text { harmless } \\ \text { hearted } & \text { helpless } \\ \text { cowardly } & \text { impotent } \\ \text { crippled } & \text { inadequate } \\ \text { debilitated } & \text { incapable } \\ \text { defective } & \text { incompetent } \\ \text { deficient } & \text { indefensible } \\ \text { demoralized } & \text { ineffective } \\ \text { disabled } & \text { inefficient } \\ \text { effeminate } & \text { inept } \\ \text { exhausted } & \text { inferior } \\ \text { exposed } & \text { infirm } \\ \text { feeble } & \end{array}$

$\begin{array}{ll}\begin{array}{l}\text { insecure } \\ \text { insufficient } \\ \text { lame }\end{array} & \begin{array}{l}\text { unable } \\ \text { unarmed } \\ \text { maimed }\end{array} \\ \begin{array}{ll}\text { unfit } \\ \text { meek }\end{array} \\ \text { nerveless } & \begin{array}{l}\text { unimportant } \\ \text { paralyzed }\end{array} \\ \text { unsound } \\ \text { punyless } & \text { unsubstantiated } \\ \text { shaken } & \text { useless } \\ \text { shaky } & \text { vulnerable } \\ \text { sickly } & \text { weak } \\ \text { small } & \text { weak-hearted } \\ \text { strengthless } & \\ \text { trivial } & \end{array}$

(Anger, Hostility, Cruelty)

\begin{tabular}{|c|c|}
\hline agitated & cranky \\
\hline aggravated & critical \\
\hline aggressive & cross \\
\hline angry & cruel \\
\hline annoyed & deadly \\
\hline antagonistic & dictatorial \\
\hline arrogant & disagreeable \\
\hline austere & discontented \\
\hline $\begin{array}{l}\text { bad-tempered } \\
\text { beligerent }\end{array}$ & dogmatic \\
\hline bigoted & $\begin{array}{l}\text { enraged } \\
\text { envious }\end{array}$ \\
\hline biting & fierce \\
\hline bloodthirsty & furious \\
\hline blunt. & gruesome \\
\hline 1lying & hard \\
\hline allous & hard-hearted \\
\hline old-blooded & harsh \\
\hline ibative & hatetul \\
\hline$n f$ & $\begin{array}{l}\text { neartless } \\
\text { hellish }\end{array}$ \\
\hline & hi \\
\hline & tile \\
\hline
\end{tabular}

hypercritical ill-tempered impatient inconsiderate inhuman insensitive intolerable intolerant irritated mad

malicious mean murderous nasty obstinate opposed oppressive outraged perturbed poisonous prejudiced pushy 


\section{APPENDIX J \\ INEFFECTIVE COMMUNICATION STYLES}

Helpee Situation 1

Fourth-grader coming in from recess, to teacher: "They wouldn't let me in their game!"

Helper responses that are not helpful:

1. DETECTIVE: "Who wouldn't?"

The Detective is eager to track down the facts of the case. He grills the helpee about the details of what happened and responds to this factual content instead of giving attention to feelings. The Detective controls the flow of the conversation, which often puts the helpee on the defensive.

2. MAGICIAN: "Recess is over, so it doesn't matter now does it?"

The Magician tries to make the problem disappear by telling the helpee it isn't there. This illusion is not lasting. Denying the existence of a problem is not respectful because it denies the helpee the validity of his own experience and perception.

3. FOREMAN: "Would you help me pass out these papers?" The Foreman believes that if a person can be kept too busy to think about a problem, there will be no problem. Doing this has the effect of telling the helpee that the assigned task is more important than his problem, which is disrespectful even if true. An effective helper communicates his awareness of the magnitude given by the helpee to any particular problem.

4. JUDGE: "Remember yesterday when you didn't play fair? of course they wouldn't want to play with you today!" The judge gives rational explanations to show the helpee that his past actions have caused the present situation--that the helpee is the guilty party. Although such responses may be accurate, they are rarely helpful because they are premature--given before the helpee is ready to accept and use them. A helper does not punish.

Helper response that follows the model: 
Helpee Situation 2

Teacher to another teacher: "Consultants! Consultants! They keep sending these people around with their impractical

Helper responses that are not helpful:

1. SWAMI: "You better make them think you follow their suggestions. If you don't, it will get back to the principal."

The Swami knows and predicts exactly what is going to happen. By declaring the forecast, the Swami relieves himself of responsibility and sits back to let his prophecy come true.

2. JUDGE: "Sounds like your attitude may have kept you from giving their ideas a fair chance."

3. SIGN PAINTER: "You're just a complainer! You don't seem to like anything that happens!"

The Sign Painter thinks a problem can be solved by being named. He has an unlimited inventory of labels to affix to persons and their problems.

4. DRILL SERGEANT: "You need to adapt their ideas to your own situations. Try thinking of it that way next time they come."

The Drill Sergeant gives orders and expects them to be obeyed. Because he knows just what the helpee should do, he sees no need to give explanations or listen to the helpee's feelings, or to explain his commands to the helpee.

Helper response that follows the model:

Helpee Situation 3

Eighth-grade student to teacher after class: "You asked me to be chairman of the panel discussion next week, but I can't do that. Please get somebody else. Anybody in the class would be better than me."

Helper responses that are not helpful:

1. DRILL SERGEANT: "When you get home tonight, figure out what each panel member will do. Give them assignments and make sure they work on it some each day. Get organized now and it will come out fine." 
2. GURU: "You won't find out what you can do if you don't try new things. It's better to try and fail than not to try at all."

The Guru dispenses proverbs and cliches on every occasion as though he were the sole possessor of the accumulated wisdom of the ages. Unfortunately, his words are too impersonal and general to apply to any individual's situation with force or accuracy, and often are too trite to be noticed at all.

3. MAGICIAN: "You don't really mean that do you?"

Helper response that follows the model:

Helpee Situation 4

Parents to teacher: "You told us at our last meeting that if we worked with Johnny at home his grades should improve. We have spent more than enough time with him, but his grades aren't any better."

Helper responses that are not helpful:

1. DETECTIVE: "Let's talk about what you are doing at home and how you go about it."

2. FLORIST: "Oh, I think your extra effort is going to pay off in the long run. These things take time, you know, but he has been trying harder in class. I think things are working out."

The Florist is uncomfortable talking about anything unpleasant, so he gushes flowery phrases to keep the helpee's problem at a safe distance. The florist mistakenly thinks that the way to be helpful is to hide the problem under bouquets of optimism.

3. GURU: "Well, you know what they say about leading a horse to water. It could be that we are pushing Johnny too hard at this time. According to some developmental theories I have read...."

Helper response that follows the model: 
Helpee Situation 5

Teacher to another teacher: "I don't know what to do with this class! They won't learn anything!"

Helper responses which are not helpful:

1. DETECTIVE: "What's causing the problem?"

2. FLORIST: "With all your ability? I can't believe that! Why, you're the best teacher in the building!"

3. JUDGE: "Have things been bad all year? You know if you got off to a bad start with your class, you are going to have a hard time changing them."

4. SIGN PAINTER: "You're a born pessimist!"

5. DRILL SERGEANT: "First get them all tested. Then ability group them. Keep your problem students busy with simple projects so they won't bother others. Then...."

6. GURU: "Things always look the worst before they get better."

7. SWAMI: "If you don't get some results with them pretty soon there will be trouble! They take achievement tests next month, you know."

8. FOREMAN: "Let's stop for pizza on the way home tonight and forget about school for a while."

9. MAGICIAN: "You're imagining things--that's a good class and you know it. They're learning a lot more than you give them credit for!"

Helper response that follows the model:

(Gazda et al., 1973, pp. 62-65). 


\section{APPENDIX K \\ EVALUATION OF THE PROGRAM}

CONTENT :

METHOD OF PRESENTATION:

APPLICATION TO NURSING:

\section{LEADER :}

TECHNIQUE :

TENDERNESS : 
